FEDERAL RESERVE BANK OF SAN FRANCISCO

WORKING PAPER SERIES

\title{
The Transmission of Monetary Policy under the Microscope
}

\author{
Martin Blomhoff Holm \\ University of Oslo \\ Pascal Paul \\ Federal Reserve Bank of San Francisco \\ Andreas Tischbirek \\ University of Lausanne \\ February 2021 \\ Working Paper 2020-03 \\ https://www.frbsf.org/economic-research/publications/working-papers/2020/03/
}

\section{Suggested citation:}

Holm, Martin Blomhoff, Pascal Paul, Andreas Tischbirek. 2021. "The Transmission of Monetary Policy under the Microscope," Federal Reserve Bank of San Francisco Working Paper 2020-03. https://doi.org/10.24148/wp2020-03

The views in this paper are solely the responsibility of the authors and should not be interpreted as reflecting the views of the Federal Reserve Bank of San Francisco or the Board of Governors of the Federal Reserve System. 


\title{
The Transmission of Monetary Policy under the Microscope
}

\author{
Martin Blomhoff Holm, Pascal Paul, Andreas Tischbirek*
}

February 2021

\begin{abstract}
We investigate the transmission of monetary policy to household consumption using administrative data on the universe of households in Norway. Based on identified monetary policy shocks, we estimate the dynamic responses of consumption, income, and saving along the liquid asset distribution of households. For low-liquidity but also for high-liquidity households, changes in disposable income are associated with a sizable consumption reaction. The impact consumption response is closely linked to interest rate exposure, which is negative at the bottom but positive at the top of the distribution. Indirect effects of monetary policy gradually build up and eventually outweigh the direct effects.
\end{abstract}

Keywords: Monetary policy, Administrative data, Household balance sheets, Liquidity constraints, Heterogeneous agent New Keynesian models

JEL Codes: D31, E21, E43, E52, G51

\footnotetext{
*We thank Adrien Auclert, Florin Bilbiie, Corina Boar, James Cloyne, Andreas Fagereng, Kilian Huber, Òscar Jordà, Greg Kaplan, Ralph Luetticke, Ben Moll, Chris Moser, Emi Nakamura, Christina Patterson, Matthew Rognlie, Morten Ravn, Jón Steinsson, and seminar participants at UC Berkeley, the University of Chicago, Columbia Business School, the University of Bonn, UCL, HU Berlin, the Federal Reserve Board, Norges Bank, the NBER Summer Institute, the "Monetary Policy and Heterogeneity" conference at the Federal Reserve, the EABCN conference on "Empirical Advances in Monetary Policy", and the World Congress of the Econometric Society for their insights. We also thank Anne Sofie Jore for helping us with the collection of archive data from Norges Bank and Chitra Marti, Ben Shapiro, Dori Wilson, and Winnie Yee for excellent research assistance. All errors are our own. This article has received funding from the European Research Council (ERC) under the European Union's Horizon 2020 research and innovation programme (grant agreement No. 851891). We also thankfully acknowledge funding from the Swiss National Science Foundation. The views expressed herein are solely those of the authors and do not necessarily reflect the views of the Federal Reserve Bank of San Francisco or the Federal Reserve System. Holm: University of Oslo, email: martin.b.holm@outlook.com. Paul: Federal Reserve Bank of San Francisco, email: pascal.paul@sf.frb.org. Tischbirek: HEC Lausanne, University of Lausanne, email: andreas.tischbirek@unil.ch.
} 


\section{Introduction}

What is the effect of monetary policy on consumption, income, and saving across the distribution of households? And what role does household heterogeneity play in the transmission mechanism? A new class of heterogeneous agent models with nominal rigidities has recently emerged that provides valuable insights into these questions. ${ }^{1}$ However, direct empirical evidence on the responses to monetary policy at the micro level is scarce. In this paper, we draw on detailed administrative data to investigate the transmission of monetary policy to household consumption and examine the empirical validity of the key predictions implied by theory.

Recent Heterogeneous Agent New Keynesian (HANK) models have several appealing features in comparison with standard Representative Agent New Keynesian (RANK) models. In RANK frameworks, consumption-saving behavior is generally closely in line with the permanent income hypothesis (Kaplan and Violante, 2014; Bilbiie, 2020). This implies that the marginal propensity to consume (MPC) associated with temporary income changes is very small, a feature that is at odds with empirical estimates. ${ }^{2}$ Almost the entire consumption response to monetary policy is therefore due to direct, partial equilibrium, effects that operate largely through intertemporal substitution. In contrast, HANK models are capable of generating MPCs that are closer to the values estimated from empirical data. In the presence of borrowing costs or constraints, income changes of households with low wealth are imperfectly smoothed and permitted to feed into consumption. Kaplan and Violante (2014) show that this continues to be the case for households with large illiquid but small liquid wealth if holdings of illiquid assets are subject to adjustment costs. ${ }^{3}$ In a two-asset model that can give rise to a realistic fraction of households with few liquid assets and therefore to a sizable MPC at the aggregate level, Kaplan, Moll and Violante (2018) demonstrate that interest rate changes influence household consumption predominantly through indirect, general equilibrium, effects by affecting the disposable income of households.

Guided by HANK models, we provide a detailed empirical account of the effects of monetary policy at the household level. In line with theory, our focus lies on the role played by household balance sheets, in particular liquid asset positions, and the relative importance of direct and indirect effects. Empirical evidence for the monetary transmission mechanism implied by HANK models has proved difficult to obtain. To investigate the micro-level responses to policy rate changes, a panel data set is required that spans many years and includes detailed information on the balance

\footnotetext{
${ }^{1}$ Several contributions extend the standard Bewley-Huggett-Aiyagari incomplete markets framework to include nominal rigidities. Examples are Oh and Reis (2012), McKay and Reis (2016), Den Haan, Rendahl and Riegler (2017), Guerrieri and Lorenzoni (2017), Ravn and Sterk (2017) and Bayer et al. (2019), among many others. Detailed analyses of monetary policy are contained in Gornemann, Kuester and Nakajima (2016), McKay, Nakamura and Steinsson (2016), Kaplan, Moll and Violante (2018), Auclert (2019), Hagedorn et al. (2019), Challe (2020), Kekre and Lenel (2020), and Luetticke (2020), for example. Influential tractable models are developed in Campbell and Mankiw (1989), Mankiw (2000), Galí, López-Salido and Vallés (2007), Bilbiie (2008), Debortoli and Gali (2018), and Bilbiie (2020).

${ }^{2}$ See, e.g., Johnson, Parker and Souleles (2006), Jappelli and Pistaferri (2010), Parker, Souleles, Johnson and McClelland (2013), Misra and Surico (2014), Bunn, Roux, Reinold and Surico (2018), and Fagereng, Holm and Natvik (2021).

${ }^{3}$ Kaplan, Violante and Weidner (2014) provide empirical support for the existence of "wealthy hand-to-mouth households" in a number of countries.
} 
sheets, income, and consumption of households. We therefore turn to a country that collects rich information from its inhabitants: Norway. Specifically, we draw on administrative data that contain records of the income and wealth of all households registered in Norway between 1996 and 2015. Using the information contained in the administrative data, we impute the consumption expenditures of households based on their budget identity. Equipped with this data set, we are able to give a comprehensive picture of the consumption response to monetary policy shocks and its determinants at fine segments along the liquid asset distribution.

To overcome monetary policy endogeneity, we derive a series of identified monetary policy shocks for Norway using the approach in Romer and Romer (2004). Before turning to the micro data, we estimate the responses to these shocks using aggregate data. We obtain textbook impulse responses across a wide range of macroeconomic aggregates: indicators for economic activity contract and prices fall after a monetary tightening. For the time series, which are available at different frequencies, the impulse responses show similar patterns independent of whether monthly, quarterly, or annual data are used in the estimation. The shape and stability of the responses across the different variables and frequencies give us confidence in the identification and in the analysis at the household level, for which we confront the shocks with the administrative data that are available at an annual frequency.

We then turn to analyzing the micro-origins of the macro responses. In congruence with the HANK literature, we divide the population of households into groups of equal size according to their location in the liquid asset distribution and estimate a separate set of impulse responses for each segment of the distribution. The consumption responses move closely with the income responses across the entire distribution. Comparing households at the bottom of the distribution with households around the median reveals differences in the consumption-saving behavior though. When disposable income begins to fall in response to a monetary policy contraction, households with low liquid asset holdings let their consumption decline, while households with intermediate amounts of liquid assets initially reduce saving or increase borrowing, as predicted by theory.

For households at the top of the liquid asset distribution, our results are not consistent with the predictions of standard HANK models. We find that households with large liquidity positions increase consumption substantially in response to a monetary tightening and that the increase on impact is related to a rise in interest income, which is directly affected by the policy rate. While HANK models can generate large and positive consumption responses to an interest rate increase for liquidity-rich households if the income effect dominates the substitution effect, they generally do not produce the large consumption response relative to the income response that we observe. In contrast to these models, our estimates indicate that households at the top of the liquid asset distribution have sizable MPCs out of the temporary changes in disposable income induced by monetary policy. 
Interest income and expenses play a significant role in shaping the response of disposable income to monetary policy shocks. The effect is particularly strong for households at both ends of the liquid asset distribution. To isolate the cash-flow channel associated with interest-sensitive asset and debt positions, we reorder households according to their net interest rate exposure, a measure closely related to the concept of "unhedged interest rate exposure" by Auclert (2019). The net financial income response of households at the bottom (net borrowers) is the mirror image of that of households at the top (net creditors) and income changes are permitted to affect household consumption at both ends of the distribution. Several factors contribute to the pronounced cash-flow effects that we observe. The ten percent of households with the highest net interest rate exposure hold large amounts of deposits with a group median across all years of about 100,000 U.S. dollars, more than twice the median annual household income after taxes in Norway. Households at the bottom of the distribution tend to have substantial mortgage debt. Since deposit rates are comparably elastic to the policy rate and around 90 percent of mortgage contracts carry an adjustable rate, interest income and expenses are highly responsive to monetary policy.

Our estimates also uncover strong ties between the responses of consumption and nonfinancial income, suggesting that general equilibrium effects play an important role for the transmission of monetary policy as argued by Kaplan, Moll and Violante (2018). We exploit the data to provide empirical estimates of the relative importance of direct and indirect effects. The relative size of these effects depends on the impulse response horizon. On impact, the aggregate consumption response is almost entirely driven by direct effects. Around two years after the shock, at the time when the nonfinancial income response builds up, the indirect effects start to dominate the direct effects. Quantitatively, the importance of the indirect effects is of comparable size as in the HANK model by Kaplan, Moll and Violante (2018), with the difference that they unfold only several years after the shock.

A growing empirical literature inspects the transmission mechanism of monetary policy to household consumption. Cloyne, Ferreira and Surico (2020) use survey data to investigate whether differences in the balance sheets of households, approximated by their housing tenure status, affect the consumption response to monetary policy shocks in the United States and the United Kingdom. They find that households with a mortgage respond more strongly than outright home owners and renters. The findings are interpreted as evidence that liquidity positions play a key role for the consumption response of households, since mortgagors tend to have low liquid asset holdings. A benefit of our data is that they allow us to observe liquidity positions directly and therefore to separate households along this dimension.

A number of contributions emphasize the importance of mortgage contracts for the pass-through of monetary policy to household consumption. In the United States, the majority of mortgages carries a fixed rate. Households can reduce interest expenses or extract housing equity if they refinance their loans in response to rate cuts. Wong (2019) finds that the consumption response to monetary policy is stronger among households that adjust their mortgages than among those that 
do not. Di Maggio et al. (2017), exploiting specifics of the mortgage design in the United States, and Floden et al. (2020), using administrative data from Sweden, reach similar conclusions about the effects exerted by adjustable-rate mortgages. The propensity to refinance has been linked to household age and loan size (Wong, 2019), the path of past interest rates (Berger et al., 2018; Eichenbaum, Rebelo and Wong, 2019), and housing equity (Beraja, Fuster, Hurst and Vavra, 2018). Our results for households with negative net interest rate exposure confirm that the cash flows associated with mortgages play an important role in monetary policy transmission. In addition, we highlight the significance of net creditors and estimate dynamic responses for several years after a shock. The latter is of considerable interest, since consumption has been shown to respond to monetary policy shocks with a sizable delay (see, e.g., Christiano, Eichenbaum and Evans, 2005). Our emphasis on the dynamic effects of policy changes in the context of household heterogeneity is shared by Auclert, Rognlie and Straub (2018), although their focus lies on fiscal policy.

Several additional papers estimate key moments in the data and use those moments as model inputs to study the channels through which monetary policy affects household consumption. Auclert (2019) decomposes the aggregate consumption response to monetary policy into different channels to evaluate the role played by redistribution in the presence of heterogeneity in MPCs. Based on survey data, he concludes that redistribution amplifies the aggregate response. Crawley and Kuchler (2020) refine these estimates using administrative data from Denmark. Slacalek, Tristani and Violante (2020) build on Auclert's decomposition to separate direct from indirect effects. Patterson (2018) relies on a similar method to study the amplification of shocks and the severity of recessions. Auclert, Rognlie and Straub (2020) also decompose the total response of monetary policy into direct and indirect effects. They find that in their setup with inattentive households the indirect effects far outweigh the direct effects.

The remainder of the paper is organized as follows. The next section derives the series of monetary policy shocks and computes aggregate responses to these shocks at different frequencies. Section 3 describes the data, discusses the consumption imputation, and presents descriptive statistics. Section 4 contains our main results on the transmission of monetary policy at the household level. Section 5 decomposes the aggregate consumption response into direct and indirect effects. Section 6 concludes and discusses implications of our findings for HANK models.

\section{Monetary Policy Identification}

Most of the variation in central bank interest rates is due to the systematic response of policy to current or expected future economic conditions. To identify the causal effects of monetary policy, it is therefore necessary to isolate shifts in monetary policy instruments that are orthogonal to policy responses to the behavior of the economy. In this paper, we rely on the approach by Romer and Romer (2004) to identify monetary policy shocks. ${ }^{4}$ The idea of this approach is to orthogonal-

\footnotetext{
${ }^{4} \mathrm{~A}$ popular alternative is to use financial markets data to extract surprise changes in interest rates around policy announcements (see, e.g., Kuttner, 2001, Guerkaynak, Sack and Swanson, 2005, and Gertler and Karadi, 2015). However,
} 
ize policy rate changes against the central bank's forecasts of its macroeconomic targets in a first step. The estimated residuals serve as a measure of monetary policy shocks. In a second step, the externally identified shock series can be employed to estimate impulse responses.

The key policy rate of Norges Bank, the Norwegian central bank, is the sight deposit rate. Its historical evolution is shown in Figure A.1 in Appendix A.1. As can be seen from the figure, the policy rate never touched the zero-lower bound over the entire interval considered. We are therefore able to study the effects of conventional policy rate changes in recent years without having to account for a period in which the policy rate was constrained. On a policy-meeting frequency, we estimate

$$
\begin{aligned}
\Delta i_{m}= & \alpha_{1}+\alpha_{2} i_{m,-1}+\sum_{k=0}^{1} \beta_{k}^{\pi} \pi_{m, t+k}+\sum_{k=0}^{1} \beta_{k}^{\Delta \pi} \Delta \pi_{m, t+k} \\
& +\sum_{k=0}^{1} \beta_{k}^{y} y_{m, t+k}+\sum_{k=0}^{1} \beta_{k}^{\Delta y} \Delta y_{m, t+k}+\gamma_{1} e x_{m,-1}+\gamma_{2} I_{m}^{I T} \cdot e x_{m,-1}+\epsilon_{m}^{M P}
\end{aligned}
$$

where $\Delta i_{m}$ is the change of the policy rate at meeting $m$ and $i_{m,-1}$ is the level of the policy rate prior to meeting $m$. Meeting $m$ takes place in period $t .^{5}$ Following Romer and Romer (2004), we include central bank forecasts for GDP $y_{m, t+k}$ and the CPI $\pi_{m, t+k}$ for horizon $t+k$ and the corresponding forecast changes, denoted $\Delta \pi_{m, t+k}$ and $\Delta y_{m, t+k}$. We rely on historical forecasts from Norges Bank for all policy meetings, whenever these were constructed shortly before a meeting. When this is not the case, we follow Cloyne and Huertgen (2016) in using forecasts by market participants to proxy for the forecasts of the central bank. Appendix A.2 describes these forecasts further and gives a detailed protocol for their assignment to the policy meetings.

The specification in (1) deviates from the one employed by Romer and Romer (2004) in three ways. First, we use annual forecasts for the current and the next year as opposed to quarterly ones since these are available for a relatively long historical sample. ${ }^{6}$ Second, we do not include a contemporaneous forecast for the unemployment rate since such a forecast is not available for a longer historical sample. Third, we also account for a switch in policy regimes over our sample. From March 2001 onward, Norges Bank officially committed itself to an inflation targeting regime. In the years before, the central bank also targeted the exchange rate. We therefore include as additional explanatory variables the level of the exchange rate on the day before the meeting $e x_{m,-1}$ and the same variable interacted with an indicator variable $I_{m}^{I T}$ that takes the value of one for the pre-inflation targeting era. ${ }^{7}$ The residual $\epsilon_{m}^{M P}$ in regression (1) is a measure of the monetary policy shock associated with meeting $m$.

for Norway, it is difficult to reconstruct with certainty at which points in time the information about policy decisions was transmitted to financial markets in the early years of the sample.

${ }^{5}$ Occasionally, there are multiple policy rate changes shortly after one another. We combine policy rate changes within one month and apply the date of the later meeting to the combined rate change. We checked that there are no such instances across months. The results are nearly identical without this adjustment.

${ }^{6}$ The earliest quarterly forecasts for the output gap and a price index start in late 2005, which would restrict the analysis to the second half of the sample.

${ }^{7}$ We use historical data of the import-weighted exchange rate from Norges Bank. 


\subsection{Estimation Results}

We estimate (1) using ordinary least squares for the sample 1994:M1-2018:M12. The results are shown in Table 1. The estimated coefficients have the expected signs and the ones associated with the forecasts and the forecast changes that are statistically different from zero are all positive. That is, if projected inflation or output growth is high or has been increasing relative to the prior comparison forecast, monetary policy tightens to lean against these macroeconomic developments. Moreover, the constant and the coefficient on the lagged policy rate are negative, reflecting the secular decline in interest rates over our sample and a mean-reversion in policy rates, respectively. However, only the coefficient on the lagged policy rate is statistically different from zero. The estimates and $R^{2}$ of around 0.3 are consistent with the findings of Romer and Romer (2004) and Cloyne and Huertgen (2016). The estimated coefficients associated with the exchange rate turn out to be not statistically significant, even though their positive signs imply that monetary policy tightens if the currency is weak before the meeting.

Table 1: Determinants of Changes in the Policy Target Rate.

\begin{tabular}{|c|c|c|c|c|c|c|}
\hline & Constant & $i_{m,-1}$ & $\pi_{m}$ & $y_{m}$ & $e x_{m,-1}$ & $I_{m}^{I T} \cdot e x_{m,-1}$ \\
\hline & $\begin{array}{r}-0.50 \\
(0.22)\end{array}$ & $\begin{array}{c}-0.02 * \\
(0.09)\end{array}$ & & & $\begin{array}{l}0.02 \\
(0.95)\end{array}$ & $\begin{array}{l}0.06 \\
(0.34)\end{array}$ \\
\hline Current Year & & & $\begin{array}{l}0.06^{* *} \\
(0.04)\end{array}$ & $\begin{array}{l}0.05 \\
(0.37)\end{array}$ & & \\
\hline Next Year & & & $\begin{array}{l}0.04 \\
(0.44)\end{array}$ & $\begin{array}{l}0.04 \\
(0.62)\end{array}$ & & \\
\hline$\Delta$ Current Year & & & $\begin{array}{l}0.02 \\
(0.28)\end{array}$ & $\begin{array}{l}0.27^{* * *} \\
(0.00)\end{array}$ & & \\
\hline$\Delta$ Next Year & & & $\begin{array}{l}0.11^{* *} \\
(0.02)\end{array}$ & $\begin{array}{r}-0.04 \\
(0.58)\end{array}$ & & \\
\hline $\begin{array}{l}N=162 \\
R^{2}=0.30\end{array}$ & & & & & & \\
\hline
\end{tabular}

Notes: Estimation results for (1). Sample: 1994:M1-2018:M12 (excluded: 1998:M8, 2008:M10/M12, see Appendix A.2 for details), $\mathrm{p}$-values in parentheses, ${ }^{* * *} \mathrm{p}<0.01,{ }^{* *} \mathrm{p}<0.05,{ }^{*} \mathrm{p}<0.1$.

Similar to Romer and Romer (2004), we convert the series of residuals $\epsilon_{m}^{M P}$ in (1) from a meeting frequency into a monthly, quarterly, and annual time series $\epsilon_{t}^{M P}$ by assigning each shock to the month, quarter, or year in which it occurred. If there are multiple meetings within a period, then we aggregate the associated shocks by summing up the shocks within that time period. If there are no policy meetings, the corresponding shock is set to zero. The monthly series of monetary policy shocks is shown in Figure 1, while the quarterly and annual shocks are shown in Figures A.2 and A.3 in Appendix A.3.

Several properties are worth mentioning. First, some shocks are large: a few are more than 50 basis points, reflecting the overall large movements of the policy rate over our sample period (see Figure A.1 in Appendix A.1). Romer and Romer (2004) find similar large movements in the shock 


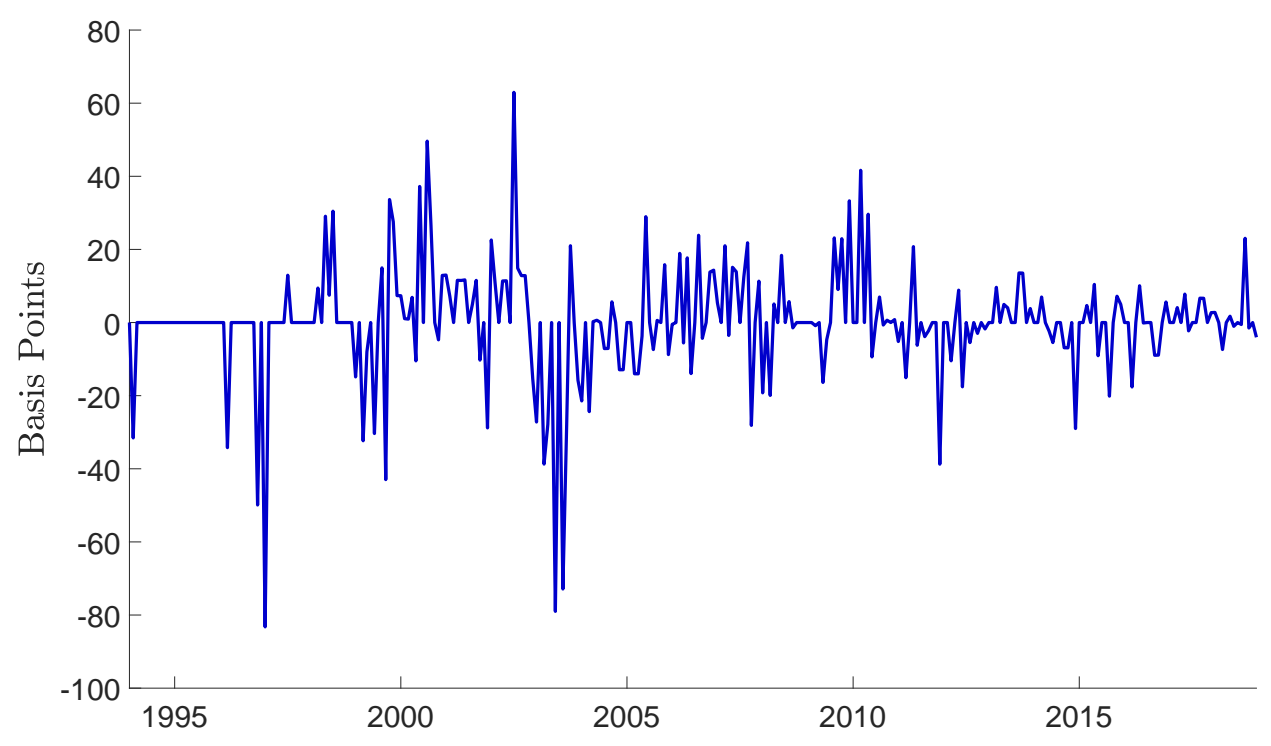

Figure 1: Monthly Series of Monetary Policy Shocks.

series for the United States. Particularly noticeable are the contractionary shocks around 2002 followed by the sharp easing shocks in 2003. The related policy rate changes were criticized by external observers who detected "policy mistakes that kept monetary policy too tight at the end of 2002 and early in 2003 and perhaps too loose at the end of 2003" (Bjørnland et al., 2004). The identification approach picks up both of these movements as relatively unrelated to the typical response to contemporaneous forecasts. In Appendix A.4, we add more texture to the identification and provide a quantitative analysis of the largest shocks that we uncover. Second, the shocks become smaller toward the end of the sample, in line with the reduced volatility of the policy rate in recent years. Third, in Figure A.4 in Appendix A.3, we compare the shock series with the actual rate changes. While the two tend to move in the same direction, as in Romer and Romer (2004), there are often significant differences. Fourth, we test whether the monthly shock series is predictable based on past data. Similar to Coibion (2012) and Cloyne and Huertgen (2016), we use lagged monthly changes of the unemployment rate, percentage changes in industrial production, and consumer price inflation as predictors. We find no evidence of predictability (see Table A.2 in Appendix A.5).

\subsection{Impulse Responses - Macro Aggregates}

Based on the identified shocks, we run a series of local projections on a monthly, quarterly, and annual frequency. Let $y_{t}$ be the outcome variable at time $t$, e.g., $(\log )$ real GDP or the unemployment rate. Following Jordà (2005), we estimate

$$
y_{t+h}-y_{t-1}=\alpha^{h}+\beta^{h} \cdot \epsilon_{t}^{M P}+\sum_{k=1}^{K} \gamma_{k}^{h} X_{t-k}+u_{t}^{h},
$$

where $h=0,1, . ., 5$ for annual data, $h=0,1, . ., 20$ for quarterly data, and $h=0,1, . ., 60$ for monthly data. The estimated coefficients $\beta^{h}$ give the percentage (point) change at horizon $h$ in response to 
a 100-basis-point monetary policy shock at the respective frequency. ${ }^{8}$ Note that we leave the contemporaneous response unrestricted, in contrast to a typical Cholesky identification. $X_{t}$ denotes a vector of controls. Our specification includes three years of lagged values of the monetary policy shock as in Romer and Romer (2004), but we do not add lagged values of the dependent variable or any other variable as regressors. ${ }^{9}$

We consider a wide range of outcome variables at the aggregate level. Table A.3 in Appendix A.6 gives precise details on the time series employed. ${ }^{10,11}$ The estimated impulse responses to a contractionary shock of 100 basis points are shown in Figure 2 (monthly frequency), Figure 3 (annual), and Figure A.8 (quarterly) in Appendix A.7. Across the different frequencies, we obtain textbook responses to a monetary tightening. The policy rate increases and subsequently reverses, a feature that we return to below when we analyze the responses based on the micro data. Economic activity contracts as the unemployment rate rises and industrial production, GDP, and consumption expenditures fall. Consumer prices and real wages and salaries decline. ${ }^{12}$ Figures A.7-A.11 in Appendix A.7 show the responses of a number of additional variables. Throughout, the responses have the expected signs: production and investment measures decline; various price indices, including house and stock prices, fall; hours worked decline; household income falls; and measures of income inequality increase, consistent with the findings by Coibion et al. (2017) for the United States. By and large, the estimated responses are statistically different from zero at the 95 or 68 percent confidence level. Further, in Appendix A.8, we check and confirm the robustness of our results to various modifications of the baseline regressions and compare the impulse responses to the analogous ones based on U.S. data, which turn out to be very similar.

Importantly, the impulse responses share a similar dynamic shape across the different frequencies. For example, the unemployment rate rises steadily in response to a monetary tightening, with a peak response after around 3.5 years, and falls thereafter. However, the size of the re-

\footnotetext{
${ }^{8}$ Throughout, we interpret the estimated shocks as direct observations of the structural monetary policy shocks as opposed to instruments (see, e.g., Mertens and Ravn, 2013; Stock and Watson, 2018). If our estimated shocks are imperfectly correlated with the true structural shocks, then the local projections in (2) are still valid. However, the impulse responses should then be interpreted as relative impulse responses, as opposed to absolute ones (see Paul, 2020, for details).

${ }^{9}$ To choose the lag length for the monetary policy shocks, we consult the Akaike and Bayesian information criteria. Across various outcome variables, the information criteria tend to favor longer than three lags of the monetary policy shock for near-term impulse responses and shorter ones for impulse responses further out. The chosen lag length is therefore a reasonable unifying compromise across variables and impulse response horizons. We further test (and confirm) the robustness of the results to the chosen lag length in Appendix A.8. We do not include lagged shocks as controls in the equation for the policy rate, since the policy rate responds on impact to the shock. The responses of the policy rate are largely unaffected by including additional controls.

${ }^{10}$ Most series are obtained from Statistics Norway. They are generally denominated in real units, seasonally adjusted, and provided for the full length of the sample. If not, we adjust the series using consumer prices, add seasonal dummies as additional regressors to equation (2), or estimate the local projections for the longest possible sample.

${ }^{11}$ The industrial production series shows a structural break over the years considered, which is due to a change in oil extraction, as illustrated in Figure A.6 in Appendix A.6. To account for this break, we consult a Chow test and, based on the result, include an additional dummy that equals one pre-2002:M2 and zero otherwise into the respective regressions.

${ }^{12}$ We use the CPI-AEL as our main indicator for consumer prices. This index excludes electricity and thereby mitigates the influence of the energy production sector (including oil and gas) on prices. We find similar responses using the overall CPI and several other consumer price indices supplied by Statistics Norway.
} 

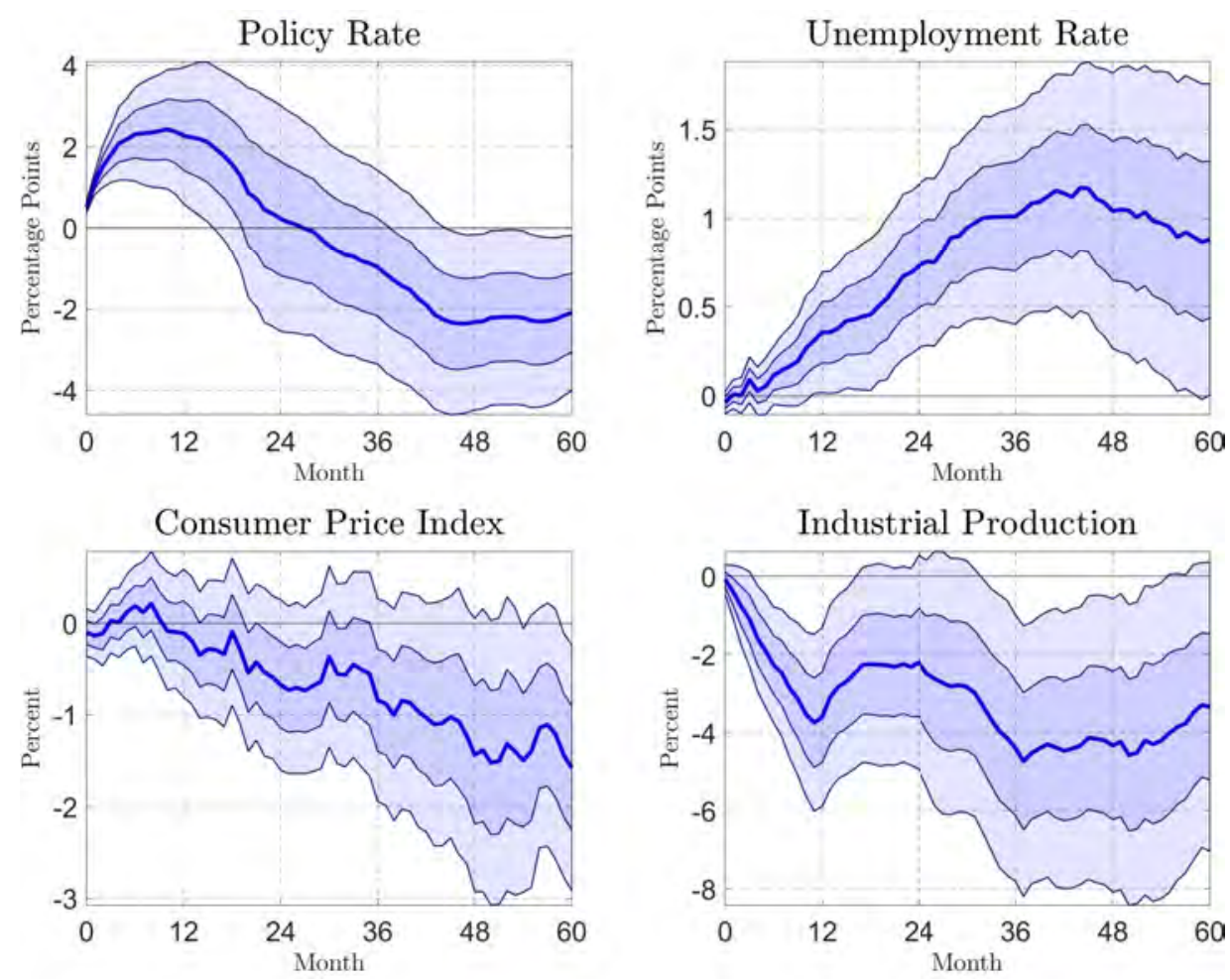

Figure 2: Impulse Responses at a Monthly Frequency.

Notes: Impulse responses to a 1 percentage point contractionary monetary policy shock at a monthly frequency, based on the local projection approach in (2). 95 and 68 percent confidence bands shown, using Newey and West (1987) standard errors. Table A.3 in Appendix A.6 lists the data sources. Additional impulse responses at a monthly frequency are shown in Figure A.7 in Appendix A.7.

sponses differs somewhat across frequencies. The response of the unemployment rate peaks at around 1.2 percent at the monthly frequency, 1.0 percent at the quarterly frequency, and 0.7 percent at the annual frequency. The policy rate equally increases by less at the annual frequency. In Appendix A.9, we show that the responses across different frequencies are of similar size if one corrects for the attenuated policy rate response at the lower frequency. Hence, both the shapes and the relative magnitudes of the responses across different frequencies are consistent.

Estimating impulse responses based on annual data yields accurate results in our setting. In principle, the approach of aggregating shocks to a lower frequency could also be applied to other environments in which detailed micro data is available only at an annual frequency. However, time aggregation can introduce bias and its effects should therefore always be carefully investigated. In Appendix A.10, we provide further intuition on the type of impulse responses that are more likely to result in similar responses across various frequencies. Apart from the aggregate responses, our interest lies in differences in the reactions to monetary policy in the cross section of households when using the micro data. Potential attenuation arising from time aggregation of the shocks therefore plays a smaller role for that part of the analysis. 

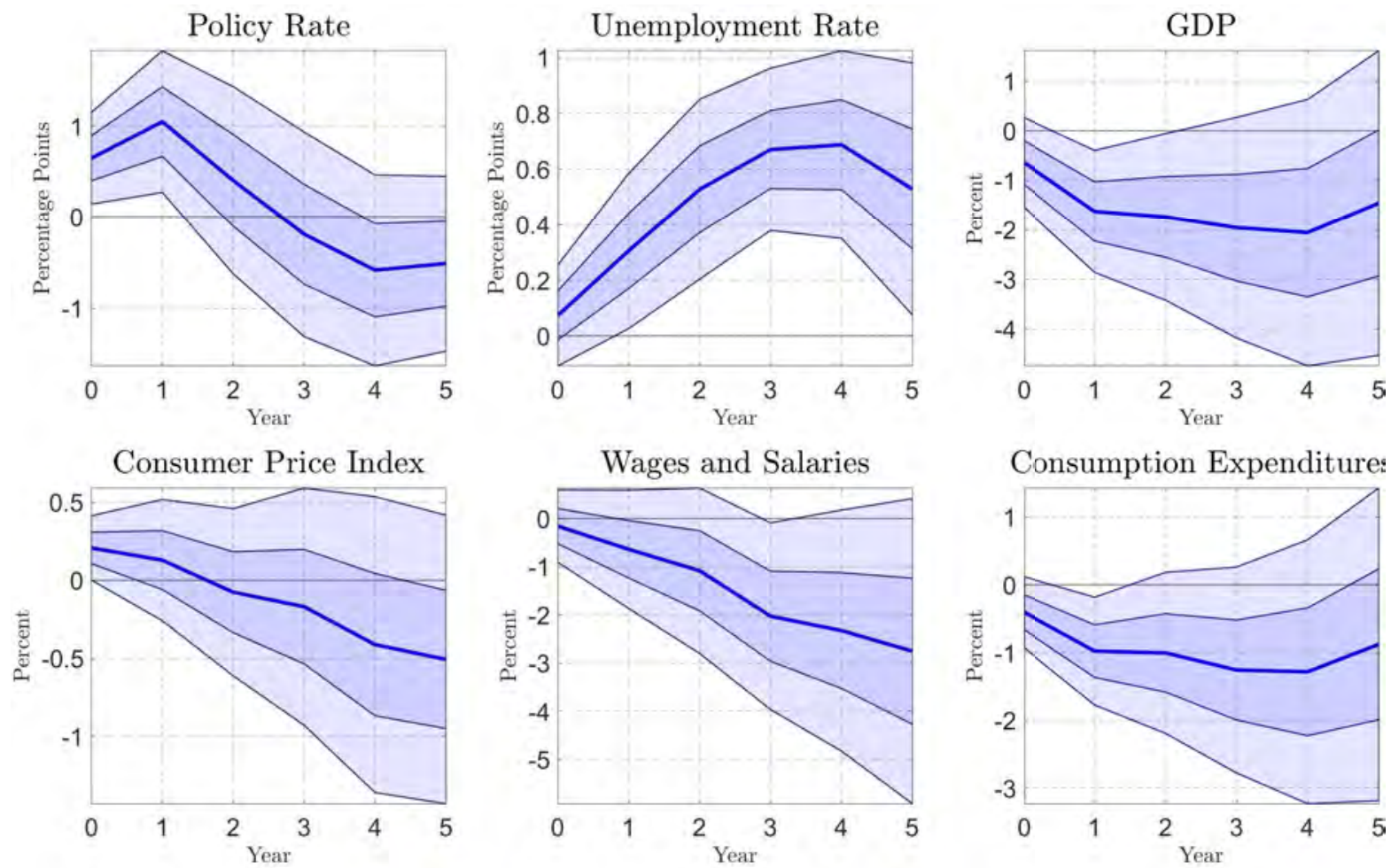

Figure 3: Impulse Responses at an Annual Frequency.

Notes: Impulse responses to a 1 percentage point contractionary monetary policy shock at an annual frequency, based on the local projection approach in (2). 95 and 68 percent confidence bands shown, using Newey and West (1987) standard errors. Additional impulse responses at an annual frequency are shown in Figures A.10 and A.11 in Appendix A.7.

\section{Administrative Data}

At the micro level, we base our study on Norwegian administrative data. Norway levies both income and wealth taxes on its inhabitants. The tax authority therefore collects information on all sources of income and balance sheet components down to detailed asset categories. The data are largely third-party reported, meaning that employers and banks report income and balance sheet information directly to the tax authorities. Below, we describe the data in detail, including the different sources, the procedure we follow to impute consumption, and the sample restrictions we impose, before turning to descriptive statistics.

\subsection{Data Sources}

We combine a number of Norwegian administrative registries maintained by Statistics Norway. All registries contain unique identifiers at the individual and household level, allowing us to link information from multiple sources. Our unit of observation is the household since saving and consumption decisions are made at the household level, and because wealth is taxed at the household level. We combine a rich longitudinal database covering every resident (containing socioeconomic information including sex, age, marital status, family links, educational attainment, and geographical identifiers), the individual tax registry, the Norwegian shareholder registry on listed 
and unlisted stock holdings, balance sheet data for listed and unlisted companies, and registries of housing transactions and ownership. All income flows are annual and assets are valued at the end of the year.

For our study, the Norwegian data have several advantages. First, the balance sheets and income statements of households are observed across multiple time periods. We are therefore able to construct a panel and follow the responses of households to monetary policy shocks across multiple years. Second, our data cover the universe of Norwegian households, allowing us to investigate the responses to monetary policy across many dimensions without running into issues of small samples. Third, the data are not top-coded and the only sources of attrition are death and migration. Fourth, the data are third-party reported with the exception of a few smaller items in the tax return, limiting the scope for measurement error. ${ }^{13}$

\subsection{Imputed Consumption Expenditures}

We compute a measure of consumption expenditures for each household using the budget constraint: ${ }^{14}$

$$
c_{i, t}=i n c_{i, t}-s_{i, t}
$$

where $c_{i, t}$ is consumption for household $i$ in year $t, i n c_{i, t}$ is disposable income, and $s_{i, t}$ is saving, defined as the change in net wealth excluding capital gains. Disposable income, inc $_{i, t}$, is observed in the data as the sum of labor income (salary and business income), capital income (dividends and interest income net of interest expenses), transfers (pensions, social security, and unemployment insurance), and retained earnings in private businesses, net of taxes. Net wealth is the sum of all assets (stocks, bonds, stock funds, private business, deposits, housing, vehicles, and outstanding claims) minus liabilities (mortgage, consumer, and student debt).

The main challenge of consumption imputation is to compute the relevant measure of saving excluding capital gains. ${ }^{15}$ A measure of saving including capital gains is directly observed because information on net wealth is available for the beginning and end of each year. To arrive at a measure of saving excluding capital gains, estimates of (realized and unrealized) capital gains are needed. Four types of assets accrue capital gains in our data (housing, stocks, stock funds, and private business) and different methods for calculating capital gains are applied for each of them. For housing, we observe transactions and compute capital gains as the change in housing wealth that is not due to housing transactions. ${ }^{16}$ For stocks, we use the stockholder registry and capital

\footnotetext{
${ }^{13}$ The most important (partially) self-reported positions are outstanding claims, inheritance, and foreign assets.

${ }^{14}$ Consumption imputation has by now been widely applied in the literature (see, e.g. Leth-Petersen 2010; Fagereng, Holm and Natvik 2021; Eika, Mogstad and Vestad 2020). Fagereng and Halvorsen (2017) provide details based on Norwegian data, although our method differs from theirs because we also utilize detailed transaction data on stocks and housing.

${ }^{15}$ Baker, Kueng, Meyer and Pagel (2018) compare imputed consumption with transaction-level data and show that systematic measurement errors could be linked to households with large holdings of assets that experience capital gains. We utilize detailed transaction data from stocks and housing to limit the extent of these measurement errors and test the robustness of our main results to the consumption imputation in Section 4.2.4 and Appendix C.3.

${ }^{16}$ Our measure of housing wealth is from Fagereng, Holm and Torstensen (2020). They combine detailed transaction
} 


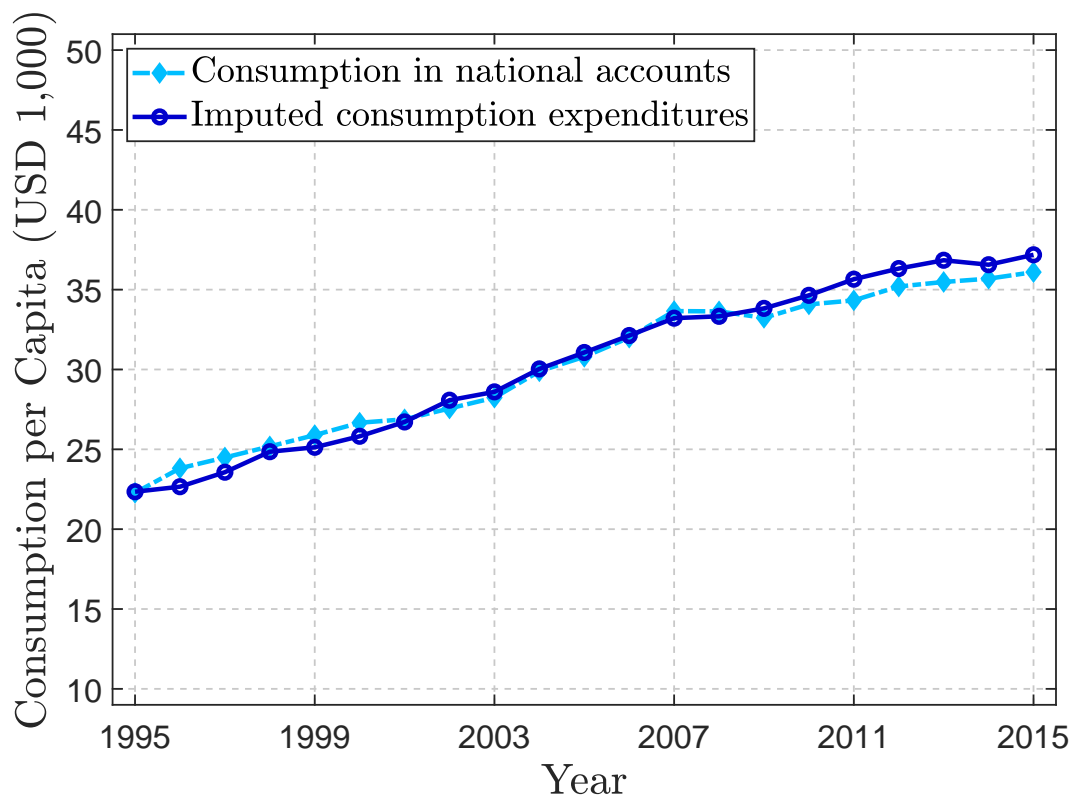

Figure 4: Imputed Consumption Expenditures and Consumption in the National Accounts.

Notes: Shown are real imputed consumption expenditures based on equation (3) and real consumption in national accounts. To make the series comparable, we exclude imputed rents for owner-occupied housing from the national accounts. All values are in real U.S. dollars.

gains on individual stocks after 2005 and average capital gains for stocks traded on the Oslo Stock Exchange prior to 2005. For stock funds, we use the measure of capital gains on stock funds from the national accounts. And for private businesses, we assume that capital gains are zero unless we observe that the company holds listed stocks on its balance sheet. If a firm holds stocks, we attribute its share of capital gains on the stocks to the owner of the private business according to the individual's ownership share in the firm. Appendix B.1 presents more details on how we compute capital gains. Figure 4 compares the imputed consumption expenditures with consumption in the national accounts. The two consumption series follow each other closely.

\subsection{Sample Restrictions}

We impose some minor sample restrictions. First, we focus on the adult population older than 20 years. Second, since our measure of consumption applies at the household level, we drop household-year observations in which individuals change marital status between single and couple. Third, we only include households that reside in Norway in at least two consecutive years. Fourth, we require individuals to have income and consumption above the minimum level in the Norwegian social security scheme. ${ }^{17}$ And finally, since there may be assets that experience sharp revaluations or assets that do not appear on the balance sheet in some years, we require the growth rate of imputed consumption expenditures to be less than 50 percent in absolute value. ${ }^{18}$ Table 2

data and information on housing unit characteristics to estimate housing wealth at the household-level using machine learning methods.

${ }^{17}$ The minimum level in the Norwegian social security was approximately USD 11,000 in 2015.

${ }^{18}$ After we impose the bound on age, the sample restrictions eliminate the following fraction of observations: change in marital status (4 percent), two consecutive tax filings in Norway (5 percent), disposable income and consumption 
Table 2: Summary Statistics.

\begin{tabular}{|c|c|c|c|c|c|}
\hline & Mean & SD & P10 & Median & P90 \\
\hline Age & 51.63 & 17.85 & 28.00 & 50.00 & 77.00 \\
\hline Consumption & 43,091 & 159,368 & 22,099 & 37,714 & 65,424 \\
\hline Disposable income & 43,437 & 81,284 & 23,616 & 39,833 & 63,817 \\
\hline Income before tax & 58,827 & 89,245 & 26,940 & 52,875 & 93,096 \\
\hline Labor income & 44,210 & 42,362 & 0 & 43,977 & 92,636 \\
\hline Net capital income & $-1,692$ & 21,031 & $-8,263$ & -892 & 2,355 \\
\hline Dividend income & 429 & 19,841 & 0 & 0 & 15 \\
\hline Interest income & 873 & 3,150 & 5 & 198 & 2,207 \\
\hline Interest expenses & 3,316 & 5,072 & 0 & 1,631 & 8,970 \\
\hline Total assets & 371,601 & $1,292,982$ & 5,588 & 281,798 & 782,215 \\
\hline Liquid assets & 31,337 & 75,379 & 565 & 11,262 & 78,912 \\
\hline Deposits & 26,569 & 59,632 & 465 & 9,065 & 67,554 \\
\hline Bonds & 1,015 & 13,660 & 0 & 0 & 0 \\
\hline Risky financial assets & 4,261 & 293,320 & 0 & 0 & 8,038 \\
\hline Stocks & 1,945 & 292,750 & 0 & 0 & 660 \\
\hline Stock funds & 2,316 & 12,507 & 0 & 0 & 5,339 \\
\hline Housing & 321,580 & 371,837 & 0 & 248,128 & 703,170 \\
\hline Total debt & 73,658 & 885,968 & 0 & 33,954 & 186,687 \\
\hline Observations per year & $1,909,603$ & 83,648 & $1,821,377$ & $1,864,722$ & $2,032,543$ \\
\hline
\end{tabular}

Notes: The table shows summary statistics for the estimation sample. Disposable income is the sum of labor income, capital income, transfers, and retained earnings in private businesses, net of taxes. Liquid assets is the sum of deposits, bonds, stocks held directly, and stock funds. Risky financial assets consist of stocks and stock funds. Stocks also includes stocks held indirectly through holding companies. Total debt includes mortgages, consumer debt, and student debt. All values except age are in U.S. dollars, 2011 prices.

presents summary statistics for the estimation sample.

\subsection{Institutional Setting}

In Norway, mortgage and deposit rates of existing contracts are sensitive to policy rate changes. The standard mortgage contract features an adjustable rate, accounting for more than 90 percent of all outstanding mortgage debt, in contrast to the United States where such contracts are typically issued with a fixed rate. ${ }^{19}$ In the deposit market, demand deposits account for more than 85 percent of all deposit contracts and deposits are the predominant form of liquid asset holdings, as can be seen in Table 2. ${ }^{20}$ Figure B.1 in Appendix B.2 demonstrates that deposit rates closely track the policy rate. In the United States, the rates paid on demand deposits are generally more sticky, resulting in substantial changes in the deposit spread over the monetary policy cycle (see, e.g., Drechsler, Savov and Schnabl, 2017).

\footnotetext{
above the social security minimum (6 percent), and bounds on consumption growth (19 percent).

${ }^{19}$ In the years, in which data on aggregate loans to households are available (2013 - 2018), between 90 and 93 percent of all outstanding debt issued to households took the form of adjustable mortgage contracts.

${ }^{20}$ Between 1996 and 2015, the share of deposits with adjustable rates was between 85 and 92 percent.
} 
A potential concern is that the data do not cover information on pension wealth. However, the absence of this information is unlikely to affect our results for the following reason. The large majority of pension wealth held by Norwegian households is made up of defined benefits associated with the public pension system. As households work, they accumulate pension points that are translated into benefit payments when they retire. The pension income they receive, which we record as transfers, is independent of monetary policy and the performance of financial markets more broadly. All risk is instead born by the Norwegian government, which holds substantial wealth in the Norwegian Government Pension Fund Global ("the oil fund").

\subsection{Income, Wealth, and Liquid Assets}

Following the recent literature on HANK models, we initially focus on the effects of monetary policy on households located at different segments of the liquid asset distribution. Below, a household's liquid assets are given by the sum of its portfolio positions in bank deposits, government debt, corporate bonds, publicly traded stocks, and stock fund shares. ${ }^{21}$ The remainder of the section illustrates characteristics of the wealth and income composition of households along the liquid asset distribution.

Asset and debt holdings are concentrated at opposite ends of the distribution. Figure 5 shows the cumulative shares of the most significant asset and liability classes. While assets, particularly financial assets, are concentrated among households with larger liquid asset holdings, those with smaller liquid asset positions hold a disproportionately large share of debt. The value fractions of deposits, stocks including mutual funds, and bonds that lie in the hands of the bottom half of the distribution are 6.7, 4.2, and 2.6 percent, respectively. Conversely, the top 10 percent of the distribution hold 50.9 percent of all deposits, 59.9 percent of all stocks, and 61.1 percent of all bonds contained in household portfolios. Illiquid assets in the form of housing are less concentrated along the liquid asset distribution, although housing wealth is equally more prevalent among households with high liquid assets. The opposite is true for debt, with consumer debt being more unequally distributed than mortgages.

The concentration of assets and debt is reflected in the composition of household portfolios and income. The left panel of Figure 6 illustrates the average portfolio shares of financial assets and housing as well as the average ratio of total debt to total assets in groups of households ordered by liquid asset holdings. The right panel shows financial and nonfinancial income as fractions of disposable income. ${ }^{22}$ Each group contains 5 percent of all observations, except at the upper end of the distribution, where we separate out observations located between the 95th and 99th, between the 99th and 99.9th, and above the 99.9th percentile of the liquid asset distribution.

\footnotetext{
${ }^{21}$ This definition follows Kaplan, Violante and Weidner (2014). The results discussed in Section 4 are robust to excluding equity and mutual fund shares from liquid assets.

${ }^{22}$ The shares of further asset classes like physical nonhousing wealth are omitted here for clarity. Net financial income is given by capital revenues net of capital expenditures. Nonfinancial income is the sum of labor income and transfers net of taxes.
} 
At the bottom and in the middle of the distribution, most wealth is held in the form of housing. Debt exceeds total assets below the 35th percentile and financial assets below the 70th percentile. This implies that, on average, net financial income is negative and hence that disposable income is smaller than nonfinancial income in the majority of groups. At the top of the distribution, financial asset holdings gain while housing and debt decline in importance. For households in the 99-99.9 percent group and in the top 0.1 percent group, the value of the financial portfolio exceeds that of real estate on average. Correspondingly, the ratio of net financial income to disposable income increases from -6.9 percent in the group containing the median household, which is negative as households are net debtors, to more than 55 percent in the top 0.1 percent group.
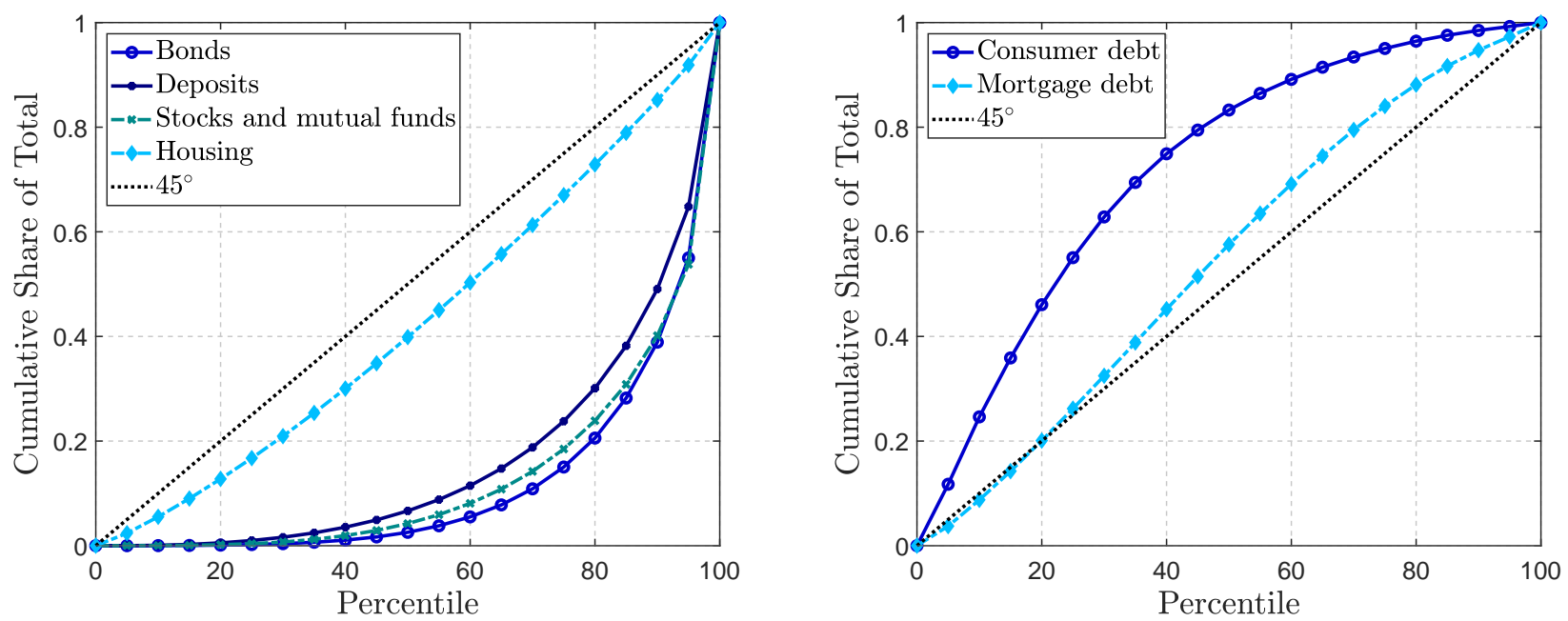

Figure 5: Cumulative Shares of Assets and Liabilities.

Notes: Cumulative shares by asset and debt type against percentiles of liquid asset distribution.
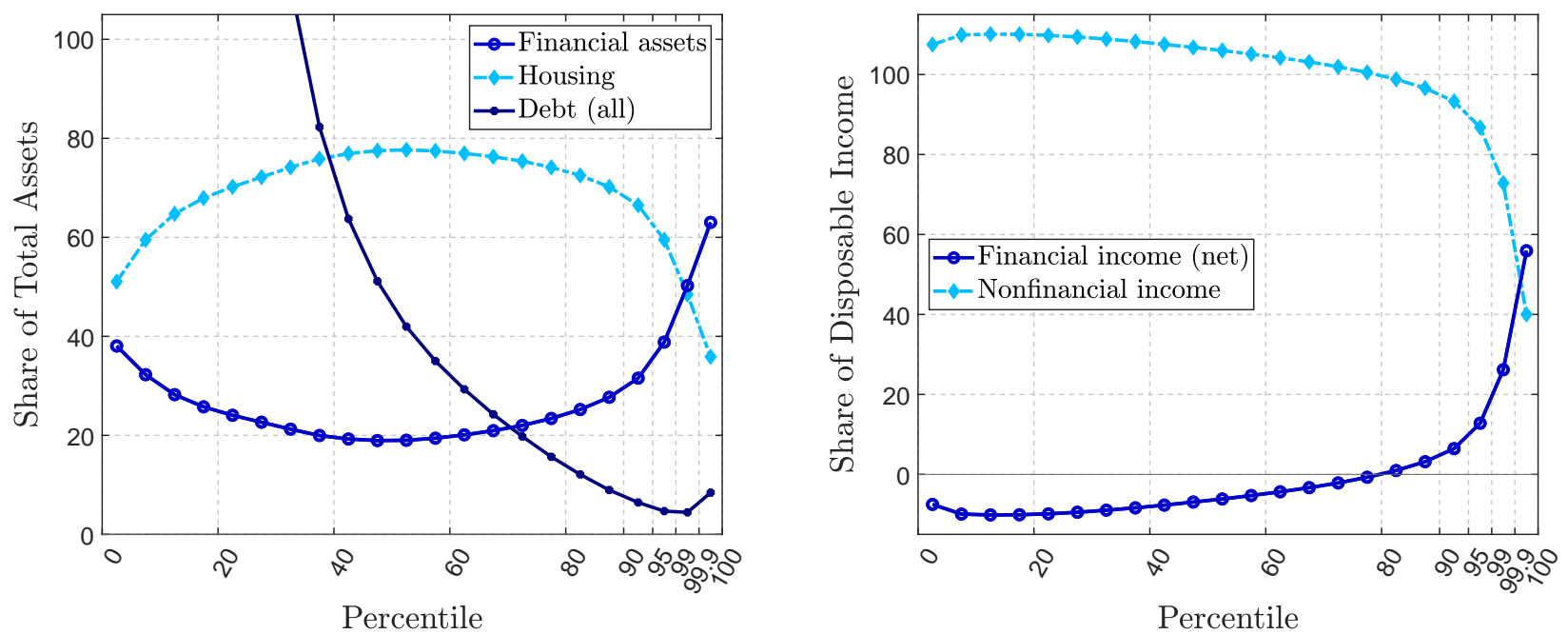

Figure 6: Portfolio and Cash-Flow Shares.

Notes: Shares of total assets (left panel) and disposable income (right panel) against percentiles of liquid asset distribution. Group averages shown. 


\section{Monetary Policy Transmission at the Household Level}

In this section, we use the shocks derived in Section 2 together with the data set described in the previous section to investigate the transmission of monetary policy at the household level. The section first shows estimates of the aggregate effects of monetary policy implied by the householdlevel data. It then disaggregates the results exploring the mechanisms that underlie them. We focus on the role played by the liquid asset positions of households to draw conclusions about the channels emphasized by the HANK literature and on interest rate exposure to assess the significance of cash-flow effects.

\subsection{Micro-Macro Responses}

As a first pass, we use the whole sample and obtain "macro impulse responses based on micro data." To this end, we estimate local projections of the form

$$
\frac{y_{i, t+h}-y_{i, t-1}}{\bar{y}_{t-1}}=\delta_{i}^{h}+\beta^{h} \cdot \epsilon_{t}^{M P}+\sum_{k=1}^{K} \gamma_{k}^{h} X_{i, t-k}+u_{i, t}^{h}
$$

where $y_{i, t}$ is some outcome variable of interest specific to household $i$ at time $t$, now denoted in (real) levels (e.g., household disposable income at constant prices). Further, $\delta_{i}^{h}$ denotes a householdspecific constant for horizon $h$, and $X_{i, t}$ is a vector of controls. Following the specification in (2), we include three years of lagged values of $\epsilon_{t}^{M P}$ and add two years of lagged one-year growth rates of the dependent variable. ${ }^{23}$ Notably, the dependent variable is given by the change in $y_{i}$ from $t-1$ to $t+h$, normalized by the average value $\bar{y}_{t-1}$ across all households at time $t-1$. This normalization makes $\beta^{h}$ comparable to the corresponding coefficient estimated on aggregate data in Section $2.2 .^{24}$

The estimated impulse responses are shown in Figure 7 for a selection of household variables. After a monetary tightening, consumption expenditures and disposable income fall. The decline of disposable income can be separated into the reactions of nonfinancial income (earned income and net transfers) and financial income (capital revenues minus capital expenditures). The former mimics the disposable income response and the latter is separated into its two subcomponents. Both capital revenues and expenditures follow the response of the policy rate in Figure 3. Initially they increase and subsequently fall. Their response suggests that they are driven by movements in interest income and expenditures, channels that we investigate in more detail below. Further, household debt, wealth, and risky financial assets fall, whereas the response of safe assets

\footnotetext{
${ }^{23}$ Specifically, we include $\left(y_{i, t-1}-y_{i, t-2}\right) / \bar{y}_{t-2}$ and $\left(y_{i, t-2}-y_{i, t-3}\right) / \bar{y}_{t-3}$ as controls. To choose the lag length for the dependent variable, we again consult the Akaike and Bayesian information criteria. Across various outcome variables and impulse response horizons, the chosen lag length of two years is again a reasonable compromise. We tested (and confirmed) the robustness of our main results to the choice of the lag length for the dependent variable and the shock.

${ }^{24}$ In contrast, when normalizing by $y_{i, t-1}$ instead, $\beta^{h}$ would give the average of the household-specific percentage changes to a monetary policy shock. While an interesting estimate in its own right, the interpretation of $\beta^{h}$ would differ from the one based on macro aggregate data and may be driven by extreme observations of some households.
} 

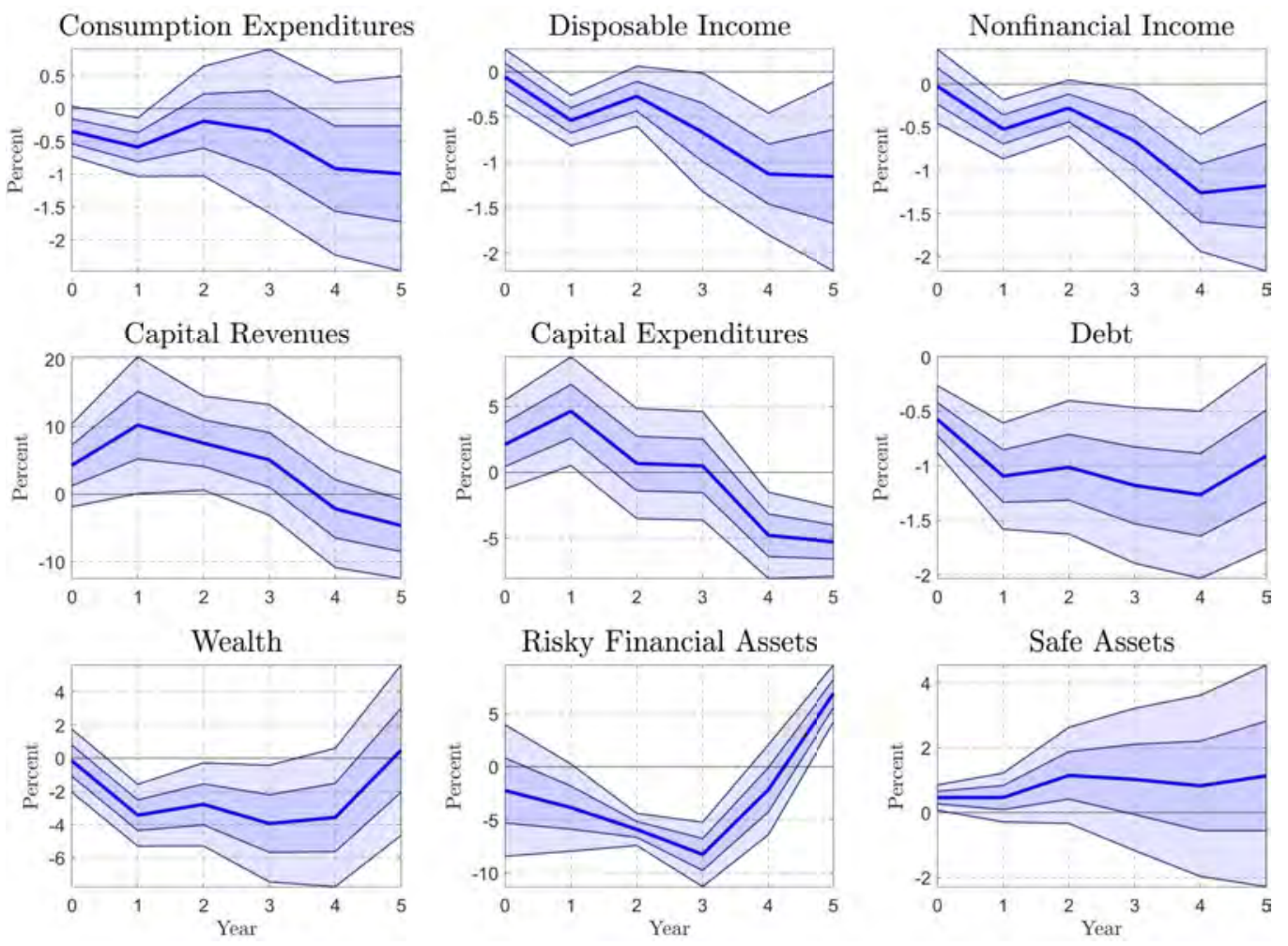

Figure 7: Micro-Macro Impulse Responses.

Notes: Impulse responses to a 1 percentage point contractionary monetary policy shock at an annual frequency, based on the local projection approach in (4). 95 and 68 percent confidence bands shown, using Driscoll and Kraay (1998) standard errors.

is slightly positive. ${ }^{25}$ Overall, the responses go in the expected directions and they are statistically different from zero at the 95 percent or at least at the 68 percent confidence interval. ${ }^{26}$

\subsection{Impulse Responses along the Liquid Asset Distribution}

To investigate the role of liquid asset holdings in monetary policy transmission, we divide households into groups of equal size indexed by $g=1,2, \ldots, 10$ and estimate separate impulse responses for each group. A household $i$ is allocated to group $g$ in period $t$ if its liquid asset holdings in $t-1$ fell between the $(g-1)$-th and $g$-th decile of the distribution. Ordering households according to lagged liquid asset holdings guarantees that the group allocation is not influenced by the shock

\footnotetext{
${ }^{25}$ Household debt consists of mortgage, consumer, and student debt. Household wealth is given by housing wealth, financial net worth, the value of vehicles (boats and cars), and outstanding claims (private loans and receivables). We find that the response of total household wealth is almost entirely driven by housing wealth, which is by far the largest component (see also Figure 4 in Fagereng, Holm, Moll and Natvik, 2019). Risky financial assets consist of stock holdings and mutual stock fund holdings. The inclusion of the latter is due to the fact that mutual stock funds typically invest in risky assets in Norway. Safe assets are given by deposits, bond holdings, and outstanding claims.

${ }^{26}$ The micro data also allow us to compute measures of inequality and their responses to monetary policy. We focus on disposable income, consumption expenditures, and wealth. For these three variables, we calculate the difference between the 90th and the 10th percentile of log levels of each distribution (p90-p10). Figure C.1 in Appendix C.1 shows the results based on the local projection approach in (2). Income and consumption inequality increase substantially after four to five years, confirming the findings by Coibion et al. (2017) based on U.S. data. In addition, we find that wealth inequality decreases in response to a monetary policy tightening, which is linked to the decline in asset prices associated with a monetary policy tightening (see Figure 14).
} 
occurring in period $t$. For each group $g$, the setup of the local projections is

$$
\frac{y_{i, t+h}-y_{i, t-1}}{i n c_{i, t-1}}=\delta_{i}^{h}+\beta_{g}^{h} \cdot \epsilon_{t}^{M P}+\sum_{k=1}^{K} \gamma_{g, k}^{h} X_{i, t-k}+u_{i, t}^{h} \quad \forall i \in g \text {, }
$$

where the notation is as in Section 4.1 and $h=0,1, \ldots, 5$. As in (4), $X_{i, t}$ includes three years of lagged values of $\epsilon_{t}^{M P}$ and two years of lagged one-year growth rates of the dependent variable. The main difference to (4), apart from the grouping of households, lies in the dependent variable. Changes of $y_{i}$ from $t-1$ to $t+h$ are expressed in $t-1$ units of disposable income $i n c_{i, t-1} \cdot{ }^{27}$ This normalization ensures that the estimated coefficients $\beta_{g}^{h}$ are comparable across different variables and that they give an indication of the economic importance of the effects for the households.

Before turning to the results, we outline the effects of monetary policy on household consumption predicted by theory to fix ideas and introduce the terminology used below. First, a change in the interest rate affects the price of consumption tomorrow relative to consumption today resulting in a substitution effect. Second, an interest rate adjustment gives rise to a standard income effect, which provides an incentive for savers to increase and for borrowers to decrease their consumption in response to a rise in the interest rate. Third, if households are particularly sensitive to transitory income changes (e.g., because they are close to a borrowing constraint or subject to information frictions), their consumption may exhibit an elevated positive response to their net interest income. We refer to the effect of changes in interest income or expenses on consumption in excess of that implied by the standard income and substitution effect as a "cash-flow effect." Fourth, monetary policy may trigger general equilibrium price responses, which themselves can affect consumption through income, substitution, and cash-flow effects, analogous to those above. For example, a consumption decline brought about by a rise in the interest rate that lowers labor earnings through the wage rate constitutes an indirect income effect of this type. Finally, interest rate changes may lead to a revaluation of financial and nonfinancial assets contained in household portfolios, which can be transmitted to consumption through their effect on household wealth or collateral, for example. We categorize these effects as consumption due to capital gains or losses. ${ }^{28}$

\subsubsection{Consumption, Income, and Saving}

Figure 8 shows the impulse responses of consumption and the ratio of consumption to disposable income to a positive 1 percentage point shock. The corresponding responses of disposable income and saving are shown in Figure 9. As before, saving is an "active" flow, that is, it is the part of the change in a household's assets which is not due to capital gains or losses. ${ }^{29}$ For each variable, the figures portray the complete impulse responses of all ten groups in the top row and a time-averaged version which facilitates a two-dimensional representation in the bottom row. Since the figures display the impulse responses across the entire distribution, they only show the

\footnotetext{
${ }^{27}$ Changes in the consumption-to-income ratio are not normalized by lagged income.

${ }^{28}$ An example is a consumption adjustment in response to stock price movements that are not merely a compensation for changes in dividends.

${ }^{29}$ Throughout, we distinguish between saving (flow) and savings (stock).
} 
point estimates, not the corresponding confidence intervals, to allow for a clear presentation. For each figure contained in this section, we include two sets of results in Appendix C.2. Figures C.2C.3 show the full impulse responses and the associated confidence intervals for selected groups $(g=1,5,10)$ and Figures C.4-C.5 the relative responses across groups, which allow to evaluate the significance of group differences.

The responses to a monetary policy shock differ systematically according to the level of liquid asset holdings. For the bottom 10 percent of households, disposable income stays nearly unchanged initially and then gradually falls. The decline is significant at the 5 percent level from year 3 onward and, on average, amounts to about 1.4 percent of disposable income in years 4 to 5 after the shock. The responses of saving and the consumption-to-income ratio are small in comparison, so that consumption closely follows income and also starts to fall statistically significantly after three years. Consumption of households located close to the median of the distribution is less responsive. In conjunction with their income decline in years 2 and 3, they allow their consumption-toincome ratio to rise and hence saving to fall. Both responses become statistically different from zero after the second year. In years 4 and 5, consumption is lowered but, relative to initial household income, the size of the decline is smaller than for the bottom 10 percent of households. The differences in the consumption response between these groups are equally significant at the 5 percent level.

At the top of the distribution, the responses are markedly different from those at the median and the bottom. Disposable income in the top group increases by about 1.4 percent on average in years 0 and 1 . Saving rises by around 0.7 percent of household income, implying that consumption increases by roughly the same amount. The positive consumption response is significant at the 5 percent level in year 1 . The ensuing sharp fall in income is associated with a statistically significant consumption adjustment of about the same size four to five years after the shock has occurred. At this impulse response horizon, the consumption response is of similar magnitude as that at the bottom of the distribution. As a result, the peak consumption response is inverse U-shaped along the liquid asset distribution.

Several of the results are worth stressing. At the bottom, the peak consumption response is significantly larger than around the median and the response of the consumption-to-income ratio is comparably small when income begins to fall. Both of these observations are consistent with the HANK literature, although the mechanisms at work may differ. The two-asset model by Kaplan, Moll and Violante (2018) predicts that households with small liquid asset holdings are close to a kink in their budget constraint and therefore have large MPCs, implying that monetary policy affects their consumption particularly strongly and the consumption-to-income ratio only weakly. Our estimates show that the disposable income of households at the bottom begins to fall in years 2 to 3 and further declines in years 4 to 5 , while saving remains relatively stable. The lack of a strong saving response is consistent with hand-to-mouth behavior at these horizons. Since saving increases initially and consumption falls somewhat when the policy rate rises, the estimates do not 

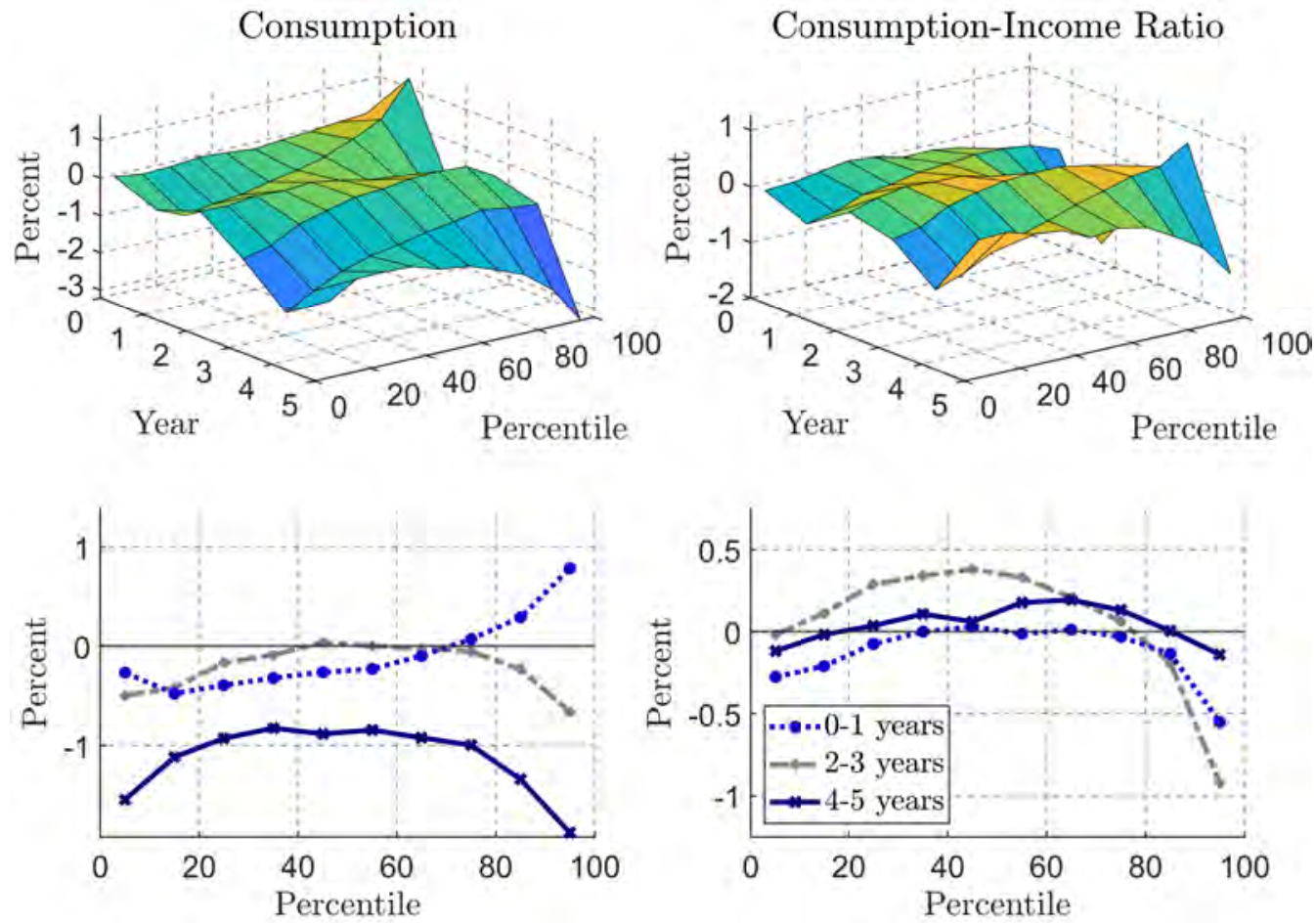

Figure 8: Impulse Responses of Consumption and Consumption-Income Ratio.

Notes: Changes relative to lagged net income (left) and changes of ratio (right) at segments of the liquid asset distribution. See Figures C.2-C.5 in Appendix C.2 for group responses and group comparisons with confidence bands.
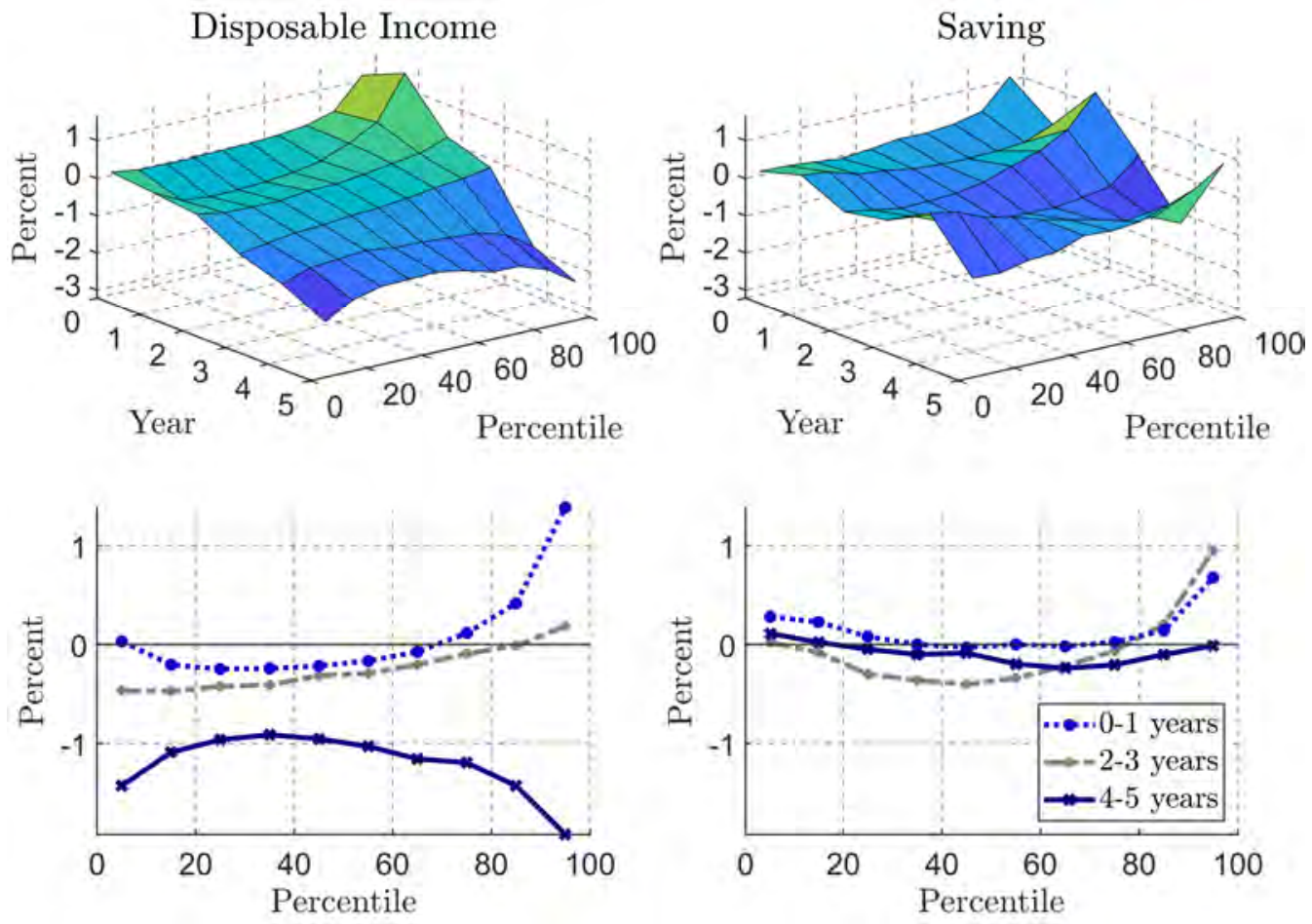

Figure 9: Impulse Responses of Net Income and Saving.

Notes: Changes relative to lagged net income at segments of the liquid asset distribution. See Figures C.2-C.5 in Appendix C.2 for group responses and group comparisons with confidence bands. 
allow us to reject that intertemporal substitution may play a role on impact. Around the median of the distribution, the decline in income after two to three years is matched by dis-saving. Hence, households in the middle of the distribution show signs of consumption-smoothing behavior, although they equally let income changes feed into consumption at the 4 to 5 year horizon. ${ }^{30}$

Our findings for the top of the distribution are inconsistent with the predictions of canonical HANK models. In these models, it is possible that households with high amounts of liquid asset holdings show a large and positive consumption response to a rise in the policy rate if the standard income effect dominates the substitution effect of the interest rate change. However, the magnitude of the consumption response relative to the income response that we observe is a lot larger than what can be generated by current HANK models. Put differently, for an income response of realistic size, structural models are unable to give rise to a consumption response that matches our estimates. The reason is that high-liquidity households in HANK models smooth the effect of temporary income changes on consumption closely in line with the permanent income hypothesis, implying that they have very low MPCs. We illustrate this point using a structural model in Appendix D. In the model, the response of consumption is too small relative to the response of disposable income even when we calibrate it such that high-liquidity households hold significantly more liquid assets than in the data and the income effect is permitted to dominate the substitution effect, as shown in Figure D.1.

Instead, our results are consistent with high MPCs even for high-liquidity households and hence with cash-flow effects playing an important role. In line with this view, Fagereng, Holm and Natvik (2021) find MPCs out of lottery prizes that are substantially larger than zero for households with substantial levels of liquidity. Based on an extended sample that matches our liquidity groups, we revisit their estimates and plot annual MPCs for the contemporaneous year in Figure 10. While the estimated MPC is declining with liquid asset holdings, it is still sizable for the top ten percent of the distribution (around 0.42), in accordance with our findings. ${ }^{31}$ In the following sections, we investigate the effect of monetary policy on household income and consumption in more detail.

\footnotetext{
${ }^{30}$ The seemingly high MPC on impact may be a result of two motives present at the same time. Households wish to increase saving and reduce consumption in response to the interest rate hike and to lower saving due to the decline in disposable income.

${ }^{31}$ In Figure E.3 in Appendix E.5, we apply these estimates, together with the ones for year 1, to the estimated disposable income response in Figure 9 and compare the implied consumption response to the estimated impact consumption response shown in Figure 8. Especially for the top of the distribution, the two estimates line up closely.
} 


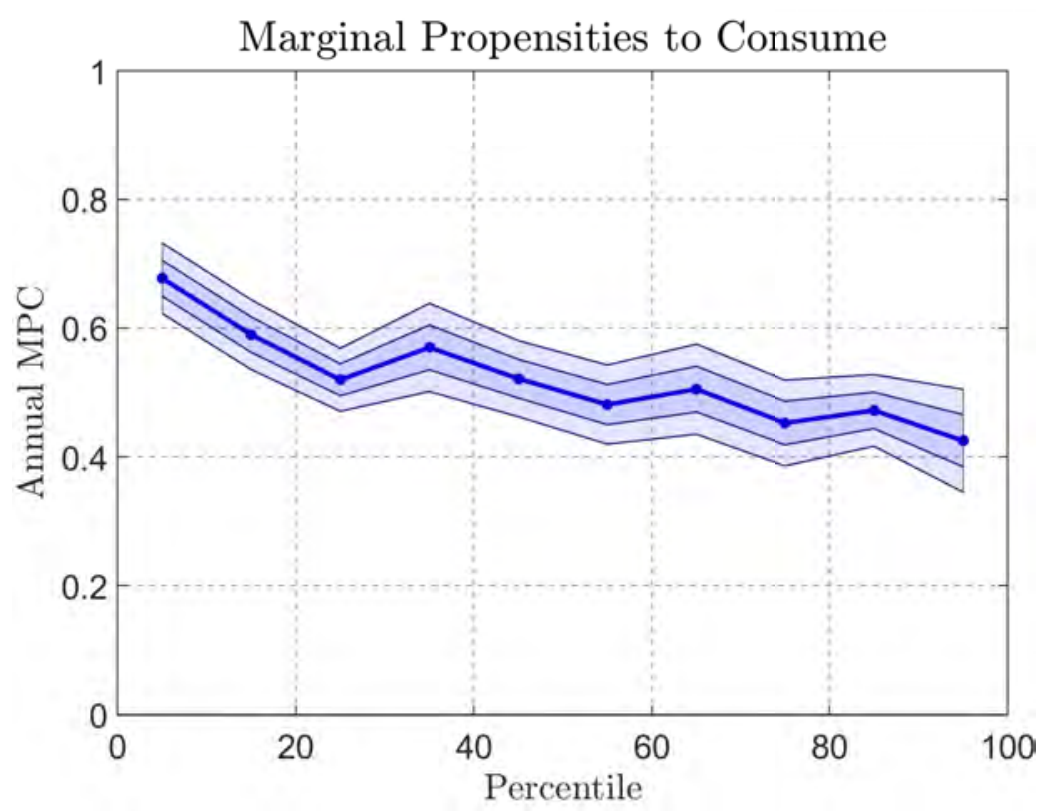

Figure 10: Estimated Annual MPCs across the Liquid Asset Distribution.

Notes: The figure shows annual MPCs for the contemporaneous year across the liquid asset distribution, with 68 and 95 percent confidence bands. The estimates are obtained using lottery winnings following Fagereng, Holm and Natvik (2021) based on an extended sample that matches the different liquidity groups.

\subsubsection{Decomposing the Income Response}

Below, we decompose the income responses portrayed in Figure 9 into various subcomponents. A first set of results is contained in Figure 11. It shows the impulse responses of the two most important income components, net financial income, defined as the difference between capital revenues and capital expenditures, and nonfinancial income, given by the sum of labor earnings, pensions, and other transfers net of taxes.

While nonfinancial income shifts household income more than financial income at the bottom of the liquid asset distribution, the opposite is true for households at the top. In the bottom group, nonfinancial income begins to gradually fall in the 2 to 3 year interval until an average decline of about 2.1 percent of lagged disposable income is reached in years 4 and 5 . Net financial income is lowered by 0.3 percent in the first two years but elevated by 0.6 percent in the final two years. For the top group, the eventual decline in nonfinancial income amounts to about 1.3 percent. Importantly, net financial income initially increases by 2.3 percent of disposable income before a decline of 1.6 percent is reached. All of these estimates are significant at the 5 percent level.

The differences in the responses along the liquid asset distribution are related to the patterns observed in the composition of income illustrated in Section 3.5. Figure 6 shows that the average labor income share is significantly larger at the bottom of the distribution than at the top. In contrast, the average net financial income share (in absolute value) is larger at the top than at the 

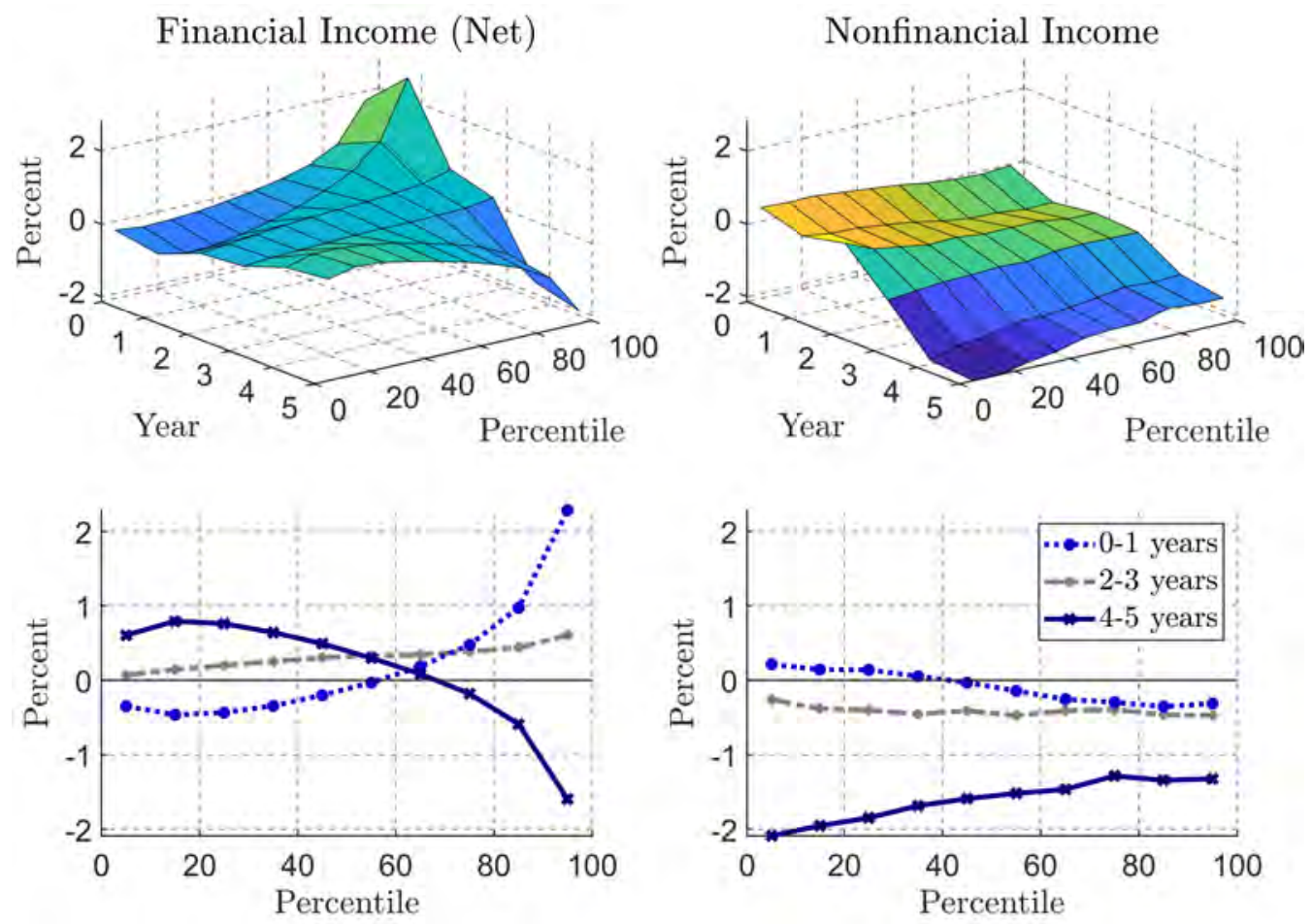

Figure 11: Impulse Responses of Net Financial Income and Nonfinancial Income.

Notes: Changes relative to lagged net income at segments of the liquid asset distribution. See Figures C.2-C.5 in Appendix C.2 for group responses and group comparisons with confidence bands.

bottom. Correspondingly, the nonfinancial income response is particularly strong for households with small liquid asset holdings, while the net financial income response is more pronounced for households with large liquid asset holdings. The initial increase in the interest rate following the shock lets financial income rise for households at the top and decline for households at the bottom, in line with average net financial income being of opposite sign. At both ends, the response in the last two years nearly mirrors that in the first two years as the policy rate drops below its initial level in year 3 after the shock.

The response of net financial income is decomposed further into the responses of capital revenues and capital expenditures in Figure 12. The estimates reflect the marked concentration of creditors at the upper end and debtors at the lower end of the liquid asset distribution. Both capital revenues and capital expenditures closely follow the policy rate. The latter is explained by the high prevalence of adjustable-rate mortgages in Norway. To investigate the former, we break the capital revenue response down further. Figure 13 shows the impulse responses of interest income and dividend income. Note that the dividend income responses are portrayed on a magnified scale. Nearly the entire capital income response is due to changes in interest income. Dividend income changes do not affect household income in a quantitatively meaningful way following monetary policy shocks. A likely explanation is corporate dividend smoothing, a well-documented empirical finding that goes back at least to Lintner (1956). 

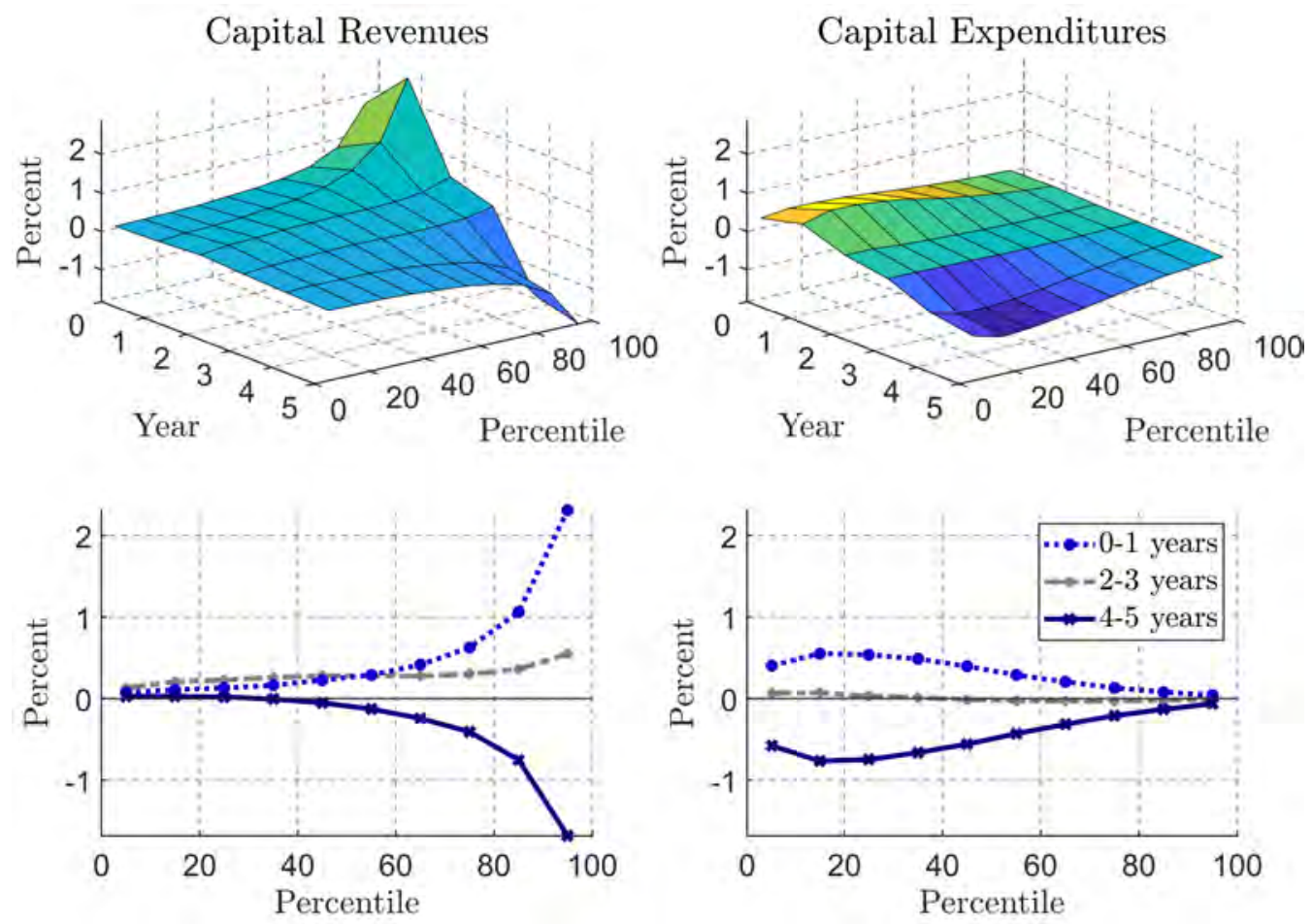

Figure 12: Impulse Responses of Capital Revenues and Expenditures.

Notes: Changes relative to lagged net income at segments of the liquid asset distribution. See Figures C.2-C.5 in Appendix C.2 for group responses and group comparisons with confidence bands.
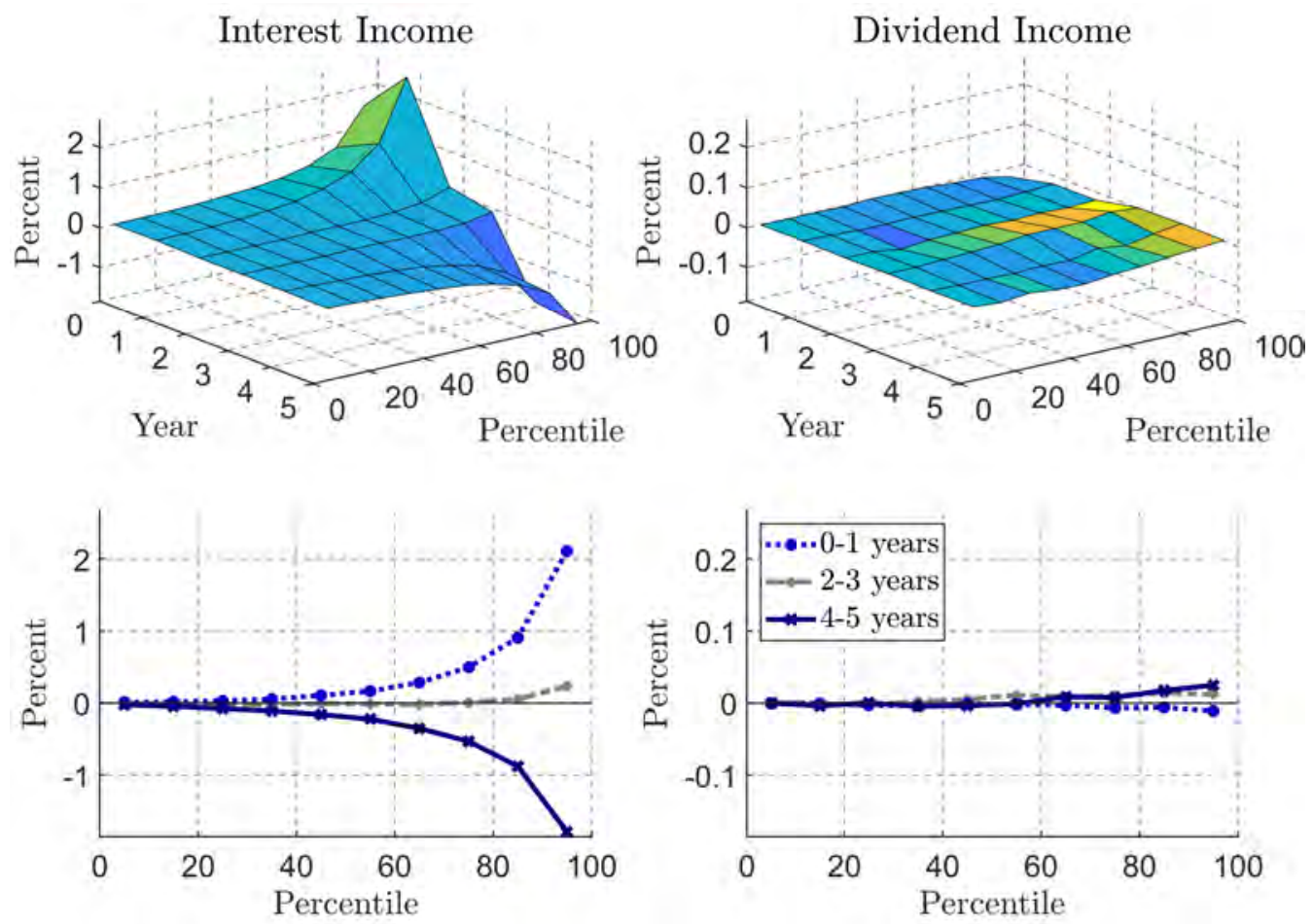

Figure 13: Impulse Responses of Interest and Dividend Income.

Notes: Changes relative to lagged net income at segments of the liquid asset distribution. See Figures C.2-C.5 in Appendix C.2 for group responses and group comparisons with confidence bands. 
Figures 11-13 show that there are slow-responding and fast-responding income components. Together with the estimates in the previous section, which suggest that household consumption is responsive to the income changes induced by monetary policy, this implies that the consumption response to a policy rate adjustment can be divided into different stages. Financial income, driven by interest income and expenses, responds on impact. Consequently, cash-flow effects play an important role in the early stages of the response. They are of opposite sign at both ends of the distribution, explaining the positive consumption response at the top and the negative response at the bottom. The nonfinancial income response takes time to build up, but is ultimately sizable and negative across the entire distribution, which suggests that indirect effects dominate the later stages of the response. A possible way to rationalize a delayed nonfinancial income response accompanied by a concurrent consumption contraction is a Keynesian consumption-investment feedback as described in Auclert, Rognlie and Straub (2020) and Bilbiie, Känzig and Surico (2020). In the HANK model by Auclert, Rognlie and Straub, a rise in the interest rate lowers investment leading to a decline in aggregate demand and wages. The fall in labor income in turn reduces consumption and thus output demand further setting off a multiplier effect. Adjustment costs imply that investment reacts sluggishly and stickiness in household expectations implies that consumption responds at the same time as labor income. ${ }^{32}$ Bilbiie, Känzig and Surico (2020) show that a multiplier of this type is amplified if the income of households with particularly high MPCs responds disproportionately strongly.

\subsubsection{Capital Gains}

To ascertain that households do not merely respond to changes in the valuation of their assets, we plot the impulse responses of capital gains in housing and risky financial assets in Figure 14. Since capital gains fall substantially in years 0 to 1 , they cannot explain the large initial consumption expansion at the top of the liquid asset distribution. This finding is consistent with the low MPCs typically estimated out of capital gains (Chodorow-Reich, Nenov and Simsek, 2021; Fagereng et al., 2019; Di Maggio, Kermani and Majlesi, 2020). The estimates reflect that housing is more equally distributed than risky financial asset holdings and that housing units on average represent a significantly larger share of household portfolios in all groups considered. The impulse responses of capital gains in housing are therefore relatively uniform across the distribution and larger in absolute value despite stock prices being more sensitive to monetary policy than house prices.

\subsubsection{Robustness}

The results are robust across a range of different specifications. The corresponding estimates are relegated to Appendix C.3. Figure C.6 demonstrates that the patterns in the consumption responses are equally pronounced if the consumption growth rate is considered. The same is true if we include a measure of housing service flows from owner-occupied housing following Fagereng,

\footnotetext{
${ }^{32}$ Their formulation of sticky information in the spirit of Gabaix and Laibson (2001) and Mankiw and Reis (2002) is silent about the sources of the information friction. However, D'Acunto et al. (2019) estimate that high-IQ men in Finland are more likely to update their information about prevailing interest rates than low-IQ men.
} 

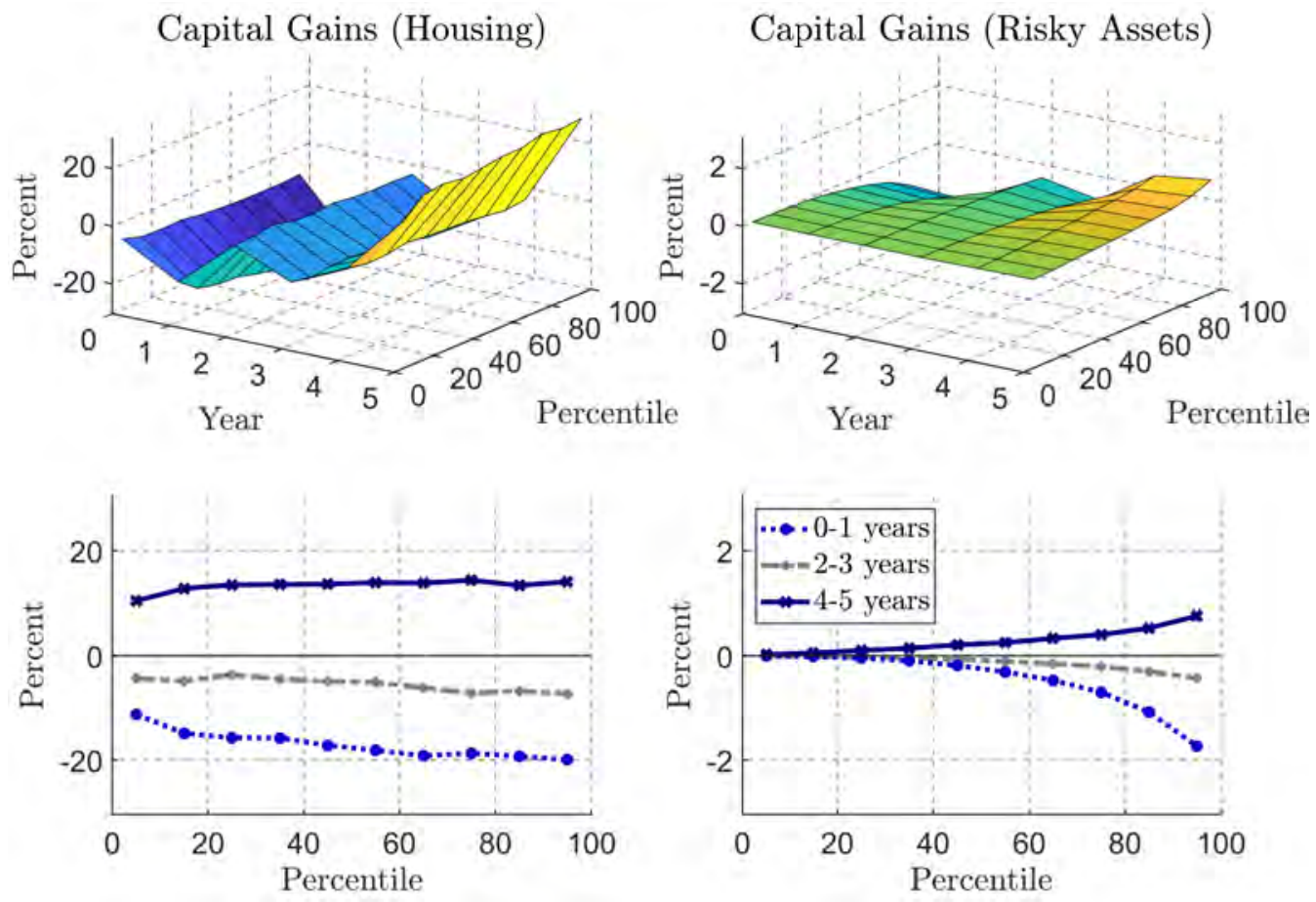

Figure 14: Impulse Responses of Capital Gains in Housing and Risky Financial Assets.

Notes: Changes relative to lagged net income at segments of the liquid asset distribution. See Figures C.2-C.5 in Appendix C.2 for group responses and group comparisons with confidence bands.

Holm and Natvik (2021) as shown in Figure C.7. Even households at the top of the liquid asset distribution may be affected by borrowing constraints if their income and consumption is large compared to their liquidity holdings. To exclude this possibility, Figure C.8 demonstrates that the results are nearly unchanged if we order households by lagged liquid asset holdings per unit of income. To verify that our procedure of imputing capital gains does not drive our results, we consider two exercises. First, we exclude equity holders from the estimation in Figure C.9. Second, we consider consumption responses based on (extreme) assumptions about capital gains in stocks in Figure C.10. ${ }^{33}$ In both cases, our results are robust. Finally, Figures C.11 and C.12 show that the responses described above are not merely an artifact of age effects or initial income differences that are correlated with liquid asset holdings. Splitting the liquidity deciles additionally into quintiles of the age or income distribution yields robust estimates across the subgroups.

An alternative explanation for the behavior at the top of the distribution could be a reverse causality between liquid asset holdings and large consumption expenditures. Households may hold liquid assets, because they plan to make large purchases, for example, of durables in the future. The strong positive consumption response of the top 10 percent in the first years may then reflect

\footnotetext{
${ }^{33}$ Note that we observe housing transactions and therefore the active component of saving in housing wealth. Hence, any potential mismeasurement in the capital gains on housing units does not affect our consumption measure. For stocks, our method of imputing capital gains ensures that the sum of individual capital gains adds up to aggregate capital gains in the stock market (before 2005) or an individual stock (after 2005). While aggregate capital gains are matched by construction, a concern could be that we distribute capital gains incorrectly across asset holders. Appendix C.3.2 demonstrates that measurement error in the capital gains on stocks does not lie at the heart of our findings.
} 
that the additional interest income received induces them to bring the durable purchase forward. However, for at least two reasons this channel is unlikely to play a significant role. First, the amount of liquid assets required to be in the top 10 percent is substantial (median of about 100,000 U.S. dollars in our sample). Second, a majority of households in the top group remain among the top 10 percent every year. ${ }^{34}$ The high persistence in liquid asset holdings makes it unlikely that households with large planned expenditures are an important source of the consumption response that we observe among high-liquidity households.

The magnitude of the responses to monetary policy shocks in units of lagged household income can differ across the liquid asset distribution due to systematic differences in both the change in the variable of interest and the level of household income prior to the shock. In Appendix C.4, we reestimate equation (5) replacing $i n c_{i, t-1}$ with average disposable income across all households to investigate the influence of the normalization. Since this makes the impulse responses summable across liquid asset groups, it also allows us to gauge whether household groups exist that are of disproportionate importance for the aggregate consumption response. The results confirm the significance of the households at the top of the liquid asset distribution, which show a large response relative to their initial income, as seen before, and in addition have comparably high income on average.

\subsection{Cash-Flow Effects}

To carve out the effect of interest rate-sensitive cash flows in more detail, we reorder households according to their net interest rate exposure and form groups based on the position of households in the resulting distribution before reestimating the local projections in (5). Net interest rate exposure is measured as deposits net of debt. Recall from Section 3 that most debt is held in the form of adjustable-rate mortgages and that both deposit and loan rates are highly elastic to the policy rate. Our measure of interest rate exposure is closely related to the concept of "unhedged interest rate exposure" in Auclert (2019). Note, however, that it abstracts from the maturity and duration of assets and liabilities.

The results are shown in Figures 15 and 16 with net debtors at the bottom of the distribution and net creditors at the top. The full impulse responses together with statistical significance tests can be found in Appendix C.5. In the year in which the shock occurs and in the year after that, the consumption responses at the top and at the bottom of the distribution are of similar magnitude but opposite sign. Both are significant at the 5 percent level in year 1 . Households with high positive net interest rate exposure tend to hold large amounts of interest rate-sensitive assets but little or no debt. Their capital revenues increase sharply and highly significantly in response to a positive interest rate shock while their capital expenditures remain unaffected. The strong reaction of net financial income overcompensates a small but significant decline in nonfinancial income, implying that disposable income rises at the top of the distribution. At the other end of the spectrum,

\footnotetext{
${ }^{34}$ On average, about 67 percent of the households in the top group in a given year were also among the top 10 percent in all of the previous five years.
} 
households with high negative interest rate exposure frequently hold little deposits and bonds but have large debt positions. Their net financial income response is nearly the mirror image of the one by households at the top of the distribution. The large decline in net financial income resulting from a strong and statistically significant increase in capital expenditures overcompensates a small rise in nonfinancial income. Disposable income therefore declines. At the top of the distribution, about half of the income change is saved in years 0 and 1 . In contrast, consumption moves nearly one-for-one with disposable income at the bottom.
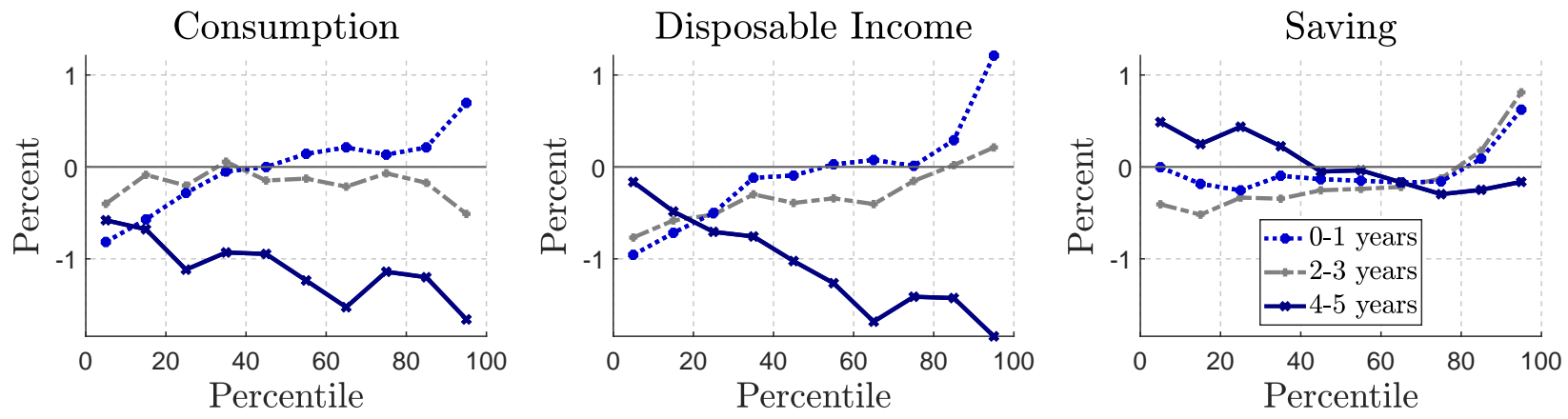

Figure 15: Impulse Responses by Net Interest Rate Exposure.

Notes: Changes relative to lagged net income at segments of the distribution of net interest rate exposure. See Figures C.23-C.26 in Appendix C.5 for group responses and group comparisons with confidence bands.
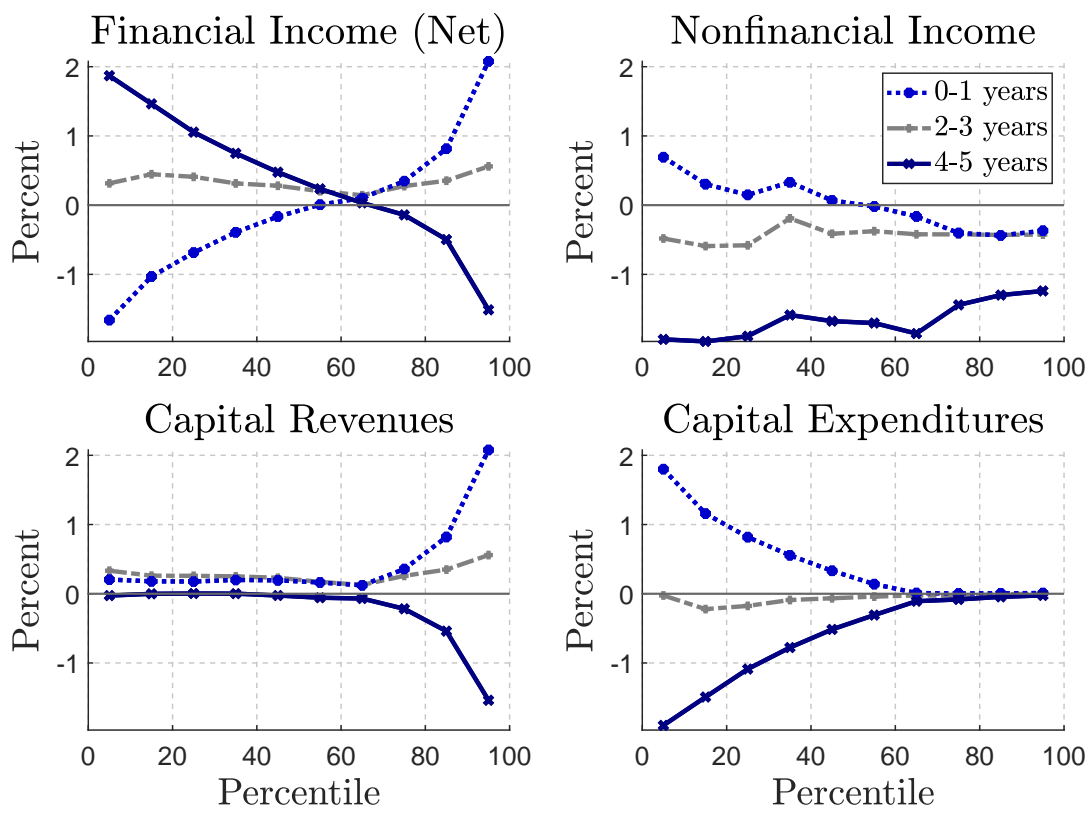

Figure 16: Impulse Responses of Income Components by Net Interest Rate Exposure.

Notes: Changes relative to lagged net income at segments of the distribution of net interest rate exposure. See Figures C.23-C.26 in Appendix C.5 for group responses and group comparisons with confidence bands.

The symmetry between the responses of households with large positive and large negative interest rate exposure disappears over time. While the financial income responses reverse after four to five years as the policy rate dips below its initial level, the responses of nonfinancial income 
are significantly negative across the entire distribution, as above. At the bottom, the sharp decline in capital expenditures is nearly offset by the fall in nonfinancial income. Since saving increases somewhat, the consumption response after four to five years is negative but small for households at the bottom. The increase in saving could be explained by debt prepayment in times of low debt-servicing costs. At the top, the financial and nonfinancial income responses are significantly negative in both years, implying that disposable income strongly declines. As the saving response is muted, consumption falls substantially more than at the bottom of the distribution.

The households can be reordered along many other dimensions. Doing so implies that net interest rate exposure is generally more dispersed within groups but less across groups. Accordingly, there are less clear patterns in the transmission of monetary policy to financial income and therefore to consumption. Figure 17 illustrates this observation for the income and the net worth distribution.
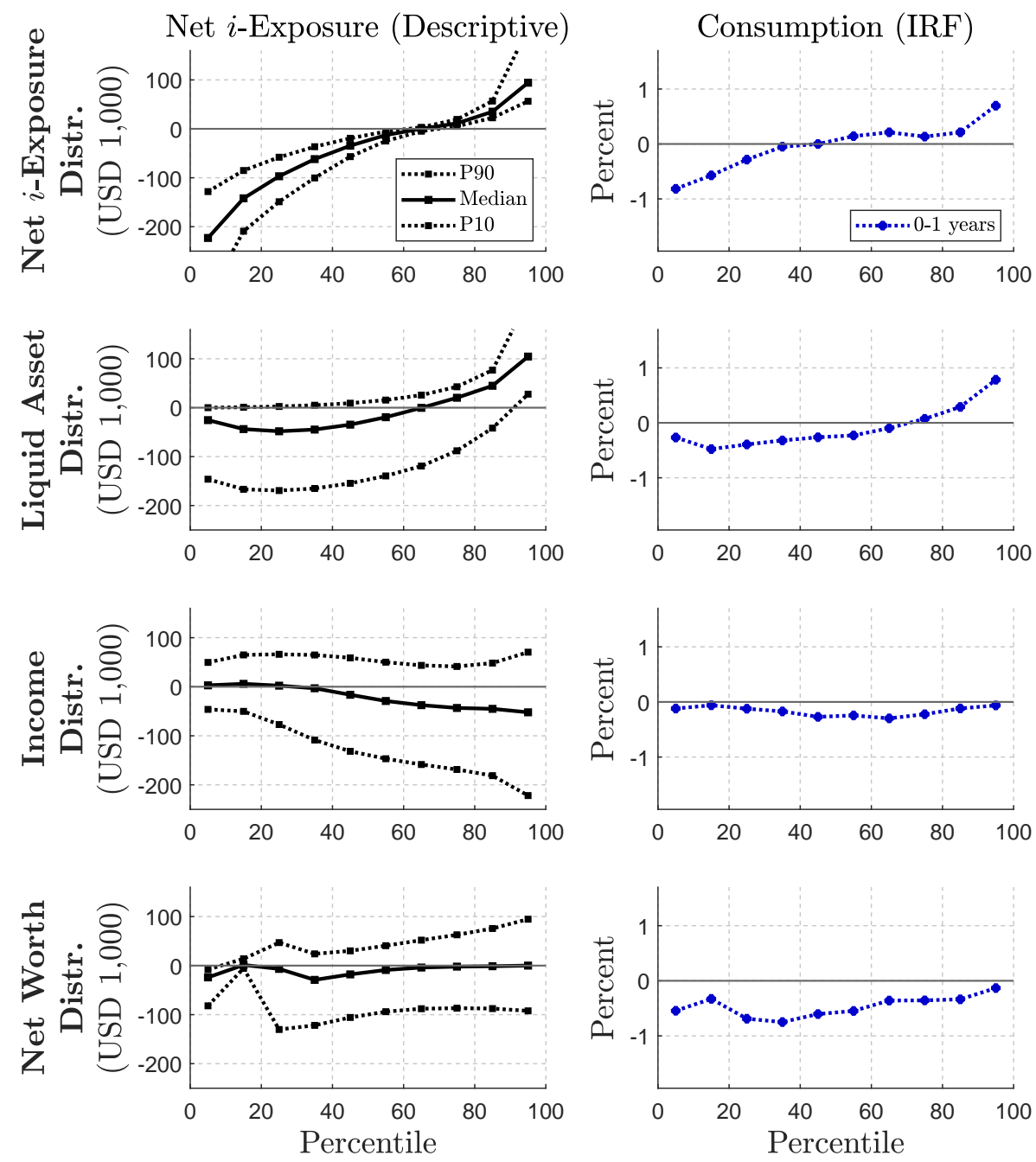

Figure 17: Net Interest Rate Exposure and Consumption Responses for Various Distributions. Notes: Median, 10th percentile, and 90th percentile of net interest rate exposure by group along the distributions of net interest rate exposure, liquid assets, income, and net worth (left column). Impulse responses in changes relative to lagged net income at segments of the same distributions (right column). 
The panels in the left column show descriptive statistics of net interest rate exposure in each of the ten groups when households are ordered by their net interest rate exposure, liquid assets, income, and net worth in the same way as above. The panels in the right column contain the corresponding consumption responses in year 0 to 1 . All income groups include households with substantial positive and negative exposure as can be seen from the dashed lines indicating the 10th and the 90th percentile. The large disparities within the income groups imply that the median exposure differs less strongly across groups than when households are ordered by their net interest rate exposure or their liquid asset holdings. The profile of consumption responses across the income distribution is therefore nearly flat. An analogous point applies to the net worth distribution demonstrating the importance of distinguishing between portfolio positions with interest rate sensitive and insensitive cash flows.

Our results are in line with the findings of other studies that evaluate the impact of cash flow adjustments induced by interest rate changes on household consumption. Di Maggio et al. (2017) examine the effects of the large declines in interest payments experienced by a number of households in the United States with adjustable-rate mortgages in the aftermath of the Great Recession. They show that households that were affected responded with sizable increases in durable consumption, namely car purchases, and voluntary repayment of mortgage debt. Based on data from Sweden, Floden et al. (2020) equally find evidence for interest rate changes to feed into household consumption through adjustable-rate mortgages.

\section{Direct and Indirect Effects of Monetary Policy}

The sizable nonfinancial income responses uncovered before and their close relation with households' consumption responses suggest that indirect effects are important for the transmission of monetary policy, as argued by Kaplan, Moll and Violante (2018). In this section, we analyze whether that is the case by separating households' consumption responses into direct and indirect effects.

To distinguish direct and indirect effects empirically, we estimate two separate types of consumption responses to monetary policy shocks. The first estimate is the one based on the regression setup (4) in Section 4.1, which considers all households and the associated responses include both direct and indirect effects. The second estimate is based on the same specification but also controls for a household's income change over the respective impulse response horizon. In particular, we consider local projections of the form

$$
\frac{c_{i, t+h}-c_{i, t-1}}{\bar{c}_{t-1}}=\delta_{i}^{h}+\beta^{h} \epsilon_{t}^{M P}+\sum_{m=1}^{3} \mu_{m}^{h} X_{i, t-m}+\sum_{k=1}^{K} \sum_{m=0}^{h} \gamma_{m}^{h, k} \widetilde{y}_{i, t+m}^{k},
$$

for $h=0,1, \ldots, 5$. The dependent variable is given by the change in consumption for household $i$ from period $t-1$ to $t+h$, scaled by the average consumption level in $t-1$ across the whole sample. As above, we include a household fixed effect $\delta_{i}^{h}$ and the same controls $X_{i, t}$ as in (4), that 
is, three years of lagged values of the monetary policy shock and two years of lagged one-year growth rates of the dependent variable.

The only difference between (4) and (6) is the additional set of income controls $\sum_{k=1}^{K} \sum_{m=0}^{h} \gamma_{m}^{h, k} \widetilde{y}_{i, t+m}^{k}$ where $\widetilde{y}_{i, t+m}^{k}=\left(y_{i, t+m}^{k}-y_{i, t-1}^{k}\right) / \bar{c}_{t-1}$ is a particular subcomponent $k$ of disposable income. ${ }^{35}$ The separate inclusion of various income types allows for the possibility that the income elasticities $\gamma_{m}^{h, k}$ vary by income type. Importantly, the timing of the income controls differs from the timing of the remaining regressors. For the impulse response horizon $h$, specification (6) controls for changes in household income that occur between $t-1$ and $t+h$. To allow for flexible dynamic relations between income and consumption changes, we decompose the income changes into $(h+1)$ changes for the response up to horizon $h$.

The estimated coefficients $\beta^{h}$ in (6) therefore give the partial effect of monetary policy on consumption at horizon $h$ holding income constant over the same time period. We exclude interest income and interest expenses from the set of income controls since changes in these items are considered direct income effects in Kaplan, Moll and Violante (2018). Hence, $\beta^{h}$ in (6) gives an estimate of the direct effects of monetary policy. In turn, any differences between the estimated coefficients $\beta^{h}$ in (4) and those in (6) are associated with indirect effects of monetary policy.

Our decomposition closely follows the theoretical separation by Kaplan, Moll and Violante (2018) (see, e.g., equation (3) in their paper). In Appendix E.1, we show that our empirical decomposition can be interpreted as an omitted variable bias problem, arising from the omission of the income controls in (4). To identify the direct effect using (6), two conditions have to be satisfied. First, households' consumption changes cannot feed back into their income within the same period, otherwise (6) would be subject to a reverse causality problem. For example, by lowering their consumption and increasing their saving, households could raise their interest income and may consume out of the additional income within the same period. However, given the exclusion of interest income and expenses from the set of income controls, such reverse causality likely plays a minor role. Second, to achieve identification, household income needs to move due to structural variation that does not also affect household consumption directly, unless it enters as a control in (6). Idiosyncratic income shocks, which are generally incorporated into HANK-models, are a prime example of such variation. Below, we show that our baseline results are robust to using lottery winnings as an instrument for idiosyncratic income movements.

While our decomposition closely resembles the one in Kaplan, Moll and Violante (2018), there are also three important differences. First, the indirect effect in Kaplan, Moll and Violante (2018) includes changes in consumption that are due to anticipated future changes in income. In contrast, we control only for changes in income up to horizon $h$ in (6), since the data only cover realized income at the household level and not household expectations of future income paths. Second,

\footnotetext{
${ }^{35}$ All income changes are scaled by the average consumption level $\bar{c}_{t-1}$ in period $t-1$ to match the dependent variable. In various robustness checks, we confirmed that this scaling of the controls does not impact the results.
} 


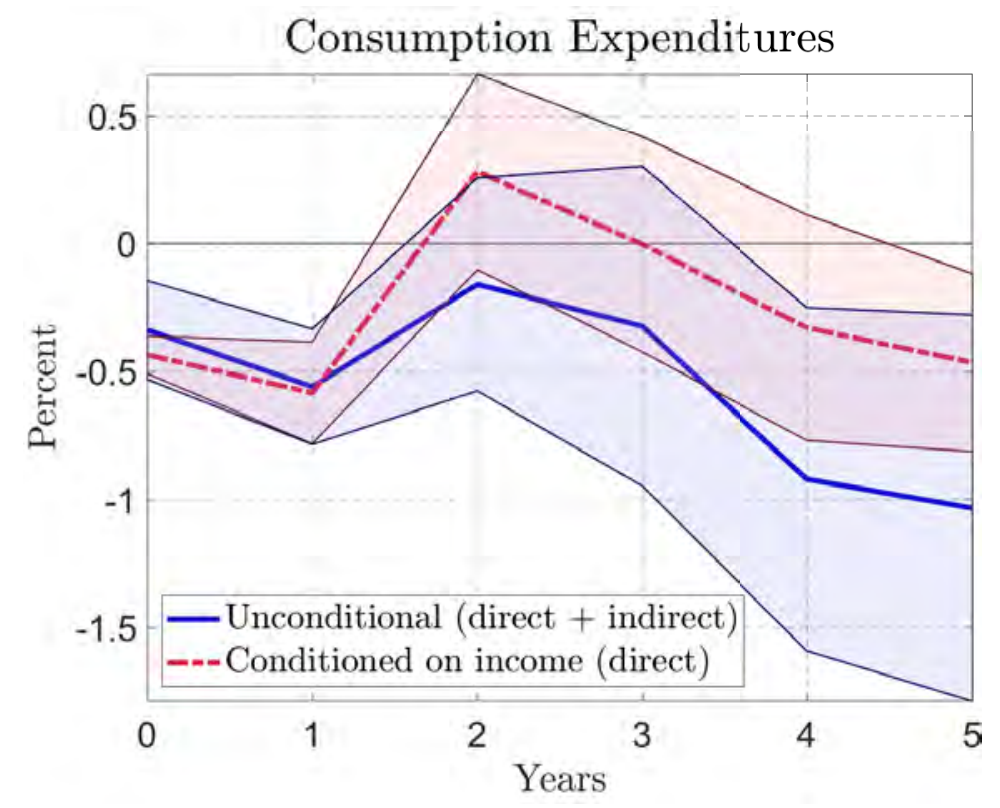

Figure 18: Direct and Indirect Effects of Monetary Policy.

Notes: Impulse responses to a 1 percentage point contractionary monetary policy shock at an annual frequency, based on the local projection approaches in (4) and (6). The blue line shows the estimated impulse responses without controlling for income, the red dashed line shows the responses with income controls. 68 percent confidence bands shown, using Driscoll and Kraay (1998) standard errors.

the indirect effect in Kaplan, Moll and Violante (2018) also includes indirect wealth effects. In a robustness exercise in Appendix E, we therefore control for changes of household wealth from risky assets. The extra capital gains controls do not affect our results. Third, Kaplan, Moll and Violante (2018) decompose the contemporaneous and first-year consumption responses into direct and indirect effects. In contrast, we analyze the path of consumption up to five years after the shock. This difference is important since the aggregate consumption response in the data builds up over time (see Figure 7 and, e.g., Christiano, Eichenbaum and Evans, 2005). ${ }^{36}$

The results are shown in Figure 18. ${ }^{37}$ The blue line shows the estimated impulse response of consumption without the income controls and the red dashed line shows those with income controls. For the contemporaneous and the subsequent year, the two lines lie nearly on top of each other. Hence, any consumption change in response to a monetary policy shock can be associated with direct effects. That is, the rise in the policy rate over this period (as shown in Figure 3) leads to an increase in saving and a fall in consumption that are unrelated to a change in nonfinancial income over this period. After year two, the two lines start to diverge. The red dashed line even turns positive in year two after a shock, which can be associated with the fall in the policy rate around this time (see Figure 3). At the five-year horizon, indirect effects dominate, accounting for more

\footnotetext{
${ }^{36}$ That is also a difference in comparison with the decomposition by Auclert (2019). He considers one-period changes in income, prices, and interest rates to separate the aggregate contemporaneous consumption response into different channels.

${ }^{37}$ For these estimations, only households that are observed for all periods over the five-year impulse response horizon are included in the sample to ensure that the estimated differences are not due to different samples.
} 


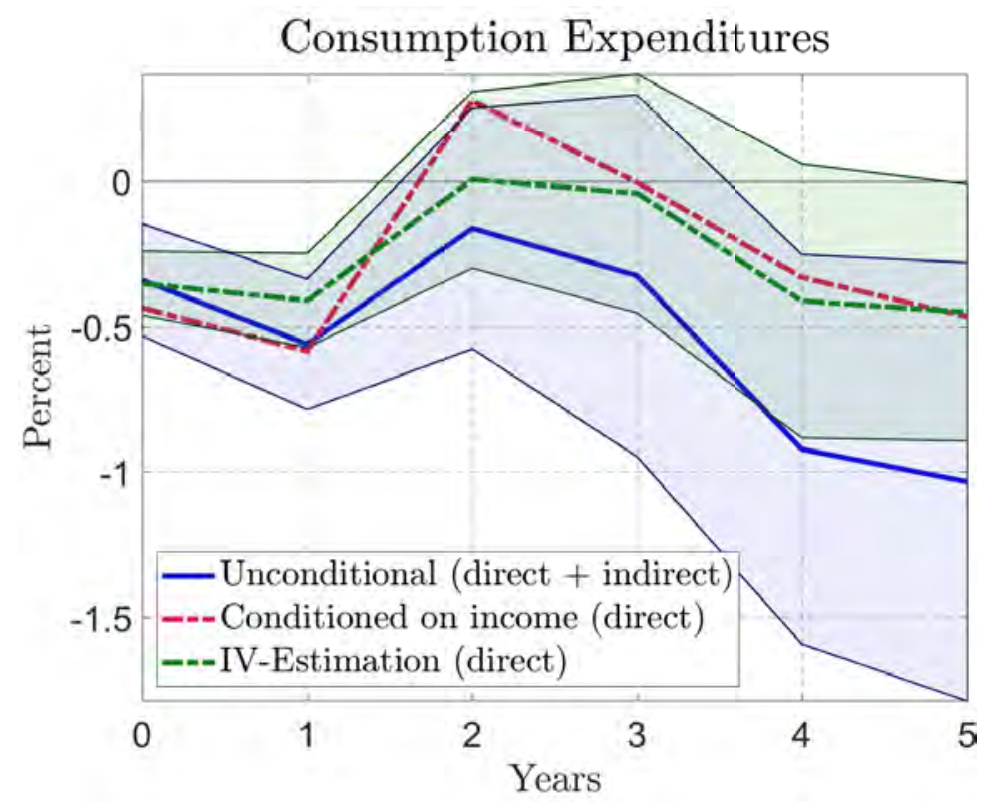

Figure 19: Direct and Indirect Effects of Monetary Policy - IV-Estimation.

Notes: Impulse responses to a 1 percentage point contractionary monetary policy shock at an annual frequency based on the local projection approach in (4) (blue solid line), the instrumental variable approach described in Appendix E.1 (green dashed line), and the local projection approach in (6) (red dashed line). 68 percent confidence bands shown, using Driscoll and Kraay (1998) standard errors.

than 50 percent of the consumption response. ${ }^{38}$

Thus, our findings show that the dominance of the indirect effect of monetary policy, described theoretically by Kaplan, Moll and Violante (2018), also holds up empirically. However, in Kaplan, Moll and Violante (2018), the indirect effect already comes into play over the first year of the shock. In contrast, our results show that it takes time for the indirect effect to build up. Initially, the consumption response is almost completely explained by direct effects. After around two to three years, the indirect effect dominates and explains most of the consumption response in the data. In Figure E.2 in Appendix E.4, we repeat the above exercise across the liquid asset distribution. Direct effects dominate initially for all households across the entire distribution. After two to three years, indirect effects account for the majority of the consumption response for the bottom half of the distribution, for which nonfinancial income is particularly important. In fact, for the bottom 10 percent, indirect effects explain nearly all of the drop in consumption. ${ }^{39}$

A potential identification concern is that household income may be driven by structural variation that also affects consumption directly and that is not controlled for in (6). If such variation

\footnotetext{
${ }^{38}$ In comparison, Kaplan, Moll and Violante (2018) show that indirect effects account for around 80 percent of the total consumption response over the first year in their model.

${ }^{39}$ Based on these regressions, Figure E. 4 in Appendix E. 5 shows the estimated coefficient with respect to the contemporaneous nonfinancial income control for the time zero impulse response horizon $\hat{\gamma}_{0}^{0, k}$ based on regression (6) across the liquid asset distribution. The estimates range from around 0.7 at the bottom to around 0.3 at the top of the distribution. While these coefficients should not be understood as MPC measures, they line up closely with the MPC estimates that are shown in Figure 10.
} 
is large, regression (6) does not identify the true direct effect. To address this concern, we use lottery winnings as instruments for household idiosyncratic income shocks based on the data in Fagereng, Holm and Natvik (2021). We describe the data and the procedure in Appendix E.2. In the first stage, household nonfinancial income is projected on the monetary policy shock and the lottery winnings, in addition to our standard controls in (6). ${ }^{40}$ In the second stage, the predicted values are used as controls as in (6). Figure 19 shows the results. Strikingly, the estimated impulse responses in Figures 18 and 19 are nearly the same.

\section{Conclusion}

The frequently estimated aggregate responses to monetary policy mask large heterogeneity at the household level. Our results about the effects of monetary policy on household consumption, income, and saving based on administrative data from Norway may guide policy makers and a new generation of HANK models alike.

We order households according to their liquid asset positions and estimate impulse responses at fine segments along the resulting distribution. Households at the bottom of the distribution show a stronger consumption response than those around the median. Following a monetary tightening, low-liquidity households reduce their consumption when their disposable income starts to fall, while households around the median initially save less or borrow more. These findings are consistent with obstacles to consumption smoothing, such as a borrowing constraint, faced by households with low liquid asset holdings, a mechanism that lies at the heart of many recent HANK models.

Monetary policy affects the net financial income of borrowers and savers. Our estimates indicate that these income changes are permitted to feed into consumption. When the policy rate rises, net creditors see their interest income increase, whereas net borrowers experience a rise in their interest expenses. Both of these effects have a substantial impact on household consumption, giving rise to an initial response that is of opposite sign at both ends of the liquid asset distribution. The finding that high-liquidity households increase their consumption in response to the rise in interest income associated with a monetary tightening is perhaps most surprising. It presents a challenge for HANK models: even households with substantial liquidity consume a sizable fraction of temporary income changes.

We expect the heterogeneity in responses that we uncover to be a feature of monetary policy in many countries beyond Norway. The distribution of assets and debt is more unequal in countries like the United States than in Norway, which by itself points to even stronger heterogeneity in the effects on consumption. The prevalence of adjustable-rate mortgages and the relatively high elasticity of deposit rates to monetary policy suggest that the household cash-flow channel may

\footnotetext{
${ }^{40}$ The F-test statistics from the various first-stage regressions are all well above typical critical values testing for weak identification, because the lottery winnings directly enter household nonfinancial income.
} 
be somewhat more pronounced in Norway than in countries where mortgages predominantly carry a fixed rate and interest rate pass-through is more subdued. However, since HANK models typically abstract from frictional interest rate pass-through, Norway is a suitable environment for testing the predictions of these models.

The relative strength of the direct and indirect effects of monetary policy depends on the impulse response horizon. Direct effects dominate in the first two years after a shock. Indirect effects gain in importance in the following years as the response of nonfinancial income builds up, suggesting that the characteristics of a country's productive sector and labor market affect monetary policy transmission to private households. Our results confirm that indirect effects play a sizable role in transmitting interest rate changes to consumption, with the important qualification that it takes time for these effects to unfold. 


\section{References}

Auclert, Adrien. 2019. "Monetary Policy and the Redistribution Channel." American Economic Review 109(6):2333-67.

Auclert, Adrien, Matthew Rognlie and Ludwig Straub. 2018. The Intertemporal Keynesian Cross. Unpublished manuscript.

Auclert, Adrien, Matthew Rognlie and Ludwig Straub. 2020. Micro Jumps, Macro Humps: Monetary Policy and Business Cycles in an Estimated HANK Model. Working Paper 26647 National Bureau of Economic Research.

Baker, Scott R, Lorenz Kueng, Steffen Meyer and Michaela Pagel. 2018. Measurement error in imputed consumption. Unpublished manuscript.

Barnichon, Regis and Christian Matthes. 2018. "Functional Approximation of Impulse Responses." Journal of Monetary Economics 99(C):41-55.

Bayer, Christian, Ralph Luetticke, Lien Pham-Dao and Volker Tjaden. 2019. "Precautionary Savings, Illiquid Assets, and the Aggregate Consequences of Shocks to Household Income Risk." Econometrica 87(1):255-290.

Beraja, Martin, Andreas Fuster, Erik Hurst and Joseph Vavra. 2018. "Regional Heterogeneity and the Refinancing Channel of Monetary Policy." Quarterly Journal of Economics 134(1):109-183.

Berger, David, Konstantin Milbradt, Fabrice Tourre and Joseph Vavra. 2018. Mortgage Prepayment and Path-Dependent Effects of Monetary Policy. Working Paper 25157 National Bureau of Economic Research.

Bilbiie, Florin O. 2008. "Limited asset markets participation, monetary policy and (inverted) aggregate demand logic." Journal of Economic Theory 140(1):162-196.

Bilbiie, Florin O. 2020. “The new Keynesian cross." Journal of Monetary Economics 114:90-108.

Bilbiie, Florin O., Diego R. Känzig and Paolo Surico. 2020. Capital, Income Inequality, and Consumption: The Missing Link. Unpublished manuscript.

Bjørnland, Hilde C, Thomas Ekeli, Petra M Geraats and Kai Leitemo. 2004. "Norges Bank Watch 2004, An Independent Review of Monetary Policymaking in Norway." Norges Bank Watch Report Series No 5 .

Bunn, Philip, Jeanne Le Roux, Kate Reinold and Paolo Surico. 2018. “The consumption response to positive and negative income shocks." Journal of Monetary Economics 96:1-15.

Campbell, John Y. and N. Gregory Mankiw. 1989. "Consumption, Income, and Interest Rates: Reinterpreting the Time Series Evidence." NBER Macroeconomics Annual 4:185-216.

Challe, Edouard. 2020. "Uninsured unemployment risk and optimal monetary policy in a zeroliquidity economy." American Economic Journal: Macroeconomics 12(2):241-83. 
Chodorow-Reich, Gabriel, Plamen T Nenov and Alp Simsek. 2021. "Stock Market Wealth and the Real Economy: A Local Labor Market Approach." forthcoming, American Economic Review .

Christiano, Lawrence J., Martin Eichenbaum and Charles L. Evans. 2005. “Nominal Rigidities and the Dynamic Effects of a Shock to Monetary Policy." Journal of Political Economy 113(1):1-45.

Cloyne, James, Clodomiro Ferreira and Paolo Surico. 2020. "Monetary Policy When Households Have Debt: New Evidence on the Transmission Mechanism." Review of Economic Studies 87(1):102-129.

Cloyne, James and Patrick Huertgen. 2016. "The Macroeconomic Effects of Monetary Policy: A New Measure for the United Kingdom." American Economic Journal: Macroeconomics 8(4):75-102.

Coibion, Olivier. 2012. "Are the Effects of Monetary Policy Shocks Big or Small?" American Economic Journal: Macroeconomics 4(2):1-32.

Coibion, Olivier, Yuriy Gorodnichenko, Lorenz Kueng and John Silvia. 2017. "Innocent Bystanders? Monetary Policy and Inequality in the U.S." Journal of Monetary Economics 88:70-89.

Crawley, Edmund and Andreas Kuchler. 2020. Consumption Heterogeneity: Micro Drivers and Macro Implications. Finance and Economics Discussion Series 2020-005 Board of Governors of the Federal Reserve System.

D'Acunto, Francesco, Daniel Hoang, Maritta Paloviita and Michael Weber. 2019. Human Frictions to the Transmission of Economic Policy. 2019 Meeting Papers 339 Society for Economic Dynamics.

Debortoli, Davide and Jordi Gali. 2018. Monetary Policy with Heterogeneous Agents: Insights from TANK models. Unpublished manuscript.

Den Haan, Wouter J, Pontus Rendahl and Markus Riegler. 2017. “Unemployment (Fears) and Deflationary Spirals." Journal of the European Economic Association 16(5):1281-1349.

Di Maggio, Marco, Amir Kermani, Benjamin J. Keys, Tomasz Piskorski, Rodney Ramcharan, Amit Seru and Vincent Yao. 2017. "Interest Rate Pass-Through: Mortgage Rates, Household Consumption, and Voluntary Deleveraging." American Economic Review 107(11):3550-88.

Di Maggio, Marco, Amir Kermani and Kaveh Majlesi. 2020. "Stock market returns and consumption." The Journal of Finance 75(6):3175-3219.

Drechsler, Itamar, Alexi Savov and Philipp Schnabl. 2017. “The Deposits Channel of Monetary Policy." Quarterly Journal of Economics 132(4):1819-1876.

Driscoll, John C. and Aart C. Kraay. 1998. "Consistent Covariance Matrix Estimation with Spatially Dependent Panel Data." Review of Economics and Statistics 80(4):549-560.

Eichenbaum, Martin, Sergio Rebelo and Arlene Wong. 2019. State Dependent Effects of Monetary Policy: The Refinancing Channel. Unpublished manuscript. 
Eika, Lasse, Magne Mogstad and Ola L Vestad. 2020. "What can we learn about household consumption expenditure from data on income and assets?" Journal of Public Economics 189:104163.

Fagereng, Andreas and Elin Halvorsen. 2017. "Imputing consumption from Norwegian income and wealth registry data." Journal of Economic and Social Measurement 42(1):67-100.

Fagereng, Andreas, Luigi Guiso, Davide Malacrino and Luigi Pistaferri. 2020. "Heterogeneity and persistence in returns to wealth." Econometrica 88(1):115-170.

Fagereng, Andreas, Martin B. Holm, Benjamin Moll and Gisle Natvik. 2019. Saving Behavior across the Wealth Distribution: The Importance of Capital Gains. Working Paper 26588 National Bureau of Economic Research.

Fagereng, Andreas, Martin B. Holm and Gisle Natvik. 2021. "MPC Heterogeneity and Household Balance Sheets." Forthcoming, American Economic Journal: Macroeconomics .

Fagereng, Andreas, Martin B Holm and Kjersti N Torstensen. 2020. "Housing Wealth in Norway, 1993 - 2015." Journal of Economic and Social Measurement 45(1):65-81.

Floden, Martin, Matilda Kilstrom, Josef Sigurdsson and Roine Vestman. 2020. "Household Debt and Monetary Policy: Revealing the Cash-Flow Channel." forthcoming, The Economic Journal .

Gabaix, Xavier and David Laibson. 2001. The 6D Bias and the Equity-Premium Puzzle. In NBER Macroeconomics Annual 2001, Volume 16. NBER Chapters National Bureau of Economic Research, Inc pp. 257-330.

Galí, Jordi, David López-Salido and Javier Vallés. 2007. “Understanding the Effects of Government Spending on Consumption." Journal of the European Economic Association 5(1):227-270.

Gertler, Mark and Peter Karadi. 2015. "Monetary Policy Surprises, Credit Costs, and Economic Activity." American Economic Journal: Macroeconomics 7(1):44-76.

Gornemann, Nils, Keith Kuester and Makoto Nakajima. 2016. Doves for the Rich, Hawks for the Poor? Distributional Consequences of Monetary Policy. Unpublished manuscript.

Guerkaynak, Refet, Brian Sack and Eric Swanson. 2005. "Do Actions Speak Louder Than Words? The Response of Asset Prices to Monetary Policy Actions and Statements." International Journal of Central Banking 1(1):55-93.

Guerrieri, Veronica and Guido Lorenzoni. 2017. "Credit Crises, Precautionary Savings, and the Liquidity Trap." Quarterly Journal of Economics 132(3):1427-1467.

Hagedorn, Marcus, Jinfeng Luo, Iourii Manovskii and Kurt Mitman. 2019. "Forward guidance." Journal of Monetary Economics 102(C):1-23.

Hansen, Bruce E. 2019. Econometrics. University of Wisconsin.

Jappelli, Tullio and Luigi Pistaferri. 2010. “The Consumption Response to Income Changes." $A n$ nual Review of Economics 2(1):479-506, 09. 
Johnson, David S., Jonathan A. Parker and Nicholas S. Souleles. 2006. "Household Expenditure and the Income Tax Rebates of 2001." American Economic Review 96(5):1589-1610.

Jordà, Oscar. 2005. "Estimation and Inference of Impulse Responses by Local Projections." American Economic Review 95(1):161-182.

Kaplan, Greg, Benjamin Moll and Giovanni L. Violante. 2018. “Monetary Policy According to HANK." American Economic Review 108(3):697-743.

Kaplan, Greg and Giovanni L. Violante. 2014. "A Model of the Consumption Response to Fiscal Stimulus Payments." Econometrica 82(4):1199-1239.

Kaplan, Greg, Giovanni L. Violante and Justin Weidner. 2014. "The Wealthy Hand-to-Mouth." Brookings Papers on Economic Activity 45(1):77-153.

Kekre, Rohan and Moritz Lenel. 2020. Monetary Policy, Redistribution, and Risk Premia. Unpublished manuscript.

Kuttner, Kenneth N. 2001. "Monetary policy surprises and interest rates: Evidence from the Fed funds futures market." Journal of Monetary Economics 47(3):523-544.

Leth-Petersen, Søren. 2010. "Intertemporal consumption and credit constraints: Does total expenditure respond to an exogenous shock to credit?" American Economic Review 100(3):1080-1103.

Lintner, John. 1956. "Distribution of Incomes of Corporations Among Dividends, Retained Earnings, and Taxes." American Economic Review 46(2):97-113.

Luetticke, Ralph. 2020. "Transmission of Monetary Policy with Heterogeneity in Household Portfolios." forthcoming, American Economic Journal: Macroeconomics .

Mankiw, N. Gregory. 2000. “The Savers-Spenders Theory of Fiscal Policy." American Economic Review 90(2):120-125.

Mankiw, N. Gregory and Ricardo Reis. 2002. "Sticky Information versus Sticky Prices: A Proposal to Replace the New Keynesian Phillips Curve." Quarterly Journal of Economics 117(4):1295-1328.

McKay, Alisdair, Emi Nakamura and Jon Steinsson. 2016. "The Power of Forward Guidance Revisited." American Economic Review 106(10):3133-58.

McKay, Alisdair and Ricardo Reis. 2016. "The Role of Automatic Stabilizers in the U.S. Business Cycle." Econometrica 84(1):141-194.

Mertens, Karel and Morten O. Ravn. 2013. "The Dynamic Effects of Personal and Corporate Income Tax Changes in the United States." American Economic Review 103(4):1212-1247.

Misra, Kanishka and Paolo Surico. 2014. "Consumption, Income Changes, and Heterogeneity: Evidence from Two Fiscal Stimulus Programs." American Economic Journal: Macroeconomics 6(4):84106. 
Newey, Whitney and Kenneth West. 1987. "A Simple, Positive-Definite, Heteroskedasticity and Autocorrelation Consistent Covariance Matrix." Econometrica 55:703-708.

Oh, Hyunseung and Ricardo Reis. 2012. "Targeted transfers and the fiscal response to the great recession." Journal of Monetary Economics 59(S):50-64.

Olivei, Giovanni and Silvana Tenreyro. 2007. "The Timing of Monetary Policy Shocks." American Economic Review 97(3):636-663.

Parker, Jonathan A., Nicholas S. Souleles, David S. Johnson and Robert McClelland. 2013. "Consumer Spending and the Economic Stimulus Payments of 2008." American Economic Review 103(6):2530-53.

Patterson, Christina. 2018. The Matching Multiplier and the Amplification of Recessions. Unpublished manuscript.

Paul, Pascal. 2020. “The time-varying effect of monetary policy on asset prices." Review of Economics and Statistics 102(4):690-704.

Ravn, Morten O. and Vincent Sterk. 2017. "Job uncertainty and deep recessions." Journal of Monetary Economics 90(C):125-141.

Romer, Christina D. and David H. Romer. 2004. "A New Measure of Monetary Shocks: Derivation and Implications." American Economic Review 94(4):1055-1084.

Slacalek, Jiri, Oreste Tristani and Giovanni L. Violante. 2020. "Household balance sheet channels of monetary policy: A back of the envelope calculation for the euro area." Journal of Economic Dynamics and Control 115:103879.

Stock, James H. and Mark W. Watson. 2018. "Identification and Estimation of Dynamic Causal Effects in Macroeconomics." Economic Journal 128(610):917-948.

Wong, Arlene. 2019. Refinancing and the Transmission of Monetary Policy to Consumption. Unpublished manuscript. 


\title{
Online Appendix for "The Transmission of Monetary Policy under the Microscope"
}

\author{
Martin Blomhoff Holm, Pascal Paul, Andreas Tischbirek
}

\section{A Monetary Policy Identification}

\section{A.1 Historical Policy Rate}

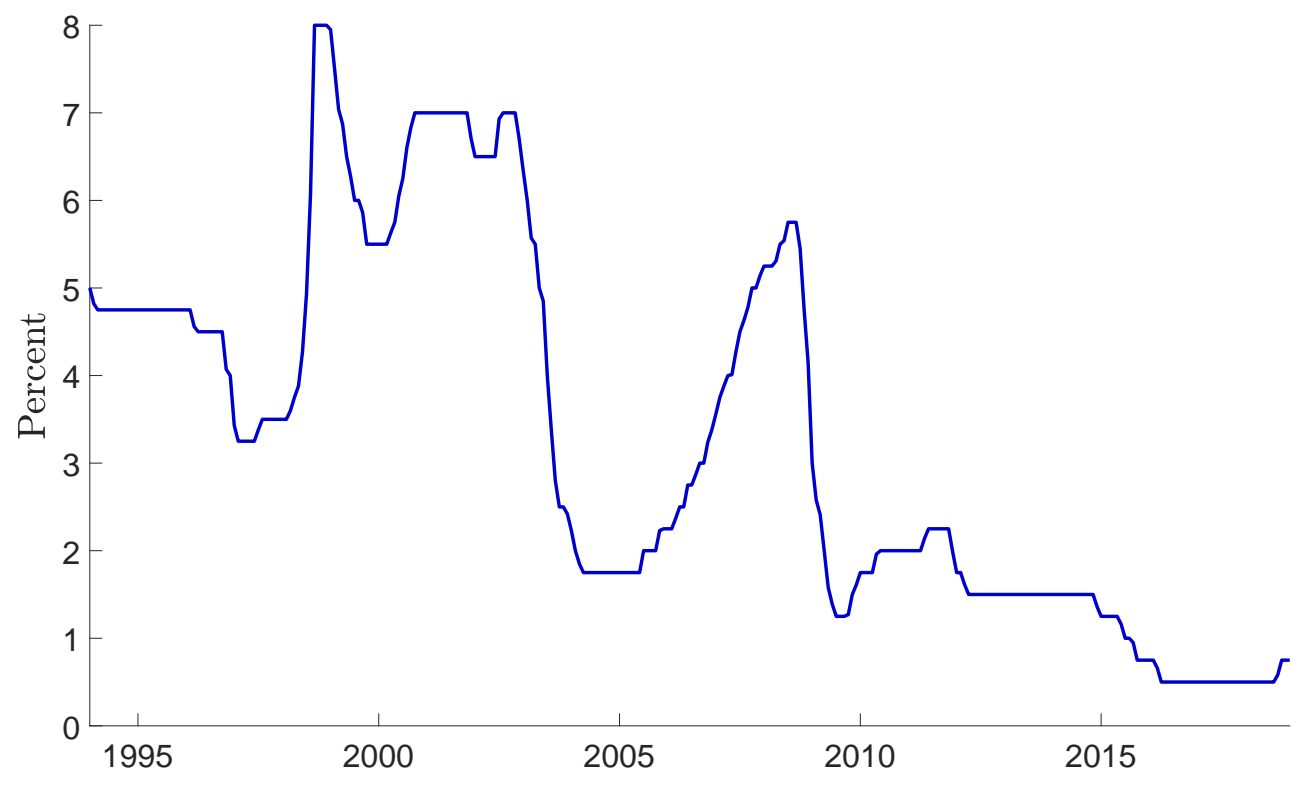

Figure A.1: Historical Policy Rate (Sight Deposit Rate).

\section{A.2 Forecasts}

In this appendix, we describe the forecasts that are used in estimation of regression (1). From 1996:M11 until 2018:M12, the forecasts by Norges Bank are obtained from reports that are publicly available. Until 2006, Norges Bank published its forecasts in the so-called Inflation Reports, and from then on in the Monetary Policy Reports. ${ }^{41}$ We additionally collect forecasts from the archives of Norges Bank for the period 1994-1996. We use annual forecasts for GDP and CPI since these

\footnotetext{
${ }^{41}$ The historical reports can be found at https://www.norges-bank.no/en/topics/Monetary-policy/monetarypolicy-report/. The forecasts are typically shown in a table at the end of a report.
} 
have the longest coverage and are consistent throughout the sample period. ${ }^{42}$ In 2005 , Norges Bank began to base its projections on its own interest rate forecasts. However, that is not a threat to the identification which allows forecasts to respond to expected systematic policy changes. ${ }^{43}$

Norges Bank prepared forecasts three or four times a year. Often, the release of these forecasts coincided with a policy meeting. If no forecasts were prepared in conjunction with the policy decision, we assign forecasts iteratively. First, we use forecasts published in the same month of the meeting or in the previous month when possible. Second, for all remaining meetings, we follow Cloyne and Huertgen (2016) in using forecasts by market participants to proxy for the forecasts of the central bank. More precisely, we use data from Consensus Economics, a survey of forecasters from several key private and public-sector institutions, and we resort to the mean of those projections.

For a number of reasons, the forecasts by Consensus Economics are particularly suitable as a proxy. They have a long coverage (starting in 1990), a monthly frequency, are consistent over time, and include annual projections of GDP and the CPI that are directly comparable to the forecasts we obtained from Norges Bank. To ensure that the data from Consensus Economics closely capture Norges Bank's forecasts, we calculate the correlation between both sets of forecasts for periods in which they are both available. Monthly projections of current and next year GDP forecasts have a correlation coefficient of 0.95 and 0.79 , and of 0.92 and 0.62 for CPI inflation, respectively. Precisely as with Norges Bank's forecasts, policy meetings are assigned projections from an earlier date in the same month or the previous month. ${ }^{44}$ To assign forecasts to the policy meetings (162 in total), we use the following rule:

1. If available, use Norges Bank forecasts that are either

- directly prepared for a policy meeting (51),

- the same month before the meeting (5), or

- in the month before the meeting (32).

2. For any remaining meetings, we use the Consensus forecasts that are

- conducted in the same month before the meeting (4), or

\footnotetext{
${ }^{42}$ We use the GDP forecast for mainland Norway, as opposed to the one for the whole country, for two reasons. First, a larger number of observations of the GDP forecast for mainland Norway are available historically. Second, the Consensus forecast that proxies for missing Norges Bank forecasts, as explained in the text, is only available for mainland Norway.

${ }^{43} \mathrm{An}$ issue for identification would arise if Norges Bank Staff are aware of non-systematic future policy changes via inside information and would incorporate those expectations into their forecasts. However, we are not aware of instances when this was the case, as Norges Bank Staff only learn about policy decisions when those are officially announced.

${ }^{44}$ Regarding the forecast changes, denoted $\Delta \pi_{t+k}^{m}$ and $\Delta y_{t+k}^{m}$ in regression (1), we use the one relative to the previous forecast for Norges Bank. For the Consensus forecasts, we compare one forecast relative to another two months prior to match the lower frequency of Norges Bank forecasts. For February forecasts, we restrict this gap to one month to increase the number of observations. Various permutations of these assumptions using shorter or longer comparisons did not change our results along relevant dimensions.
} 
- in the month before the meeting (70).

Hence, for a total of 162 policy meetings within our sample period, we associate Norges Bank forecasts to 88 of those and the remaining 74 are filled in using Consensus forecasts. Last, we exclude the policy meetings that occurred in 1998:M8, 2008:M10, and 2008:M12 from the estimation. The latter two months are associated with meetings that were exceptionally summoned in response to the 2007-09 financial crisis. At this time, macroeconomic projections changed quickly and the forecasts that we have available do not capture those rapid changes. By including these meetings, we would therefore incorrectly assign a larger fraction of the policy rate changes to the shock series, when they were in fact endogenous responses to rapidly changing expectations about the future path of the economy. ${ }^{45}$ We also exclude rate changes that occurred in 1998:M8 in response to volatile exchange rate movements and expected exchange rate adjustments, which our controls in regression (1) may not fully capture, though we find that the results are close to our benchmark when including the 1998:M8 meetings.

\section{A.3 Monetary Policy Shock Series}

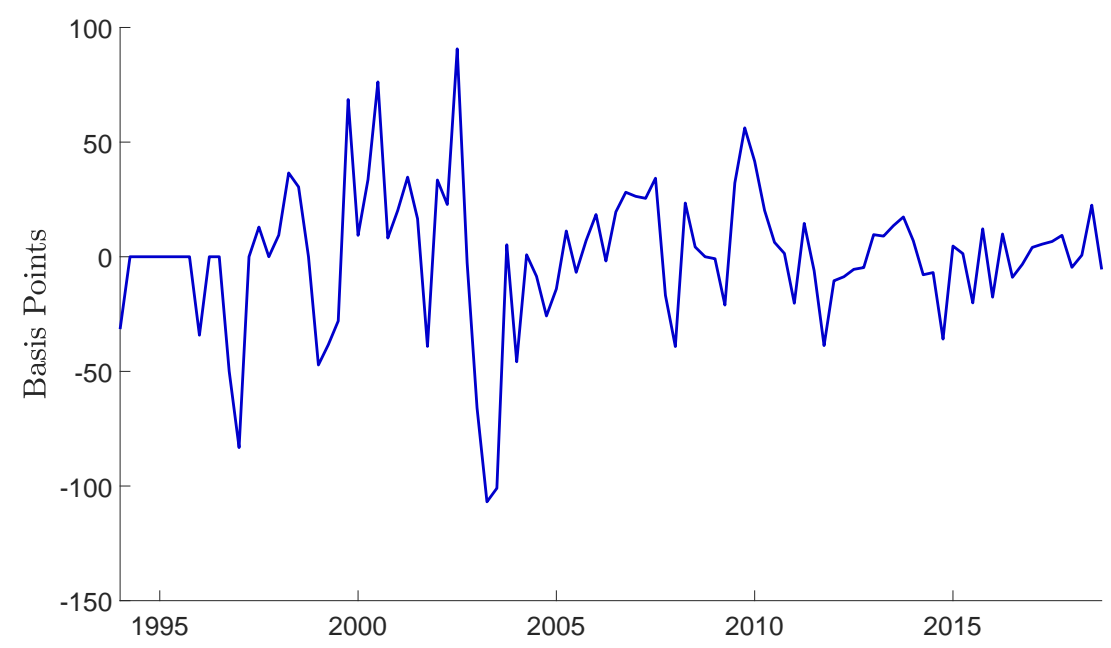

Figure A.2: Quarterly Series of Monetary Policy Shocks.

\footnotetext{
${ }^{45}$ For example, for the meetings on $10 / 15 / 2008$ and 12/17/2008, the latest Norges Bank forecasts were prepared on 6/25/2008 and 10/29/2008, respectively. During such emergency meetings, the central bank likely possesses private information vis-à-vis the market (see, Paul, 2020). Thus, we do not use Consensus forecasts as proxies in these instances.
} 


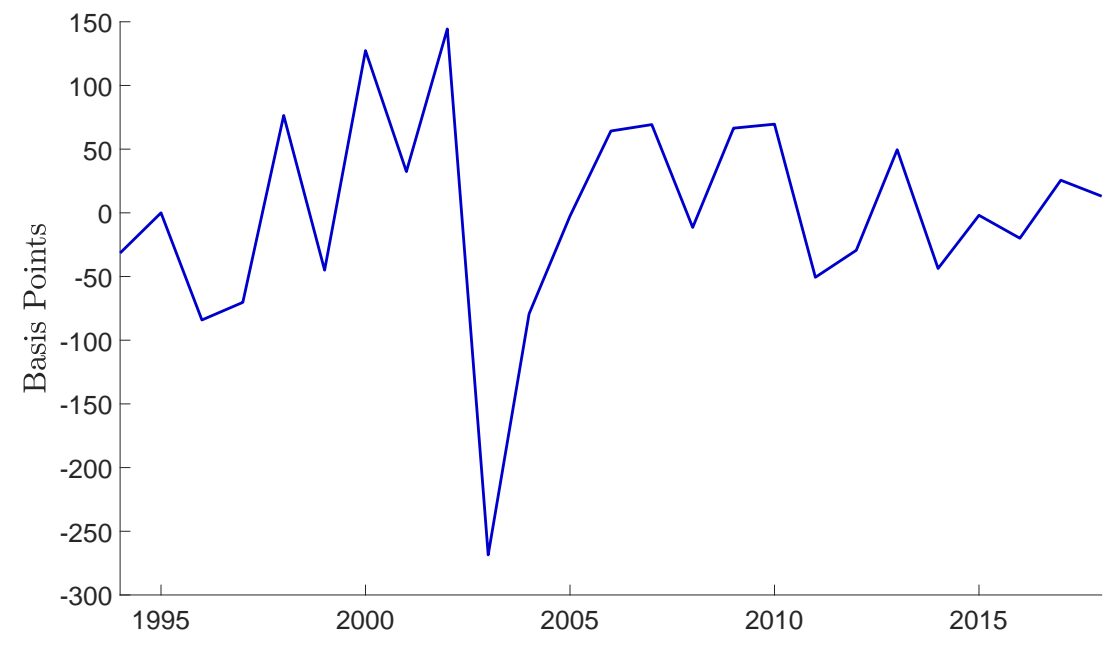

Figure A.3: Annual Series of Monetary Policy Shocks.

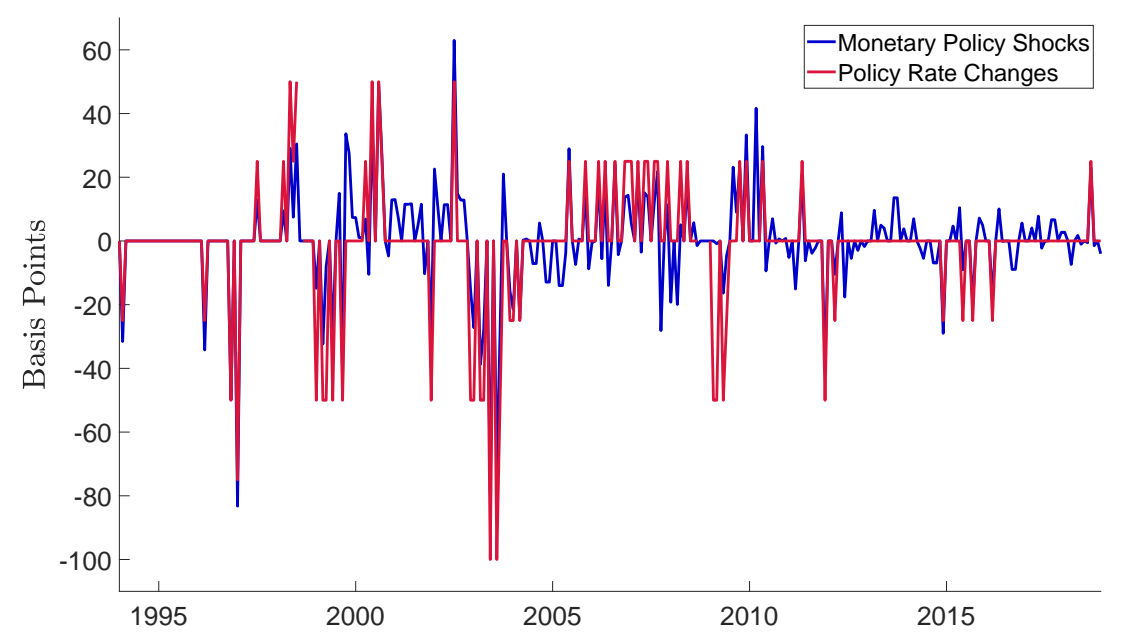

Figure A.4: Monetary Policy Shocks vs. Policy Rate Changes.

\section{A.4 Analysis of Largest Monetary Policy Shocks}

In this section, we provide a quantitative analysis of the largest shocks that we uncover. Based on the monthly shock series (see Figure 1), we focus on the four largest shocks that stand out. These are reported in Table A.1, together with the associated rate changes, links to the related press releases, and the main reason for each rate change that is stated in the press releases. The rate change for 1997:M1 consists of two consecutive moves quickly after one another, which we combine to one joint rate change (see footnote 5). 


\begin{tabular}{ccccc}
\hline Date & Estimated Shock & Rate Change(s) & Reason for Change & Press Release(s) \\
\hline \hline 1997:M1 & $-83 \mathrm{bp}$ & $-75 \mathrm{bp}(-50 \mathrm{bp},-25 \mathrm{bp})$ & Stabilize exchange rate & Link 1, Link 2 \\
2002:M7 & $+63 \mathrm{bp}$ & $+50 \mathrm{bp}$ & Inflation forecast & Link \\
2003:M6 & $-79 \mathrm{bp}$ & $-100 \mathrm{bp}$ & Inflation forecast & Link \\
2003:M8 & $-73 \mathrm{bp}$ & $-100 \mathrm{bp}$ & Inflation forecast & Link \\
\hline
\end{tabular}

Table A.1: List of largest monetary policy shocks.

Recall that we estimate

$$
\begin{aligned}
\Delta i_{m}= & \alpha_{1}+\alpha_{2} i_{m,-1}+\sum_{k=0}^{1} \beta_{k}^{\pi} \pi_{m, t+k}+\sum_{k=0}^{1} \beta_{k}^{\Delta \pi} \Delta \pi_{m, t+k} \\
& +\sum_{k=0}^{1} \beta_{k}^{y} y_{m, t+k}+\sum_{k=0}^{1} \beta_{k}^{\Delta y} \Delta y_{m, t+k}+\gamma_{1} e x_{m,-1}+\gamma_{2} I_{m}^{I T} \cdot e x_{m,-1}+\epsilon_{m}^{M P}
\end{aligned}
$$

To understand the contribution of the lagged policy rate $\left(i_{m,-1}\right)$, inflation forecasts $\left(\pi_{t+k}^{m}\right.$ and $\left.\Delta \pi_{t+k}^{m}\right)$, output forecasts $\left(y_{t+k}^{m}\right.$ and $\left.\Delta y_{t+k}^{m}\right)$, and the exchange rate $\left(e x_{m,-1}\right.$ and $\left.I_{I T} \cdot e x_{m,-1}\right)$ to changes in the policy rate $\Delta i_{m}$ for the meetings that are listed in Table A.1, we apply the following approach. One can rewrite regression (7) as

$$
\Delta i_{m}=\overline{\Delta i}+\left(\boldsymbol{x}_{m}-\boldsymbol{\mu}_{x}\right)^{\prime} \boldsymbol{\beta}+\epsilon_{m}^{M P}
$$

where $\overline{\Delta i}$ denotes the mean of the dependent variable. The remaining regressors are collected in vector $x_{m}$ and are centered at their means $\mu_{x} \cdot{ }^{46}$ Equation (8) resembles a typical Taylor rule and can be used to assess the pressure coming from the various regressors relative to their typical influence. Given the transformed regression in (8) and the estimated parameters from Table 1, Figure A.5 shows the predicted contribution of the various regressors. ${ }^{47}$ As stated in Table A.1, the motivation to lower the policy rate in 1997:M1 was to stabilize the exchange rate. However, we find relatively little contribution from the exchange rate component associated with that meeting. Moreover, inflation and output forecasts actually pushed the policy rate in the opposite direction. On net, the estimated shock is larger than the actual rate change. ${ }^{48}$

\footnotetext{
${ }^{46}$ See, for example, equation (2.36) in Hansen (2019, page 39) for such a transformation.

${ }^{47}$ To account for the indicator variable, we compute the mean for the term $I_{m}^{I T} \cdot e x_{m,-1}$ conditional on the pre-inflation targeting era and adjust the constant accordingly. For the inflation targeting era, we omit the term $I_{m}^{I T} \cdot e x_{m,-1}$ and again adjust the constant accordingly.

${ }^{48}$ We experimented with alternative specifications for regression (7) to account for the exchange rate targeting in 1990s. In particular, instead of using the level of the exchange rate, we have used the change of the exchange rate relative to the previous meeting, but found that this change did not impact our results. Similarly, allowing for additional interactions between the remaining regressors and the pre-inflation target indicator $I_{m}^{I T}$ did not affect the estimated impulse responses either.
} 

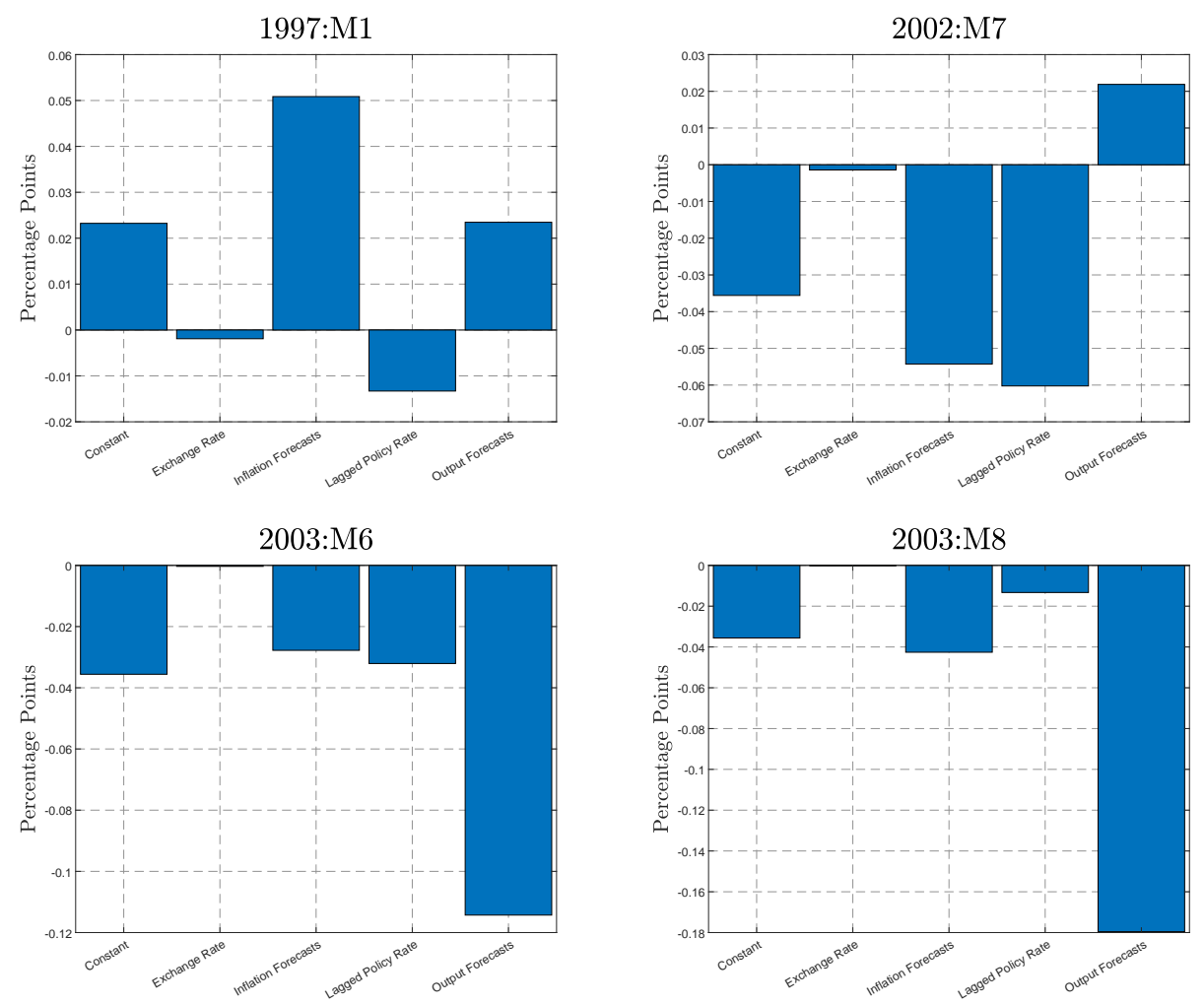

Figure A.5: Decomposition of largest shocks.

The rate changes for the remaining meetings were all motivated by inflation forecasts. For the policy meetings in 2003 we indeed find that inflation forecasts put pressure to lower rates, though output forecasts had an even stronger contribution. However, the policy rate changes were substantially larger than the overall predictions, giving relatively sizable expansionary shocks. Last, the meeting in 2002:M7 was associated with an increase in the policy rate and policy-makers stated inflation pressures as the main reason for the change. In contrast, we find that inflation forecasts pushed the policy rate in the opposite direction, though this predicted change is partly offset by the output forecasts. Our estimated rule predicts an expansionary policy change overall, while the actual policy change was contractionary, resulting in a substantial tightening shock. 


\section{A.5 Predictability of Monetary Policy Shocks}

Table A.2: Predictability of Monthly Monetary Policy Shocks.

\begin{tabular}{|c|c|c|c|c|c|c|}
\hline \multirow[b]{2}{*}{ Variables } & \multicolumn{2}{|c|}{3 Lags } & \multicolumn{2}{|c|}{6 Lags } & \multicolumn{2}{|c|}{9 Lags } \\
\hline & F-statistic & P-value & F-statistic & P-value & F-statistic & P-value \\
\hline Unemployment Rate & 0.90 & 0.44 & 0.83 & 0.55 & 0.60 & 0.80 \\
\hline CPI-AEL Inflation & 1.15 & 0.33 & 1.42 & 0.21 & 1.36 & 0.21 \\
\hline Industrial Production & 0.25 & 0.86 & 0.25 & 0.96 & 0.27 & 0.98 \\
\hline All of the above & 0.84 & 0.58 & 0.86 & 0.63 & 0.73 & 0.84 \\
\hline
\end{tabular}

Notes: The dependent variable is the monthly series of monetary policy shocks. The regressors are three, six, or nine lagged values of the change in the unemployment rate, monthly CPI-AEL inflation, the monthly growth rate of industrial production, or a joint regression with all three variables. The table reports Fstatistics and the associated p-values given the null hypothesis that all coefficients are zero. 


\section{A.6 Macro Data}

Table A.3: Macro Time Series.

\begin{tabular}{|c|c|c|c|c|c|}
\hline Variable Name & Annual & Quarterly & Monthly & Start & Source \\
\hline Policy Rate: Sight Deposit Rate & $x$ & $\mathrm{x}$ & $\mathrm{x}$ & 1993 & Norges Bank \\
\hline Unemployment Rate: Registered, SA & $\mathrm{x}$ & $\mathrm{x}$ & $\mathrm{x}$ & 1995 & FRED \\
\hline Consumer Price Index: AEL, All-Item Index & $\mathrm{x}$ & $\mathrm{x}$ & $\mathrm{x}$ & 1995 & Statistics Norway \\
\hline Industrial Production: Smoothed Index, SA & $\mathrm{x}$ & $\mathrm{x}$ & $\mathrm{x}$ & 1993 & Statistics Norway \\
\hline Manufacturing Production: Index, SA & & & $\mathrm{x}$ & 1993 & FRED \\
\hline Producer Prices Manufacturing: Index & & & $\mathrm{x}$ & 1993 & FRED \\
\hline Exchange Rate: Norway Kroner/U.S. Dollar Exchange Rate & & & $\mathrm{x}$ & 1993 & FRED, Norges Bank \\
\hline Stock Prices: All Shares, Index & & & $\mathrm{x}$ & 1993 & FRED \\
\hline GDP: Real GDP, COP, SA & $\mathrm{x}$ & $\mathrm{x}$ & & 1993 & FRED \\
\hline GDP Deflator: Implicit Price Deflator Norway, Index, SA & $\mathrm{x}$ & $\mathrm{x}$ & & 1993 & FRED \\
\hline Real Gross Fixed Capital Formation: COP, SA & $\mathrm{x}$ & $\mathrm{x}$ & & 1993 & Statistics Norway \\
\hline House Prices: Price index for existing dwellings, CPI-ADJ. & $\mathrm{x}$ & $\mathrm{x}$ & & 1993 & Statistics Norway \\
\hline Wages and Salaries: Mainland Norway, CPI-ADJ., SA & $\mathrm{x}$ & $\mathrm{x}$ & & 1995 & Statistics Norway \\
\hline Consumption Expenditures: COP, SA & $\mathrm{x}$ & $\mathrm{x}$ & & 1993 & Statistics Norway \\
\hline Hours Worked: Employees \& self-employed, Mainland, SA & $\mathrm{x}$ & $\mathrm{x}$ & & 1995 & Statistics Norway \\
\hline Household Income: After-tax income, COP & $\mathrm{x}$ & & & 1993 & Statistics Norway \\
\hline Top 10\% Income Share: After-tax income distribution & $\mathrm{x}$ & & & 1993 & Statistics Norway \\
\hline Gini coefficient: After-tax income distribution & $\mathrm{x}$ & & & 1993 & Statistics Norway \\
\hline P90/P10: After-tax income distribution & $\mathrm{x}$ & & & 1993 & Statistics Norway \\
\hline Extraction and Related Services: SA & & & $\mathrm{x}$ & 1993 & Statistics Norway \\
\hline Average Loan Rate & $\mathrm{x}$ & & & 1993 & Statistics Norway \\
\hline Average Deposit Rate & $\mathrm{x}$ & & & 1993 & Statistics Norway \\
\hline \multicolumn{6}{|c|}{ U.S. Data } \\
\hline Policy Rate: Effective Federal Funds Rate & & & $\mathrm{x}$ & 1970 & FRED \\
\hline Unemployment Rate: Civilian, SA & & & $\mathrm{x}$ & 1970 & FRED \\
\hline Industrial Production: Index, SA & & & $\mathrm{x}$ & 1970 & FRED \\
\hline
\end{tabular}

Notes: "SA" stands for "Seasonally-adjusted", "CPI-ADJ." indicates that the series was converted into real units using the consumer price index, "COP" stands for "Constant Prices". Monthly, quarterly, and annual indicate the frequency at which the data are used. "Start" indicates the year of the earliest observations that are employed. While the analysis starts in 1993, time series may be available beforehand. 


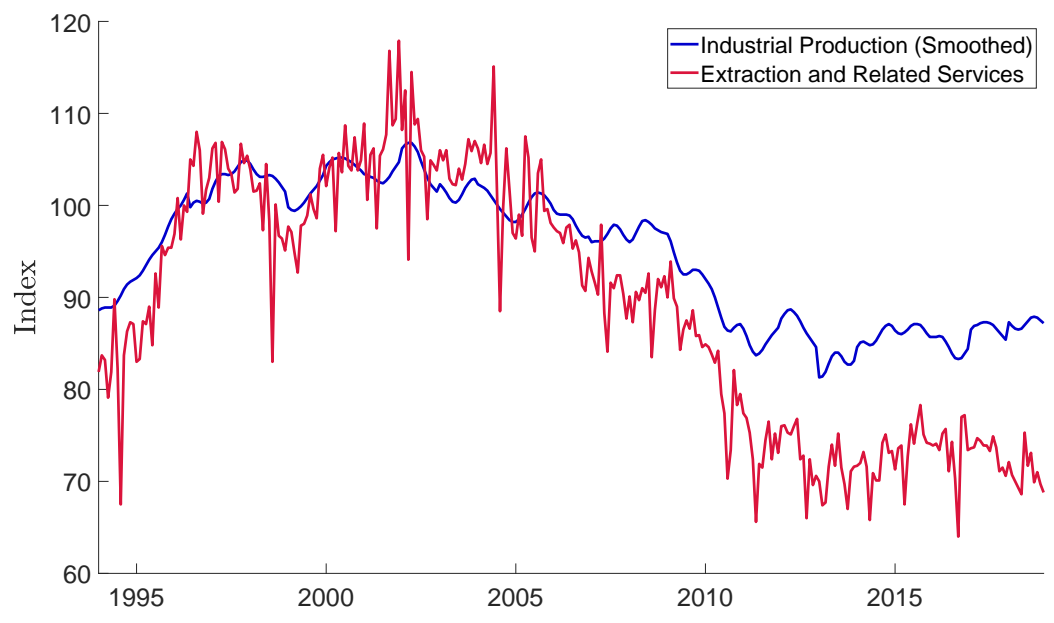

Figure A.6: Structural Break in Industrial Production.

Notes: Table A.3 in Appendix A.6 lists the data sources.

\section{A.7 Additional Impulse Responses}
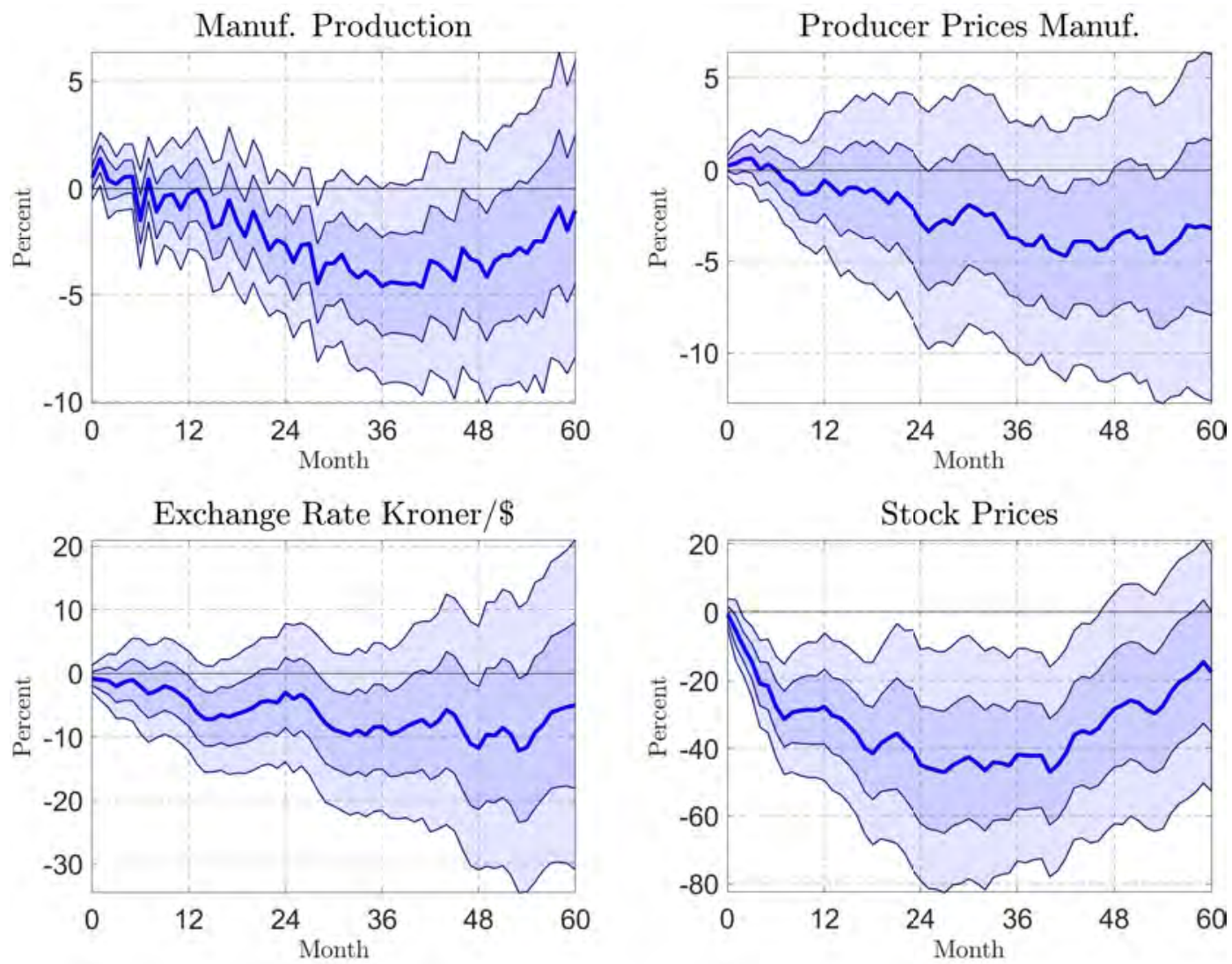

Figure A.7: Impulse Responses at a Monthly Frequency.

Notes: Impulse responses to a 1 percentage point contractionary monetary policy shock at a monthly frequency, based on the local projection approach in (2). 95 and 68 percent confidence bands shown, using Newey and West (1987) standard errors. Table A.3 in Appendix A.6 lists the data sources. 

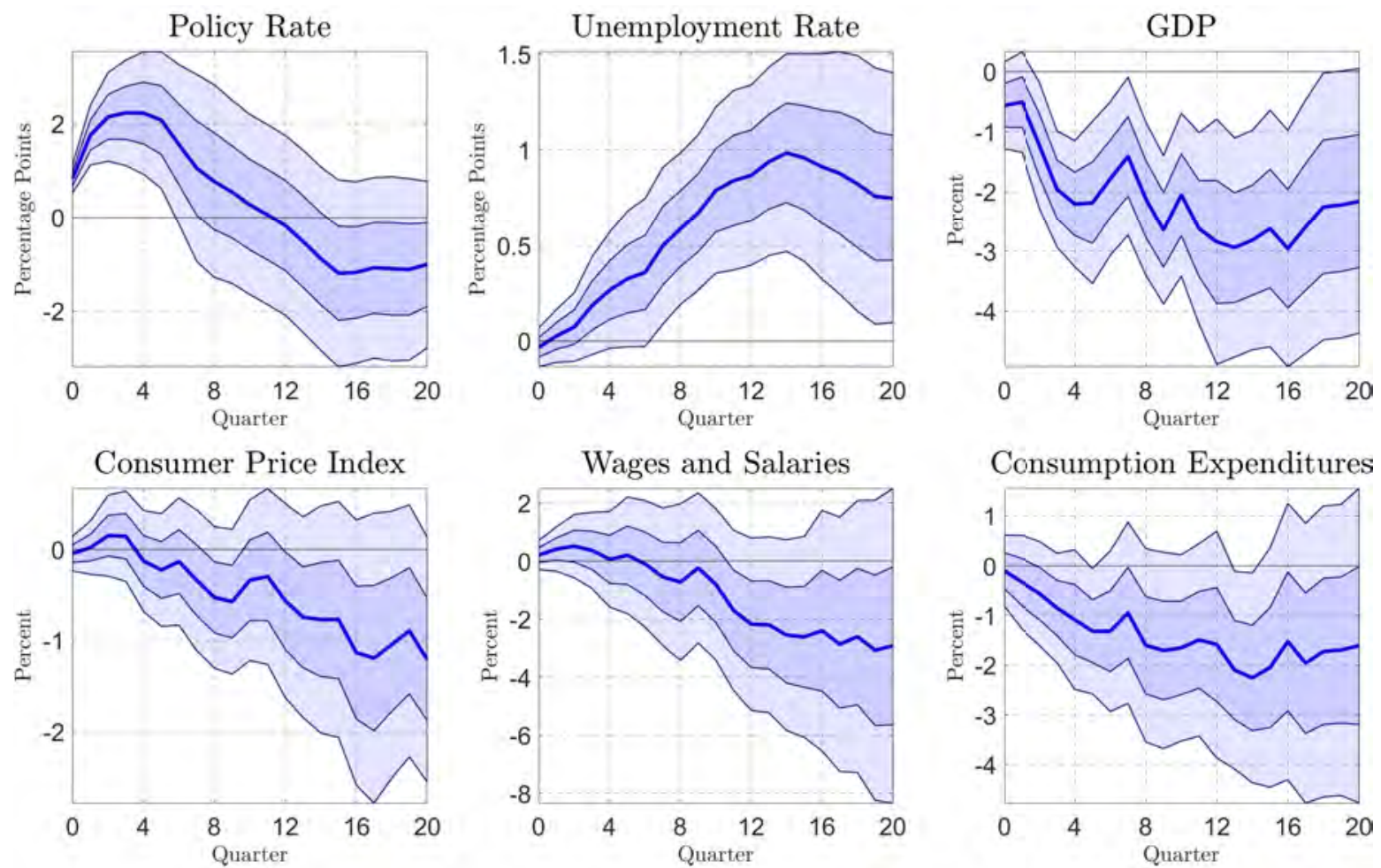

Consumption Expenditures

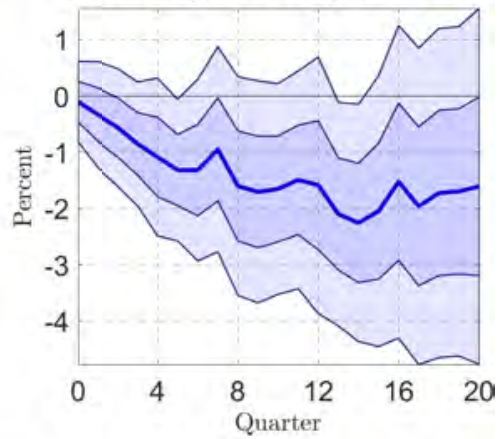

Figure A.8: Impulse Responses at a Quarterly Frequency.

Notes: Impulse responses to a 1 percentage point contractionary monetary policy shock at a quarterly frequency, based on the local projection approach in (2). 95 and 68 percent confidence bands shown, using Newey and West (1987) standard errors. Table A.3 in Appendix A.6 lists the data sources. Additional impulse responses at a quarterly frequency are shown in Figure A.9. 

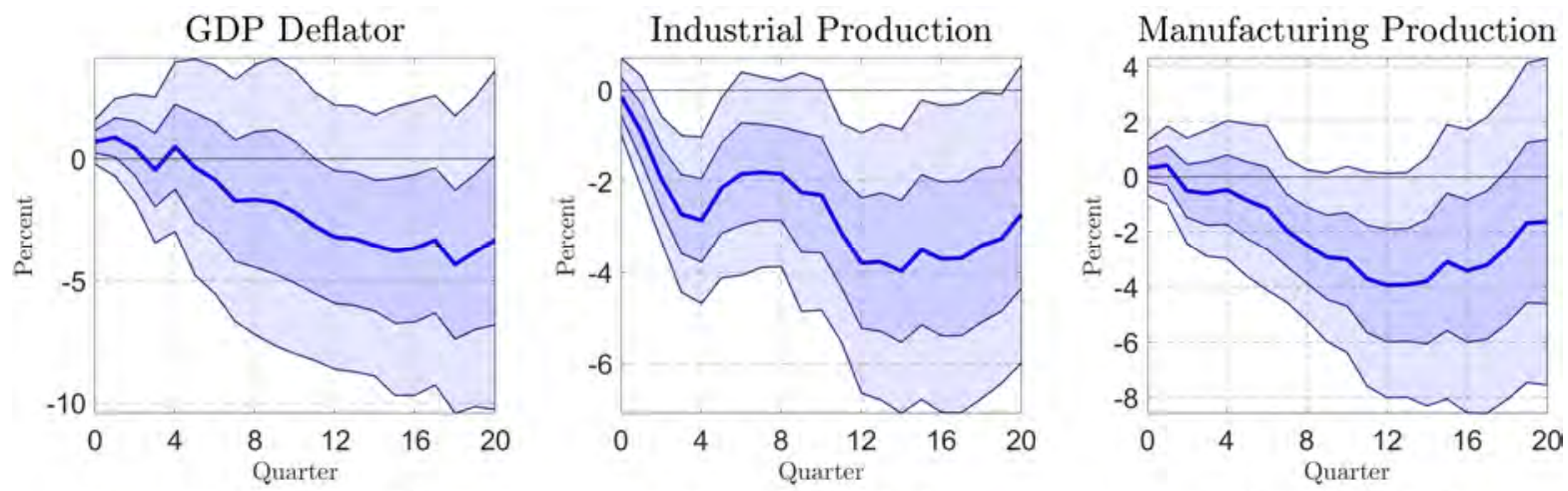

Gross Fixed Capital Form.
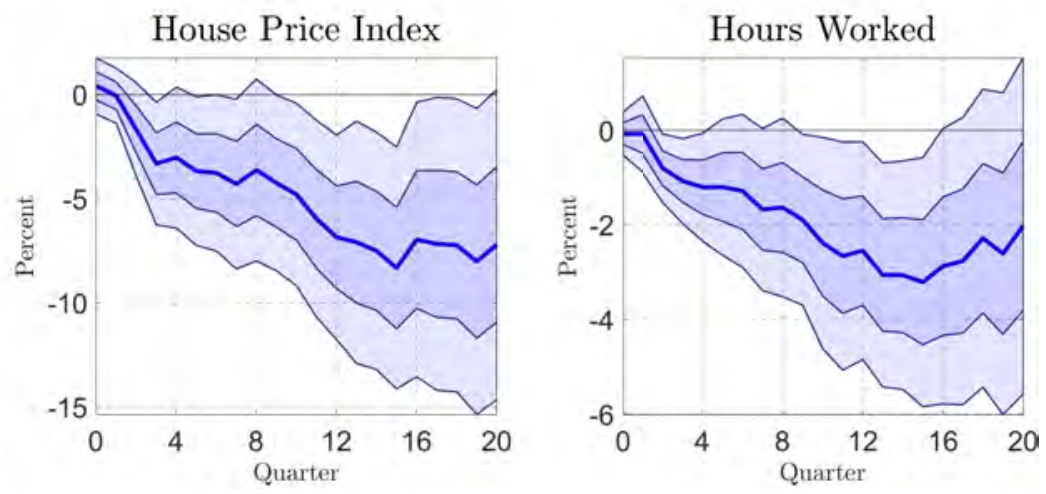

Figure A.9: Impulse Responses at a Quarterly Frequency.

Notes: Impulse responses to a 1 percentage point contractionary monetary policy shock at a quarterly frequency, based on local projection approach in (2). 95 and 68 percent confidence bands shown, using Newey and West (1987) standard errors. Table A.3 in Appendix A.6 lists the data sources. 

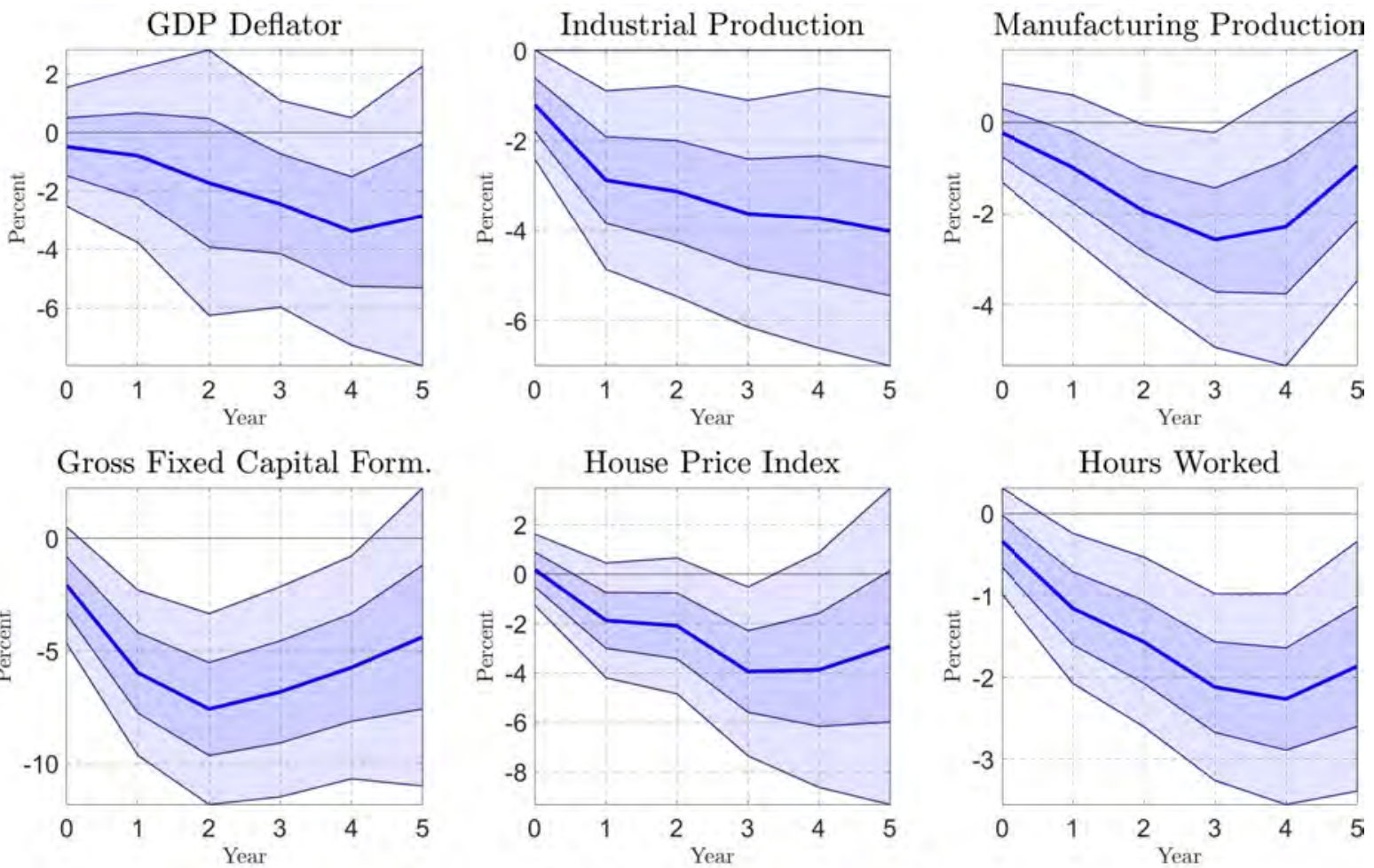

Figure A.10: Impulse Responses at an Annual Frequency.

Notes: Impulse responses to a 1 percentage point contractionary monetary policy shock at a annual frequency, based on the local projection approach in (2). 95 and 68 percent confidence bands shown, using Newey and West (1987) standard errors. Table A.3 in Appendix A.6 lists the data sources. 

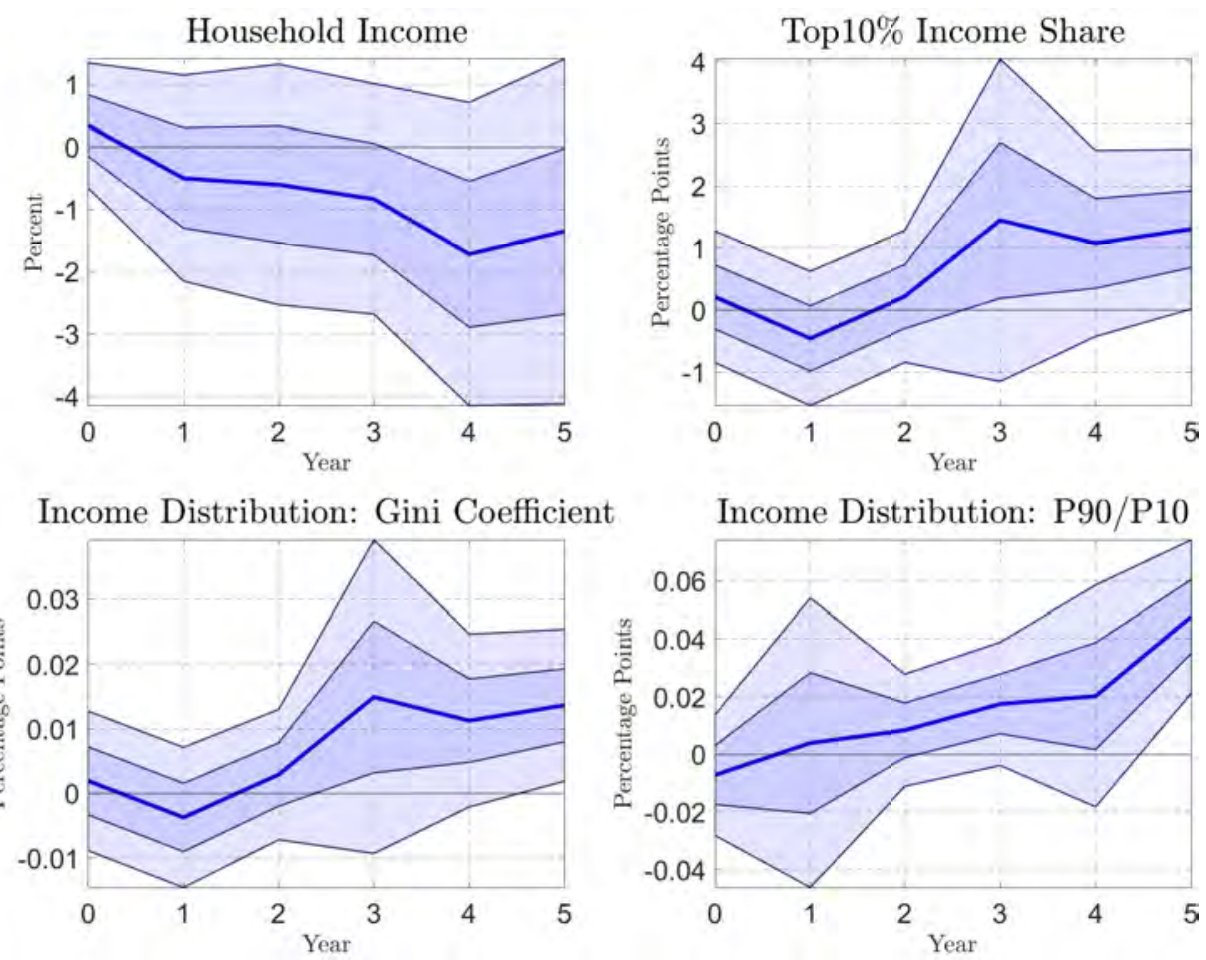

Figure A.11: Impulse Responses of Income Inequality Measures.

Notes: Impulse responses to a 1 percentage point contractionary monetary policy shock at an annual frequency, based on the local projection approach in (2). 95 and 68 percent confidence bands shown, using Newey and West (1987) standard errors. Table A.3 in Appendix A.6 lists the data sources.

\section{A.8 Robustness and Additional Evidence}

In this section, we conduct a number of robustness exercises for the impulse responses at the macro-level and compare them to the ones based on U.S. data. A noticeable feature of our impulse responses is the inverse J-curve reaction of the policy rate. The policy rate initially increases to a contractionary shock, but then falls below its initial level after several months. In Figure A.12, we show that this response is inherited from positive (contractionary) shocks. Monetary easings (negative shocks) are not followed by strong subsequent increases. A possible explanation for this result is the following. When the central bank tightens policy beyond the typical reaction to inflation and output forecasts, policymakers subsequently correct their initial "mistake" and try to boost the economy by easing policy. In contrast, when loosening policy too much, policymakers simply let the boom die out without leaning strongly against it. The estimated responses are close to the ones based on U.S. data, including the inverse J-curve response of the policy rate. Figure A.13 shows the responses of the policy rate, industrial production, and the unemployment rate for the United States to monetary policy shocks taken from Romer and Romer (2004) (1970:M11996:M12) and Coibion et al. (2017) (1970:M1-2007:M12). Figure A.14 shows the policy rate responses to positive and negative shocks for the U.S. Both figures include the equivalent responses for Norway, which tend to be close to the responses based on U.S. data. 
We conduct a battery of robustness checks. First, using only forecasts from Consensus Economics gives similar impulse responses at various frequencies (shown in Figure A.15). Second, the estimated shocks and impulse responses remain nearly unchanged when leaving out the exchange rate terms in (1), but omitting all forecast variables changes the impulse responses significantly. For example, as illustrated in Figure A.16, the unemployment rate falls in the wake of a tightening, while wages rise and consumer prices increase. Third, including interaction terms between the output and inflation forecasts and the pre-inflation targeting regime dummy in (1) gives nearly identical shocks and impulse responses. Fourth, Coibion (2012) notices the importance of the lag length for the results in Romer and Romer (2004). Figure A.17 shows that the results are robust to including only one year of lagged values of the monetary policy shock. The same holds for the responses at lower frequencies and when controlling for one year of lagged one-period growth rates of the dependent variable in (2). Fifth, a potential concern related to the aggregation of shocks to annual frequency is that the effects of shocks that take place early in the year are different from those that occur late in the year (e.g., Olivei and Tenreyro, 2007), resulting in biased responses. Figure A.18 shows that the results remain similar when considering impulse responses that take place in either the first half or the second half of the year. ${ }^{49}$ Finally, as shown in Figure A.19, we find nearly identical results when restricting the samples to 1997:M1-2015:M12 or 2001:M12018:M12, and the same holds again for the responses at quarterly and annual frequency. Inflation responds slightly less for the sample that starts in 2001, likely because of the official regime switch to inflation targeting in that year.
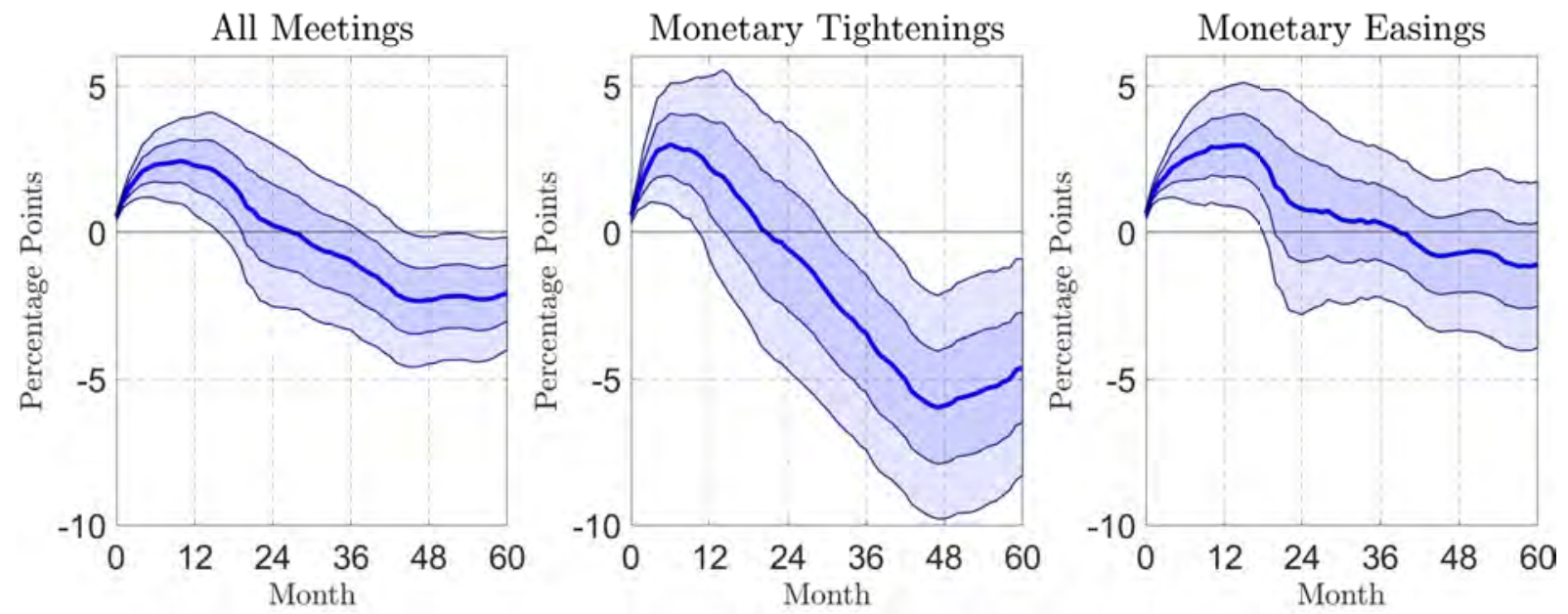

Figure A.12: Policy Rate Responses to Monetary Tightenings \& Easings.

Notes: Impulse responses of the policy rate to a 1 percentage point contractionary monetary policy shock at a monthly frequency, based on the local projection approach in (2). Only positive shocks are included in the series of monetary tightenings, only negative ones in the series of monetary easings. Sample: 1994:M12018:M12. 95 and 68 percent confidence bands are shown, using Newey and West (1987) standard errors.

\footnotetext{
${ }^{49}$ In addition, the policy meetings are fairly evenly distributed throughout the year. Out of the 162 meetings in our sample, 36 take place in the first quarter, 48 in the second quarter, 38 in the third quarter, and 40 in the fourth quarter.
} 

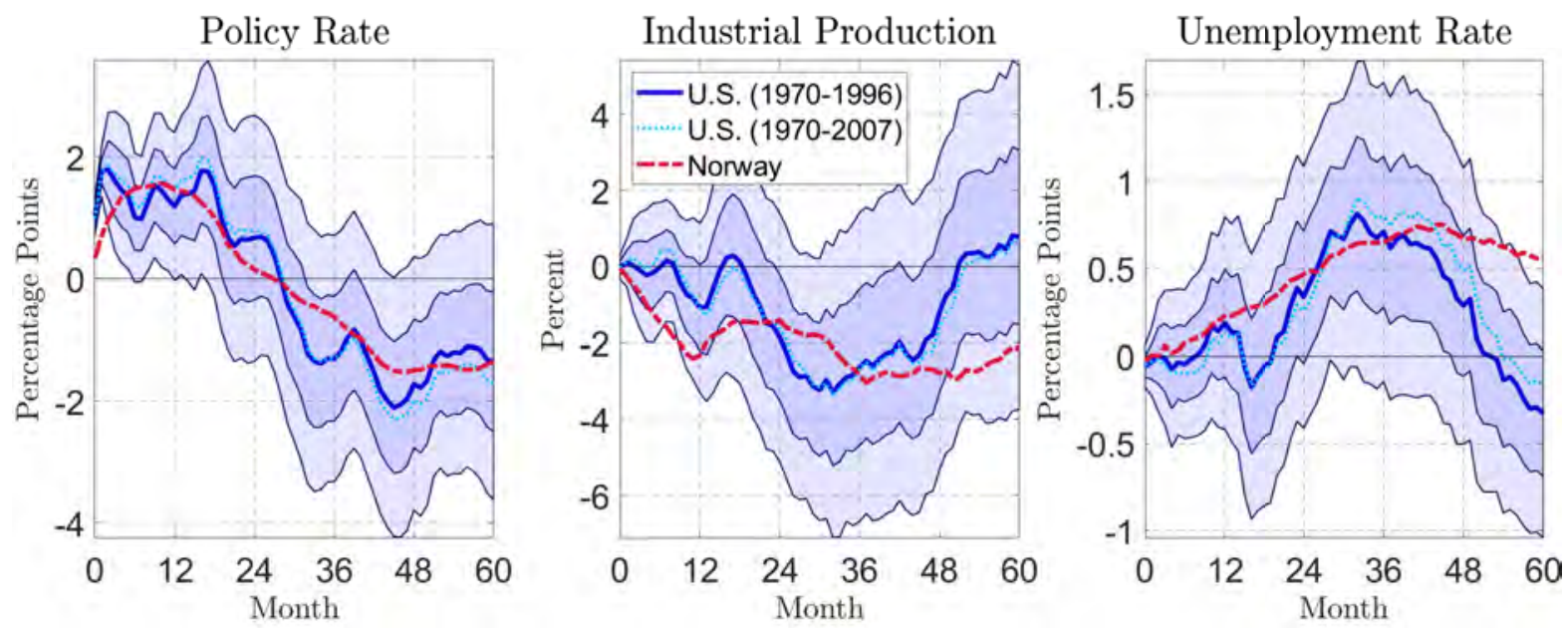

Figure A.13: Comparison of Impulse Responses with U.S Data.

Notes: Impulse responses to a 1 percentage point contractionary monetary policy shock taken from Romer and Romer (2004) (1970:M1-1996:M12) and Coibion et al. (2017) (1970:M1-2007:M12), based on the local projection approach in (2). Following Coibion (2012), 1980:M4-M6 and 1980:M9-M11 are excluded. Matching the assumptions based on Norwegian data, three years of lagged values of the monetary policy shocks are added as controls apart from the policy rate. The impulse responses for Norway are the ones shown in Figure 2, but scaled such that the policy rate response matches the one for the United States (1970-1996) after 10 months. 95 and 68 percent confidence bands are shown for the responses based on U.S. data (1970-1996), using Newey and West (1987) standard errors.
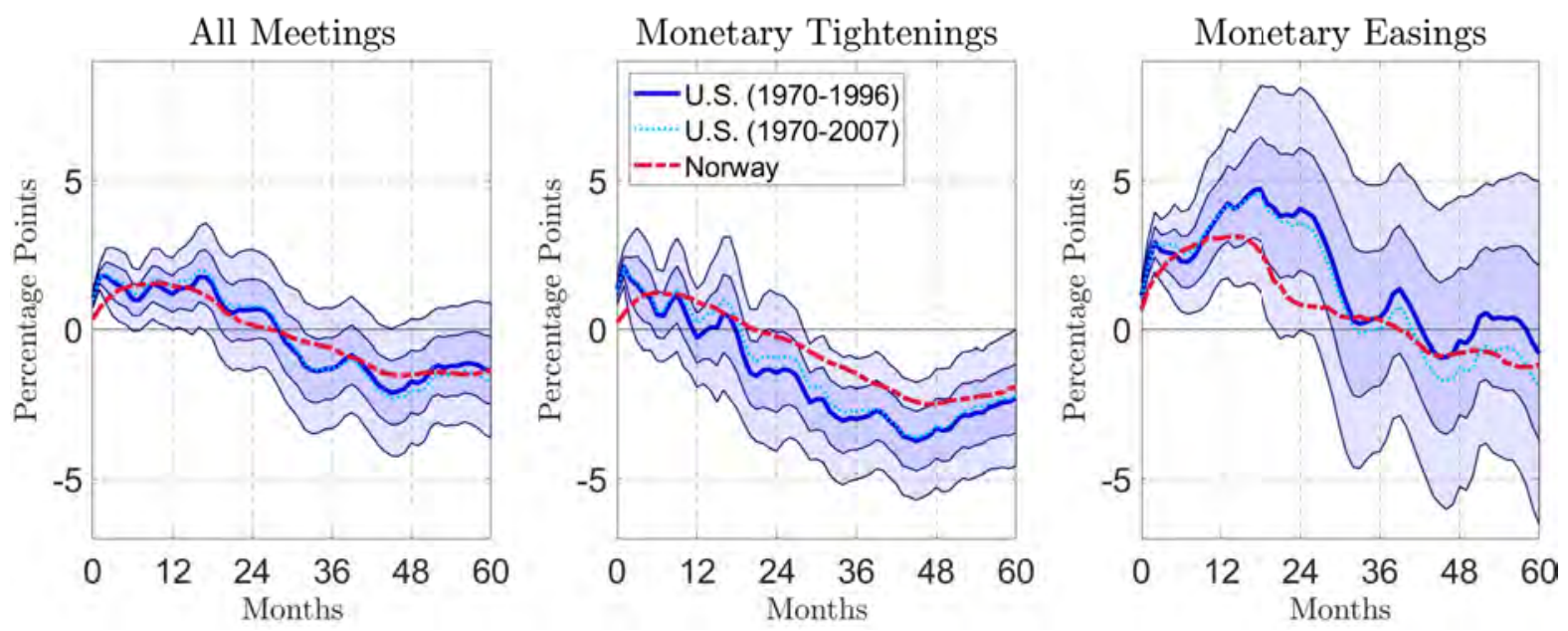

Figure A.14: Policy Rate Responses - Comparison with U.S Data.

Notes: Impulse responses of the policy rates to a one percentage point contractionary monetary policy shock taken from Romer and Romer (2004) (1970:M1-1996:M12) and Coibion et al. (2017) (1970:M12007:M12), based on local projection approach in (2). Only positive shocks are included in the series of monetary tightenings, only negative ones in the series of monetary easings. Following Coibion (2012), 1980:M4-M6 and 1980:M9-M11 are excluded. The impulse responses for Norway are the ones shown in Figure (2), but scaled such that each respective policy rate response matches the one for the United States (1970-1996) after 10 months. 95 and 68 percent confidence bands are shown for the responses based on U.S. data (1970-1996), using Newey and West (1987) standard errors. 

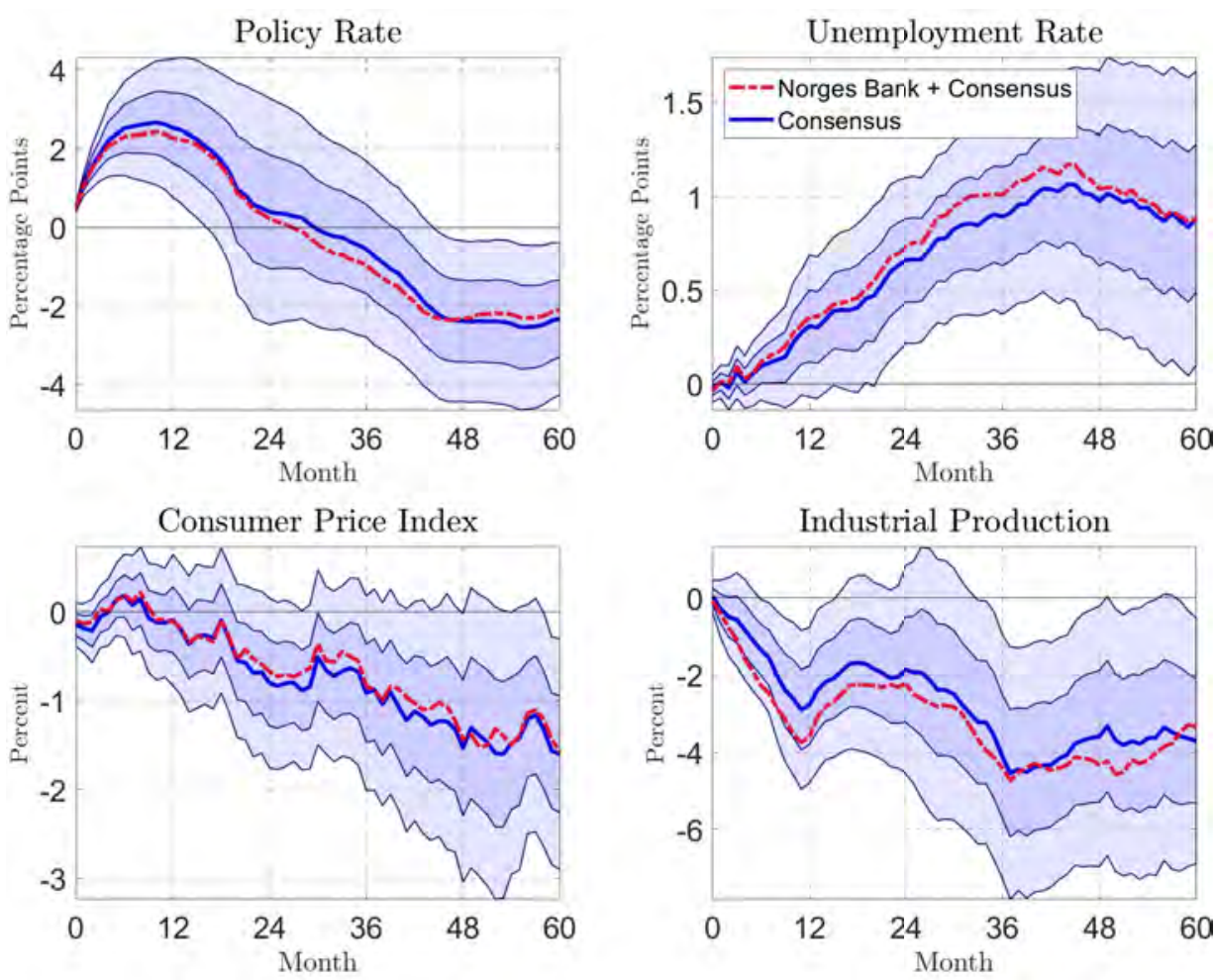

Figure A.15: Impulse Responses - Consensus Forecasts.

Notes: Impulse responses to a 1 percentage point contractionary monetary policy shock at a monthly frequency, based on the local projection approach in (2). "Norges Bank + Consensus" indicates the identification approach used in the main analysis, "Consensus" excludes Norges Bank forecasts leaving the rest unchanged. 95 and 68 percent confidence bands shown, using Newey and West (1987) standard errors. Table A.3 in Appendix A.6 lists the data sources. 
Policy Rate

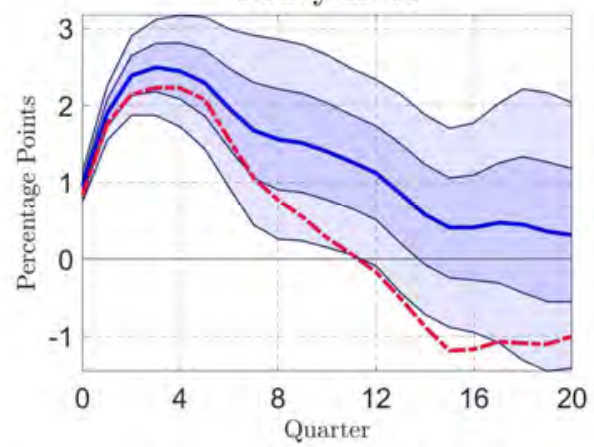

Consumer Price Index

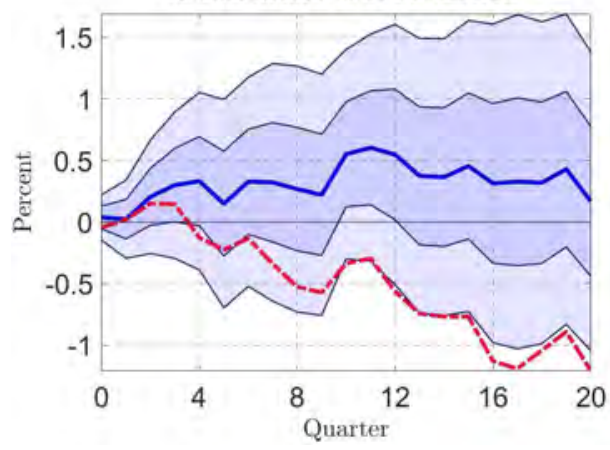

Unemployment Rate

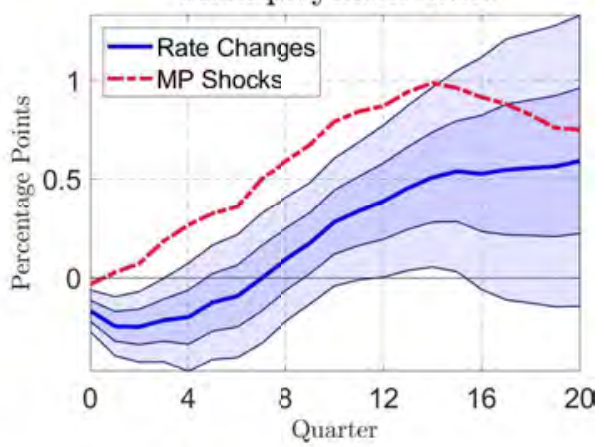

Wages and Salaries

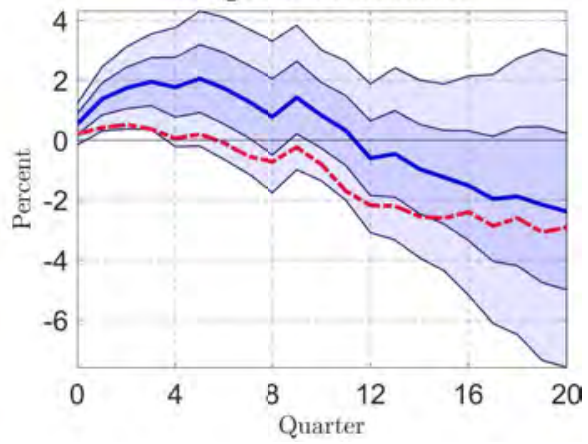

Figure A.16: Impulse Responses - Rate Changes.

Notes: Impulse responses to a 1 percentage point contractionary monetary policy shock or rate change at a quarterly frequency, based on the local projection approach in (2). "MP Shocks" indicates the identification approach used in the main analysis, "Rate Changes" uses rate changes instead of shocks in (2). 95 and 68 percent confidence bands shown, using Newey and West (1987) standard errors. Table A.3 in Appendix A.6 lists the data sources. 

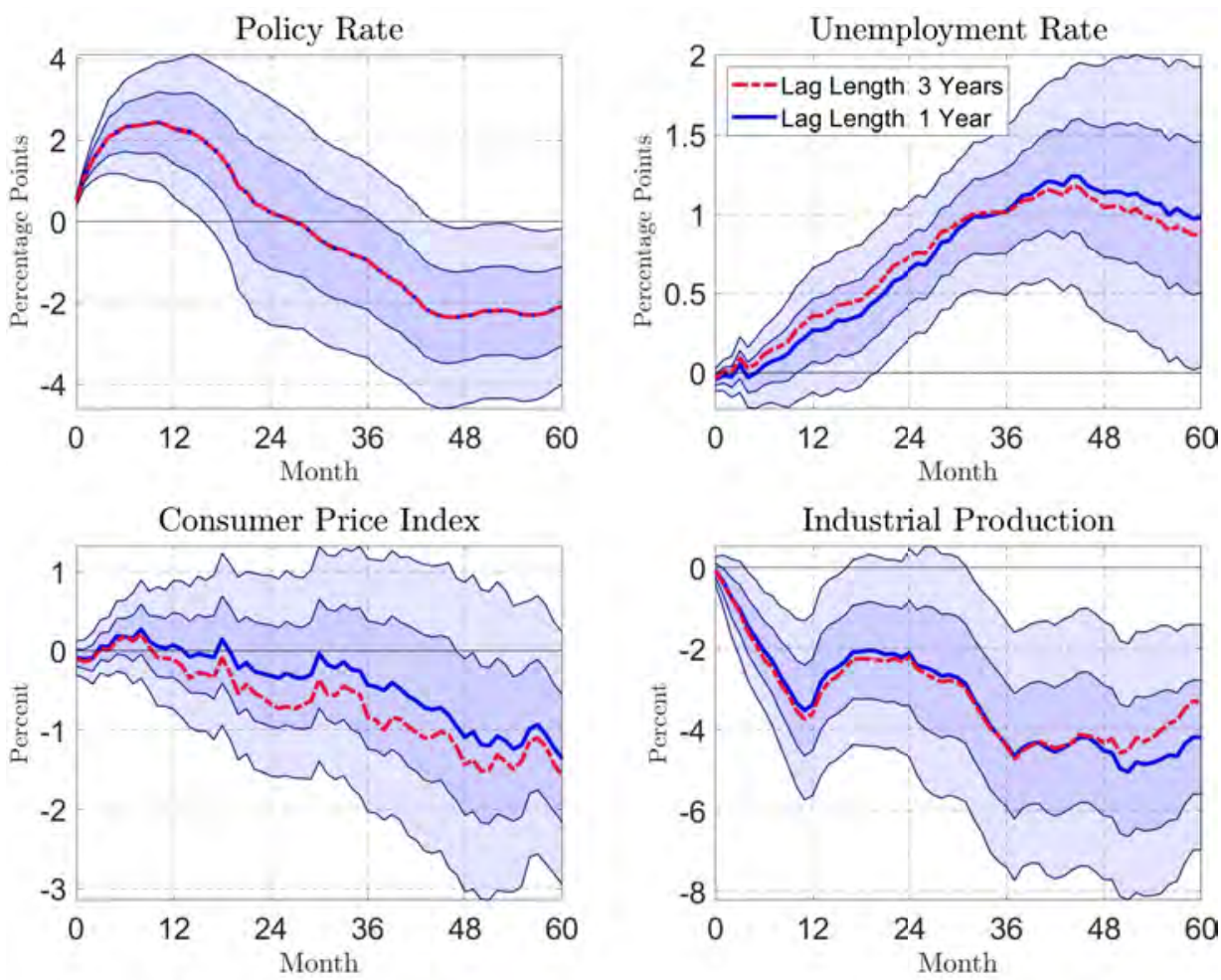

Figure A.17: Impulse Responses - Lag Length.

Notes: Impulse responses to a 1 percentage point contractionary monetary policy shock at a monthly frequency, based on the local projection approach in (2). "Lag Length: 3 Years" indicates the baseline assumption of three years of lagged shocks as controls, "Lag Length: 1 Year" uses only the shocks from the prior year as controls. 95 and 68 percent confidence bands shown, using Newey and West (1987) standard errors. Table A.3 in Appendix A.6 lists the data sources. 
Policy Rate
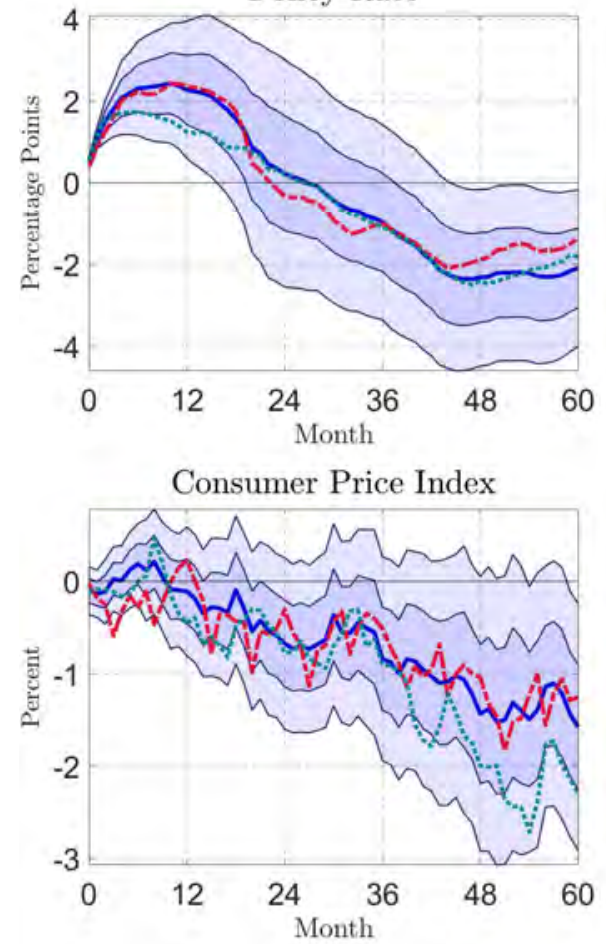

Unemployment Rate
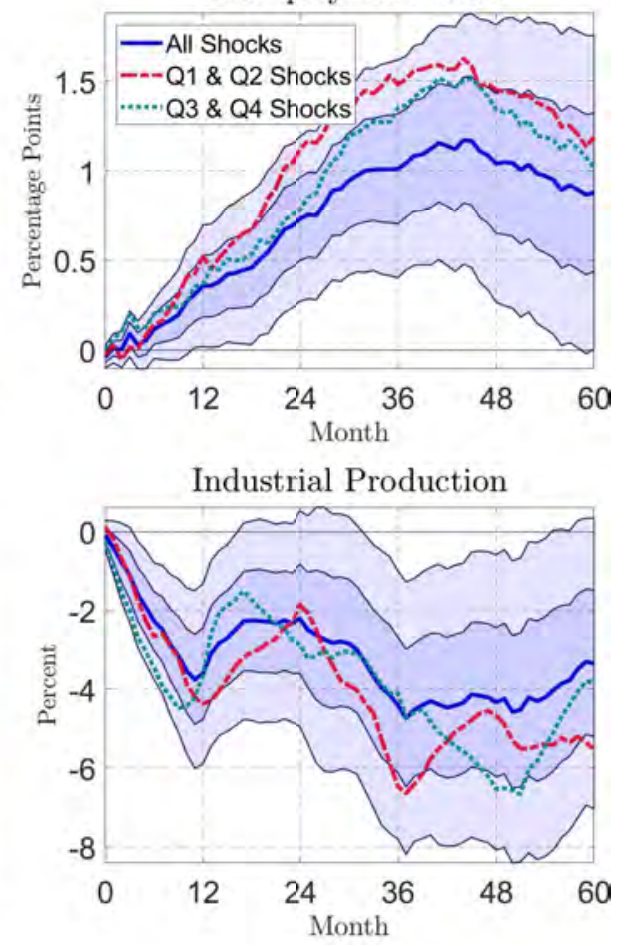

Figure A.18: Impulse Responses - Timing of Shocks.

Notes: Impulse responses to a 1 percentage point contractionary monetary policy shock at a monthly frequency, based on the local projection approach in (2). "All Shocks" indicates the baseline assumption that considers all monetary policy shocks, "Q1 \& Q2 Shocks" excludes shocks that occurred in the second half of a year, and "Q3 \& Q4 Shocks" excludes shocks that occurred in the first half of a year. 95 and 68 percent confidence bands shown, using Newey and West (1987) standard errors. Table A.3 in Appendix A.6 lists the data sources. 

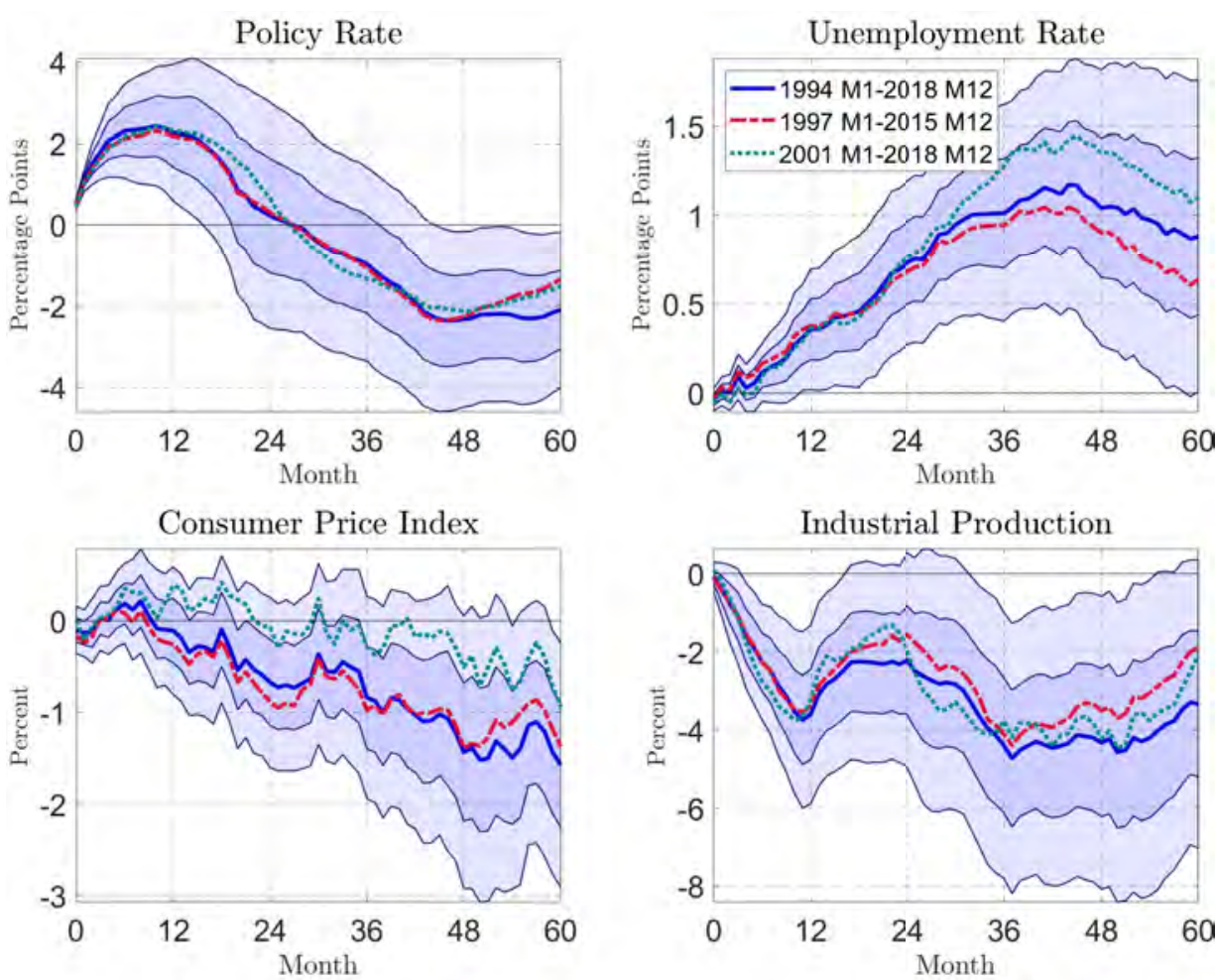

Figure A.19: Impulse Responses - Sample.

Notes: Impulse responses to a 1 percentage point contractionary monetary policy shock at a monthly frequency, based on the local projection approach in (2). "1994:M1-2018:M12" refers to baseline sample, which are restricted to "1997:M1-2015:M12" and "2001:M1-2018:M12" for the other estimations. 95 and 68 percent confidence bands shown, using Newey and West (1987) standard errors. Table A.3 in Appendix A.6 lists the data sources.

\section{A.9 Time Aggregation - Norway}

Figures 2, 3, and A.8 show that the impulse responses at an annual frequency are generally of smaller magnitude compared with the ones at monthly and quarterly frequencies. To test whether the size of the responses is still similar in relative terms though, we proceed as follows. Using the estimated monthly response of a particular variable, we aggregate this response to an annual frequency. To this end, we assume that the monthly response is the same for all months and that shocks are equally distributed throughout the year. Hence, this procedure takes the estimated monthly response as the true response and computes the corresponding reaction at the annual frequency. The results for several variables that are observed at the monthly frequency are shown in blue in Figure A.20 as "annualized monthly" responses. In comparison, the red lines indicate the "estimated annual" responses, which are of smaller magnitude.

Next, we rescale the "annualized monthly" responses. The scaling factor is obtained by comparing "estimated annual" and "annualized monthly" of the average policy rate response over the years 0 to 2 , the years for which the response is positive. Based on the "estimated annual" responses, 

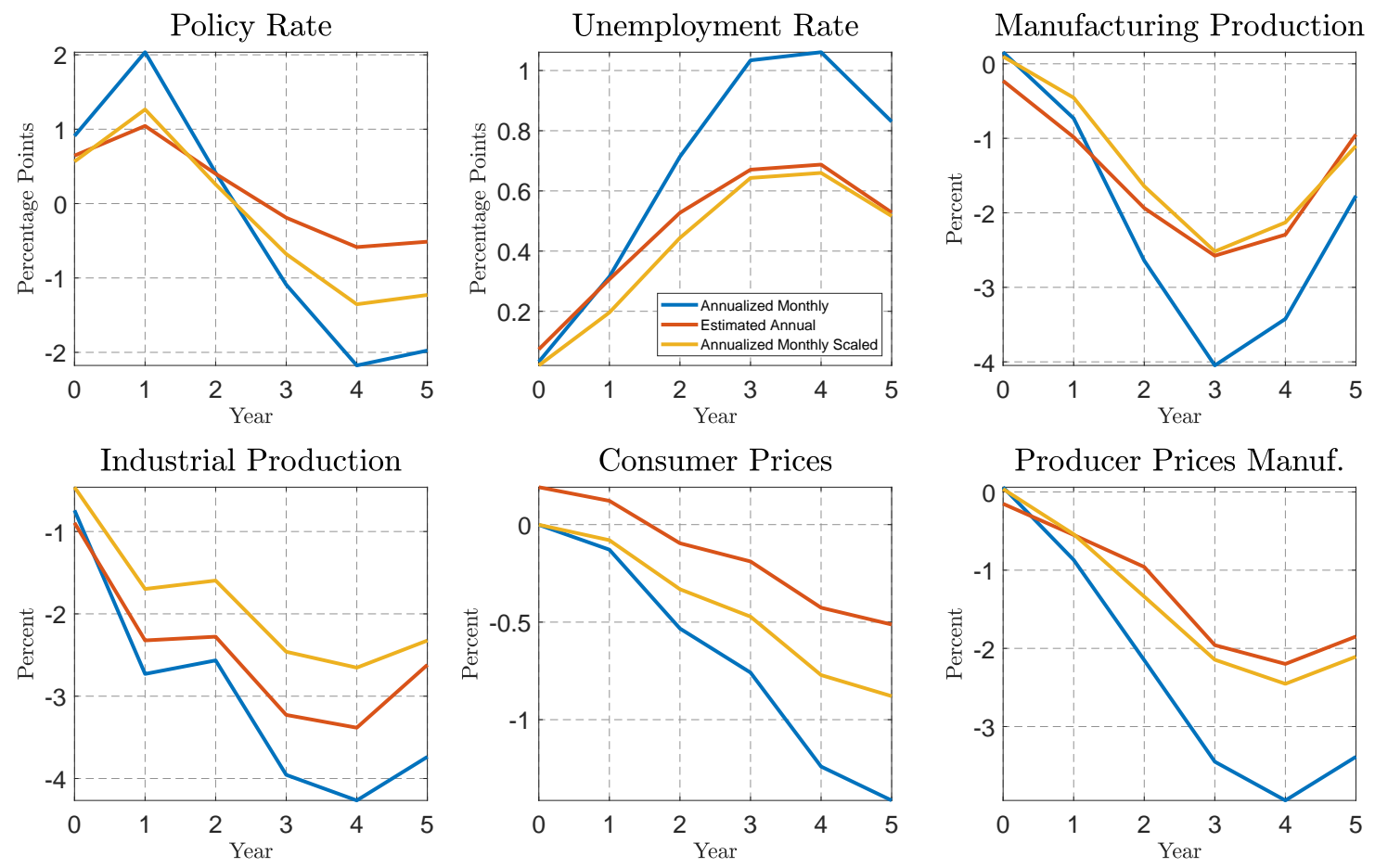

Figure A.20: Time Aggregation.

Notes: Impulse responses at an annual frequency; see description in text for the computation of the three types of responses.

the policy rate increases on average by around 70 basis points over this period, and by around 112 basis points based on the "annualized monthly" responses. The scaling factor is given by the ratio of the two, that is, around 0.62. Using this scaling factor, we rescale all "annualized monthly" responses, which are shown in yellow as "annualized monthly scaled" responses. Based on this rescaling, the "estimated annual" and the "annualized monthly scaled" responses for the unemployment rate, manufacturing production, and producer prices (manufacturing) are close to each other. Somewhat larger gaps remain for industrial production and consumer prices. Overall, this exercise shows that the smaller size responses at the annual frequency are largely driven by an attenuation across all variables. In relative terms, the responses are in fact similar, though we also show that this finding does not apply exactly for all variables.

\section{A.10 Time Aggregation - General Intuition}

In this section, we provide some general intuition on the time aggregation of shocks and impulse responses. Let us assume the following functional form for an impulse response function

$$
\psi(h)=a e^{-\left(\frac{h-b}{c}\right)^{2}},
$$

following Barnichon and Matthes (2018, equation (6), page 43). Figure A.21 illustrates how the parameters $a, b$, and $c$ determine the shape of the impulse response function. 


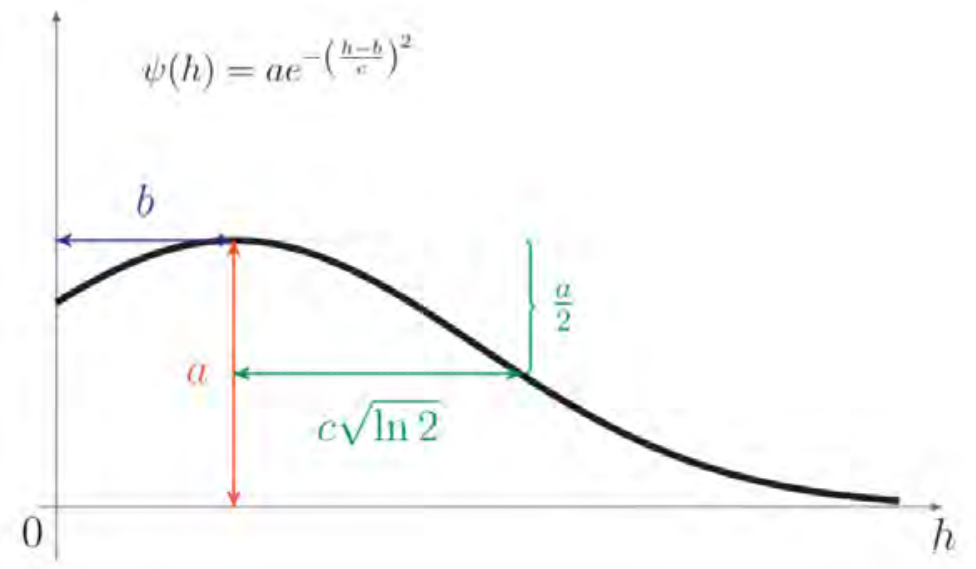

Figure A.21: Functional approximation of an impulse response (see Figure 1 in Barnichon and Matthes, 2018).

Next, let us consider specific parameterizations for two cases: (i) when time aggregation works well and (ii) when it does not. First, assume that $a=1, b=20$, and $c=20$ at the monthly frequency, giving the impulse response function that is shown in panel (a) in Figure A.22. The monthly response takes a similar shape as a range of responses that we obtain using the Norwegian data. To aggregate the monthly response to a lower frequency, we take the following approach. We assume that the monthly response is the "true" response and that it is the same for each month in which the shock occurs. Moreover, under the assumption that the shocks that initiate the responses occur with equal probability across all months, one can aggregate the monthly responses to lower frequencies, as illustrated in panels (b) and (c) in Figure A.22. While there is some natural attenuation when moving from the monthly frequency to the annual frequency, by and large, the responses take a similar shape across all frequencies.

(a) Monthly

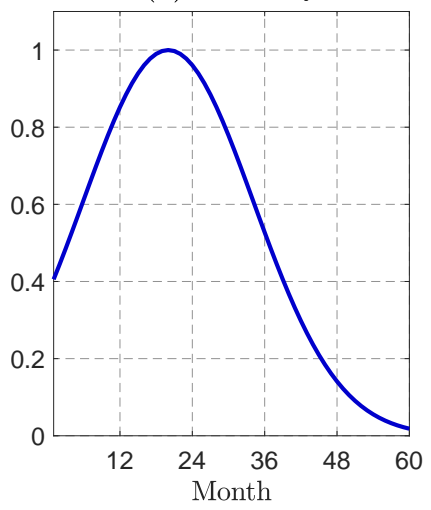

(b) Quarterly

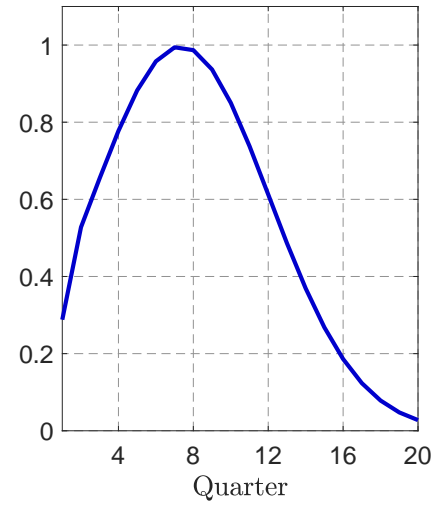

(c) Annual

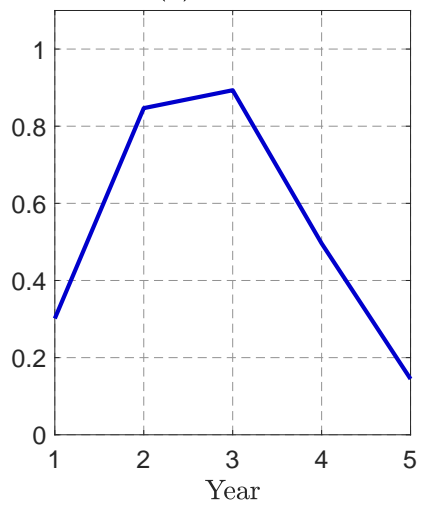

Figure A.22: Functional approximation of an impulse response based on (9) using the parametrization $a=1, b=20$, and $c=20$.

In comparison, let us assume an extreme parameterization to illustrate when the time aggregation 
fails, in the sense that the impulse responses take a substantially different form across frequencies. We assume $a=1, b=20$, and $c=1$. The new responses are shown in Figure A.23. The monthly response spikes after 20 quarters, but it is very short-lived. When moving from the monthly to the annual frequency, the responses take a very different form and are strongly attenuated. Hence, time aggregation to a quarterly and an annual frequency can in principle produce responses that have a similar shape across the different frequencies, but that relies on the impulse responses being relatively persistent as in Figure A.22. In addition, the time aggregation is more likely to succeed in other environments when (i) the shocks are well measured and give precise impulse responses even at higher frequencies, (ii) longer time series are available, and (iii) the shocks explain a larger fraction of macro volatility.

(a) Monthly

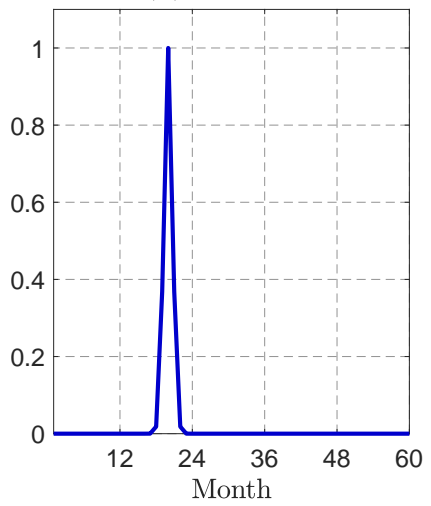

(b) Quarterly

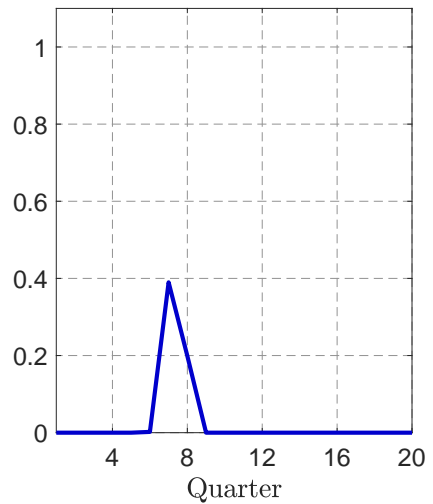

(c) Annual

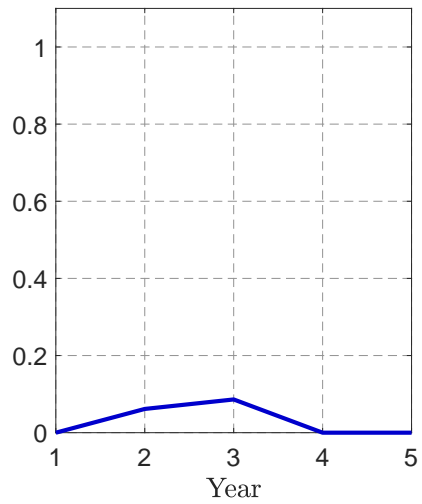

Figure A.23: Functional approximation of an impulse response based on (9) using the parametrization $a=1, b=20$, and $c=1$.

\section{B Micro Data}

\section{B.1 Details on Consumption Imputation}

In this section, we outline the procedure to impute consumption expenditures. Note that we directly observe all information required to infer consumption expenditure except active saving. To derive a measure of active saving from observed gross saving (change in wealth), we have to account for the capital gains on housing and stock holdings including stock funds. Below, we provide details on how we impute capital gains within each asset class.

Housing. For housing, we observe housing transactions directly in the data. Capital gains in housing are the change in housing wealth that is not due to housing transactions.

Stocks. For stocks listed at Oslo Stock Exchange, we use two approaches to compute capital gains: (i) when we observe individual level stock ownership (2005-2015) and (ii) when we do not observe individual level stock ownership (1993-2004). For the latter period, we observe each 
household's ownership of individual stocks (both volume and price) at the end of each year. In addition, we observe the daily price and turnover of each individual stock from the stock exchange. To compute a measure of capital gains, we make two simplifying assumptions:

1. All transactions are in the same direction throughout the year. That is, if the household is a net seller, it is a net seller throughout the year.

2. A household's share of transactions in a given day is equal to that day's share of transactions as a share of total transactions over the year.

With these two assumptions at hand, we can compute a measure of capital gains for each stock at the household level using only the data available to us. To see this, note that the value of net transactions over the year is equal to $\sum_{n=1}^{N} p_{j, n, t} d q_{j, n, t}$, where $N$ is the number of days, $p_{j, n, t}$ is the price of stock $j$ on day $n$ in year $t$, and $d q_{j, n, t}$ is the transactions of the stock on day $n$. The two assumptions above imply that $d q_{j, n, t}=\left(q_{j, t}-q_{j, t-1}\right) \omega_{j, n, t}$ where $q_{j, t}$ is the number of shares at the end of the year, $q_{j, t-1}$ is the number of shares at the beginning of the year, and $\omega_{j, n, t}$ is the share of yearly transactions taking place on day $n$ for stock $j$ in year $t$. We can therefore compute a measure of net transactions as

$$
\sum_{n=1}^{N} p_{j, n, t} d q_{j, n, t}=\sum_{n=1}^{N} p_{j, n, t}\left(q_{j, t}-q_{j, t-1}\right) \omega_{j, n, t}=\left(q_{j, t}-q_{j, t-1}\right) \sum_{n=1}^{N} p_{j, n, t} \omega_{j, n, t} .
$$

Capital gains for an individual asset are then equal to $p_{j, t} q_{j, t}-p_{j, t-1} q_{j, t-1}-\left(q_{j, t}-q_{j . t-1}\right) \sum_{n=1}^{N} p_{j, n, t} \omega_{j, n, t}$ and can be obtained from observables in our data.

For the early period, 1993-2005, for which we do not observe individual stock ownership, we utilize the same method as above but apply it to total holdings of stocks. Between 1993 and 2005, the capital gains for stocks in year $t$ are equal to

$$
p_{t} q_{t}-p_{t-1} q_{t-1}-\left(q_{t}-q_{t-1}\right) \sum_{n=1}^{N} p_{n, t} \omega_{n, t}=p_{t} q_{t}-p_{t-1} q_{t-1}-\left(p_{t} q_{t}-\frac{p_{t}}{p_{t-1}} p_{t-1} q_{t-1}\right) \sum_{n=1}^{N} \frac{p_{n, t}}{p_{t}} \omega_{n, t}
$$

where $p_{t}$ is the price of the stock index at the end of the year, $q_{t}$ is the number of shares at the end of the year, $p_{n, t}$ is the price on day $n$ in year $t$, and $\omega_{n, t}$ is the share of yearly transactions on day $n$ in year $t$. Note that we do not observe the number of shares for stocks in total, only total wealth in stocks $\left(p_{t} q_{t}\right)$ and the price movements $\left(p_{t} / p_{t-1}\right)$. We are therefore using the expression for capital gains after the equality sign in (11).

Stock Funds. We do not have access to household-level holdings of individual stock funds. We therefore use a measure of capital gains on stock funds from the Financial Accounts from 1996 to 2015. In particular, we assume that the capital gains on the stock funds portfolio of each household obtain the same percentage change as the total from the Financial Accounts. 
Private Business. We attribute no capital gains to private businesses unless they hold stocks on the Oslo Stock Exchange. For the case that a private business owns stocks, these stocks are allocated to household portfolios using the ownership registry of private businesses before computing capital gains on those stocks using the method described above.

\section{B.2 Details on Institutional Setting}

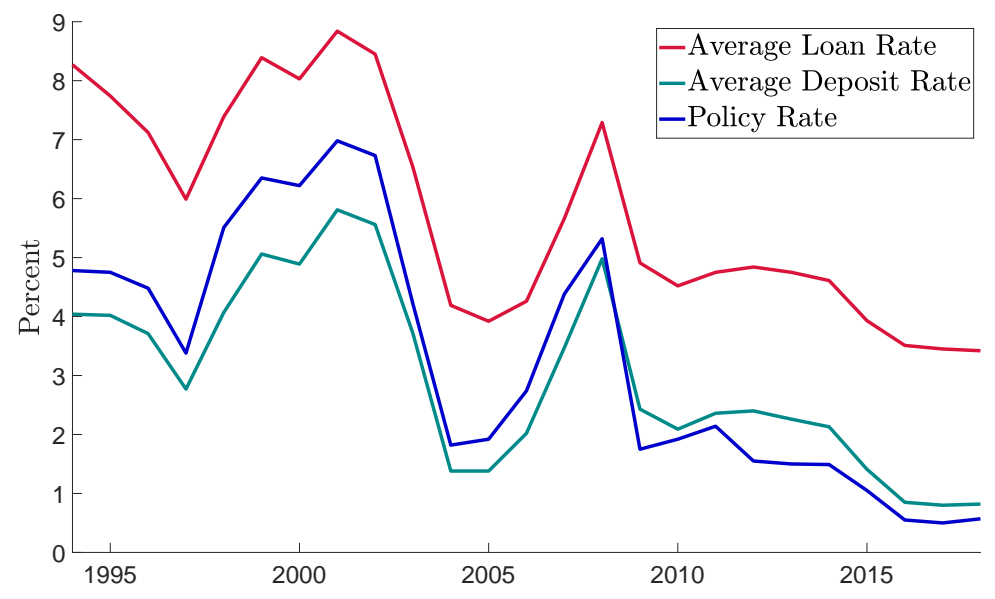

Figure B.1: Historical Average Policy Rate, Loan Rate, and Deposit Rate.

Notes: This figure shows the weighted average interest rates on all outstanding loans and deposits in Norwegian banks together with central bank policy rate. Table A.3 in Appendix A.6 lists the data sources. 


\section{Monetary Policy Transmission at the Household Level}

\section{C.1 Inequality}
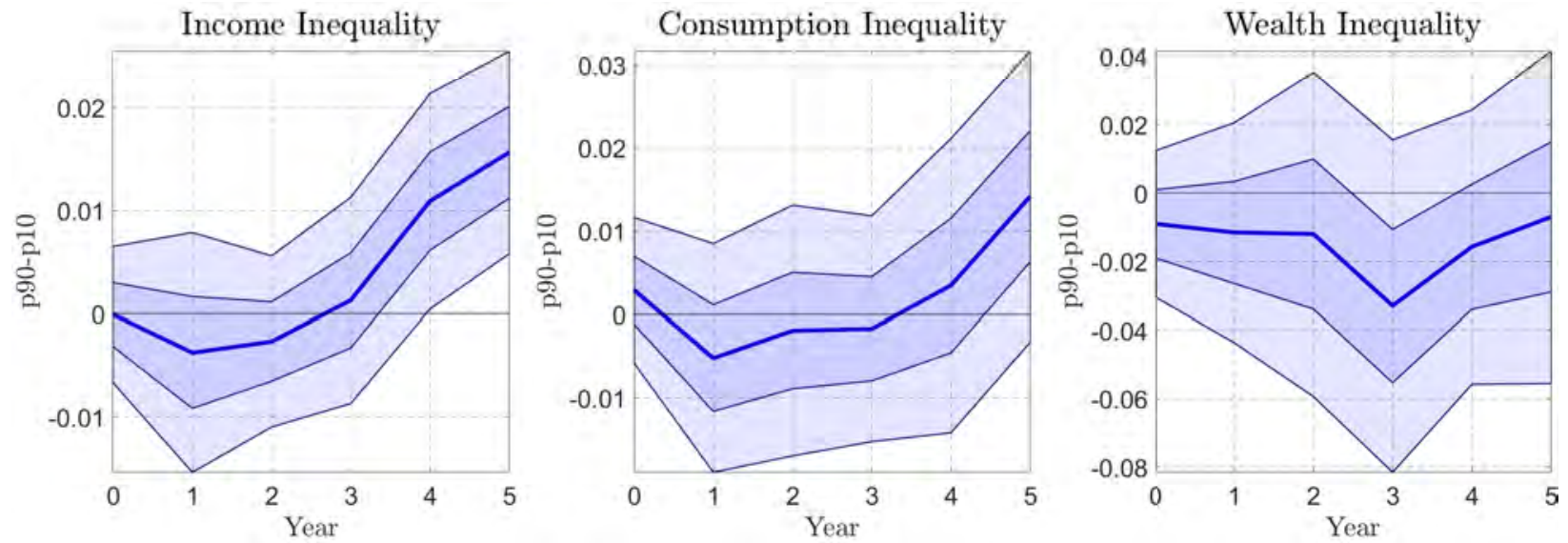

Figure C.1: Impulse Responses of Inequality Measures.

Notes: Impulse responses of p90-p10 measure to a 1 percentage point contractionary monetary policy shock at an annual frequency, based on the local projection approach in (2). The p90-p10 measure is the difference between the 90th and 10th percentile of log levels of each distribution. 95 and 68 percent confidence bands shown, using Newey and West (1987) standard errors. 


\section{C.2 Baseline Results}
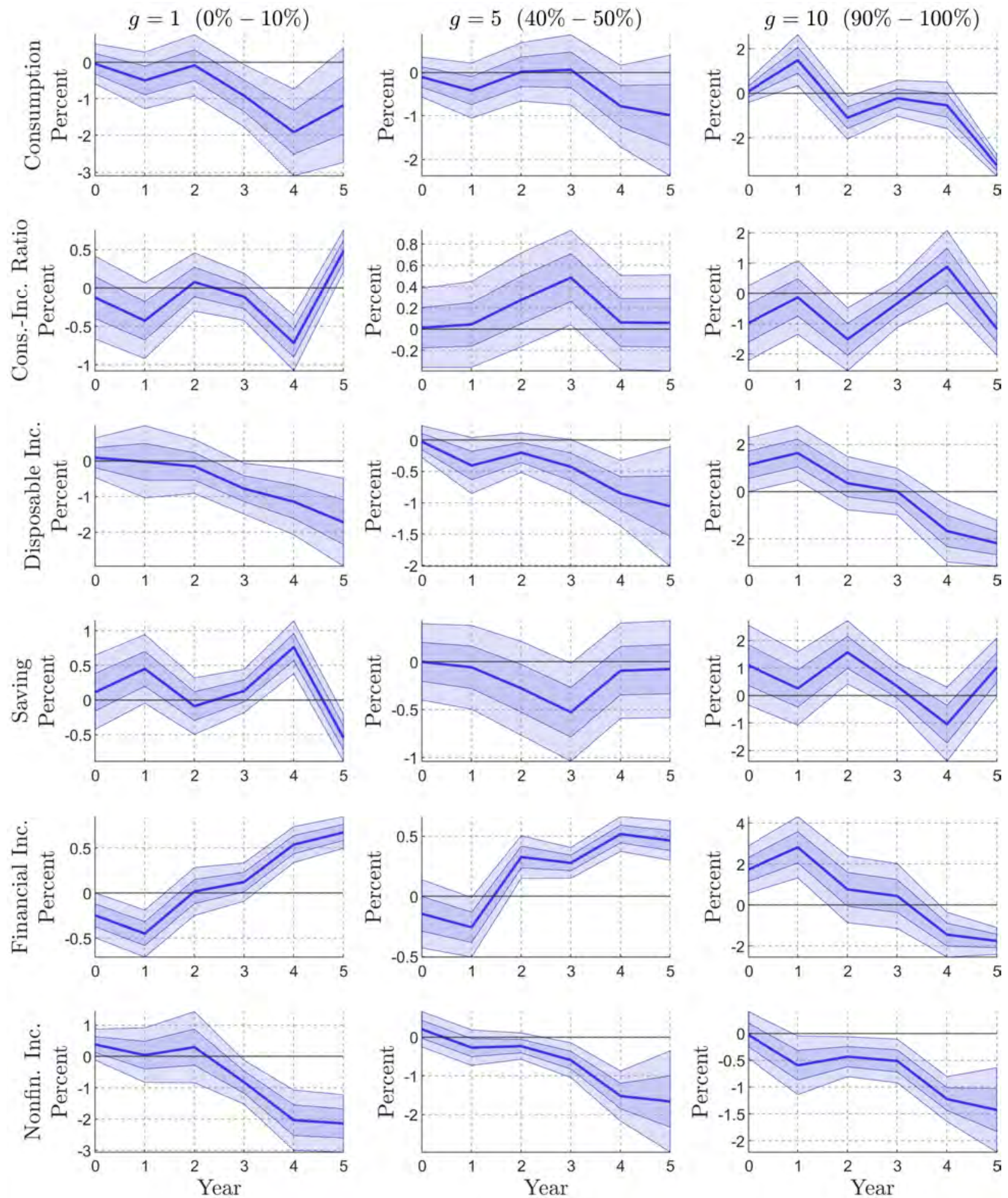

Figure C.2: Impulse Responses of Selected Groups.

Notes: Changes relative to lagged net income at segments of the liquid asset distribution. 95 and 68 percent confidence bands shown, computed using Driscoll and Kraay (1998) standard errors. 

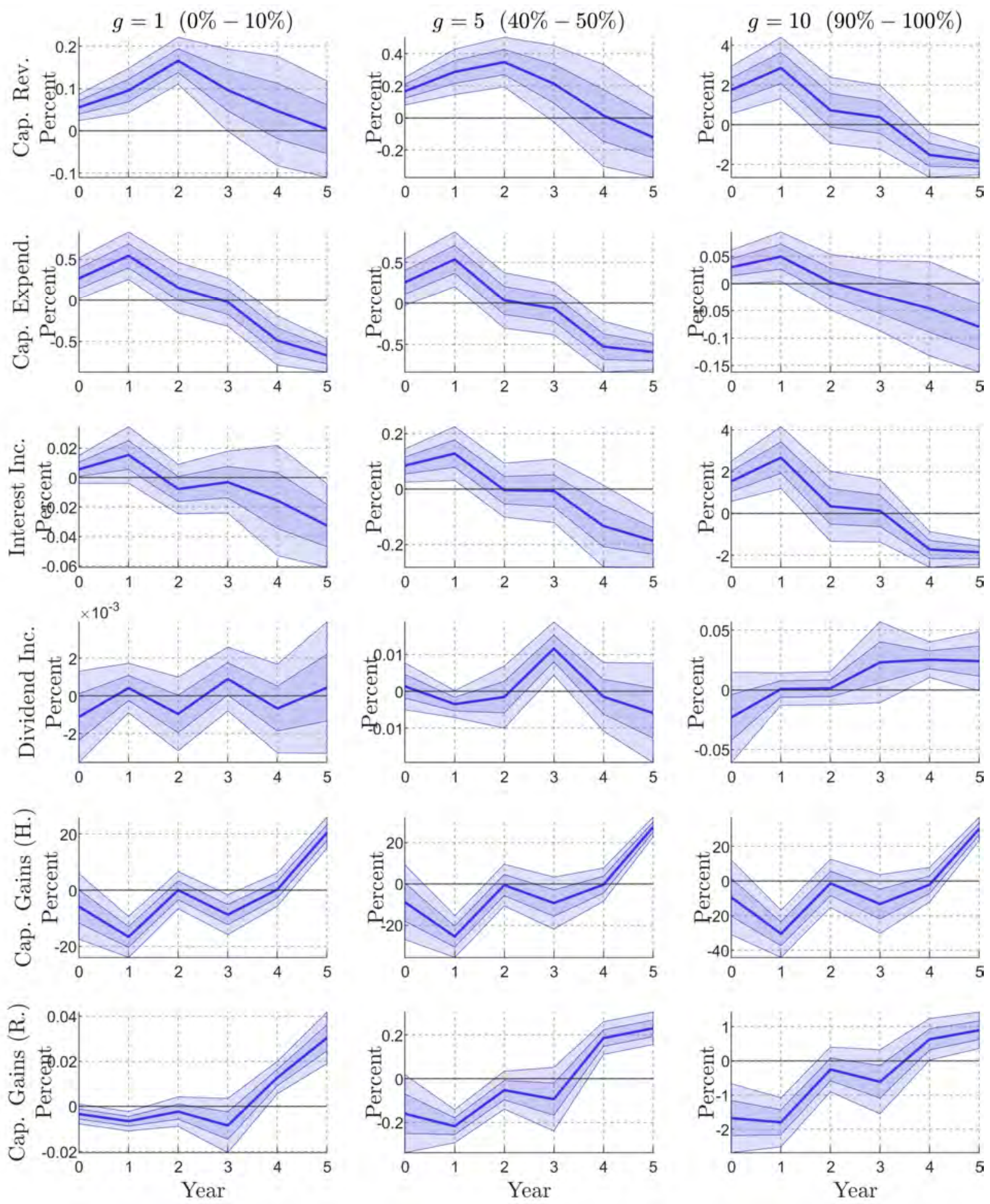

Figure C.3: Impulse Responses of Selected Groups (Continued).

Notes: Changes relative to lagged net income at segments of the liquid asset distribution. 95 and 68 percent confidence bands shown, computed using Driscoll and Kraay (1998) standard errors. 

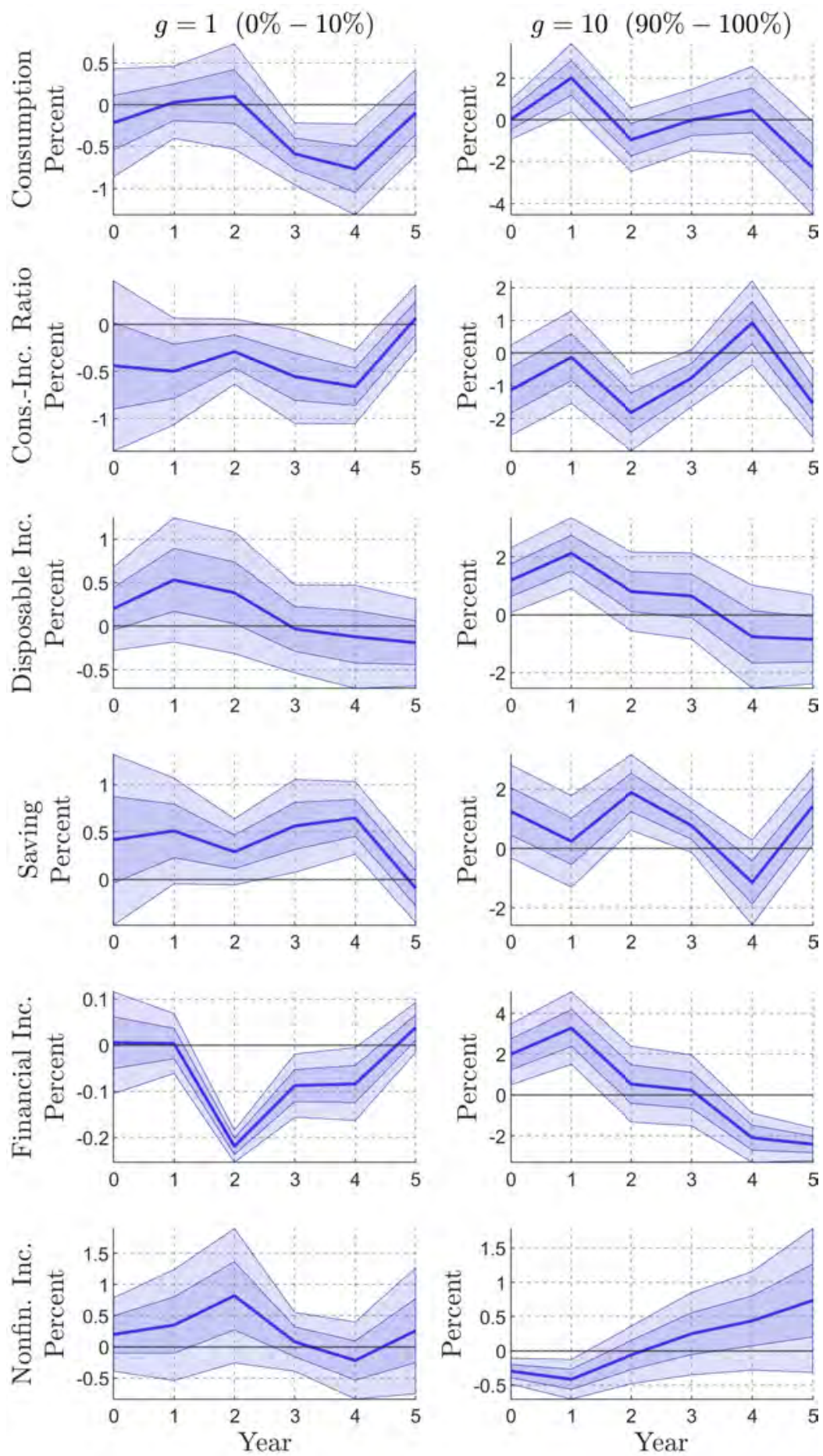

Figure C.4: Impulse Responses at Bottom and Top Relative to Group at Median.

Notes: Differences between impulse responses of 0-10 percent group and 40-50 percent group (left column); differences between impulse responses of 90-100 percent group and 40-50 percent group (right column). Changes relative to lagged net income at segments of the liquid asset distribution.

The model estimated is given by $\left(y_{i, t+h}-y_{i, t-1}\right) / i n c_{i, t-1}=\delta_{i, g}^{h}+\beta^{h} \cdot \epsilon_{t}^{M P}+\sum_{g=1,10} \beta_{g}^{h} D_{i, t-1}^{g} \cdot \epsilon_{t}^{M P}+$ $\sum_{g=1,5,10} \sum_{k=1}^{K} \gamma_{g, k}^{h} X_{i, t-k} D_{i, t-1}^{g}+u_{i, t}^{h}$ for all $i$ in groups $g=1,5,10$, where $D_{i, t-1}^{g}$ equals 1 if $i$ is in $g$ in $t-1$. $\beta_{1}^{h}$ and $\beta_{10}^{h}$ shown with 95 and 68 percent confidence bands based on Driscoll and Kraay (1998) std. errors. 

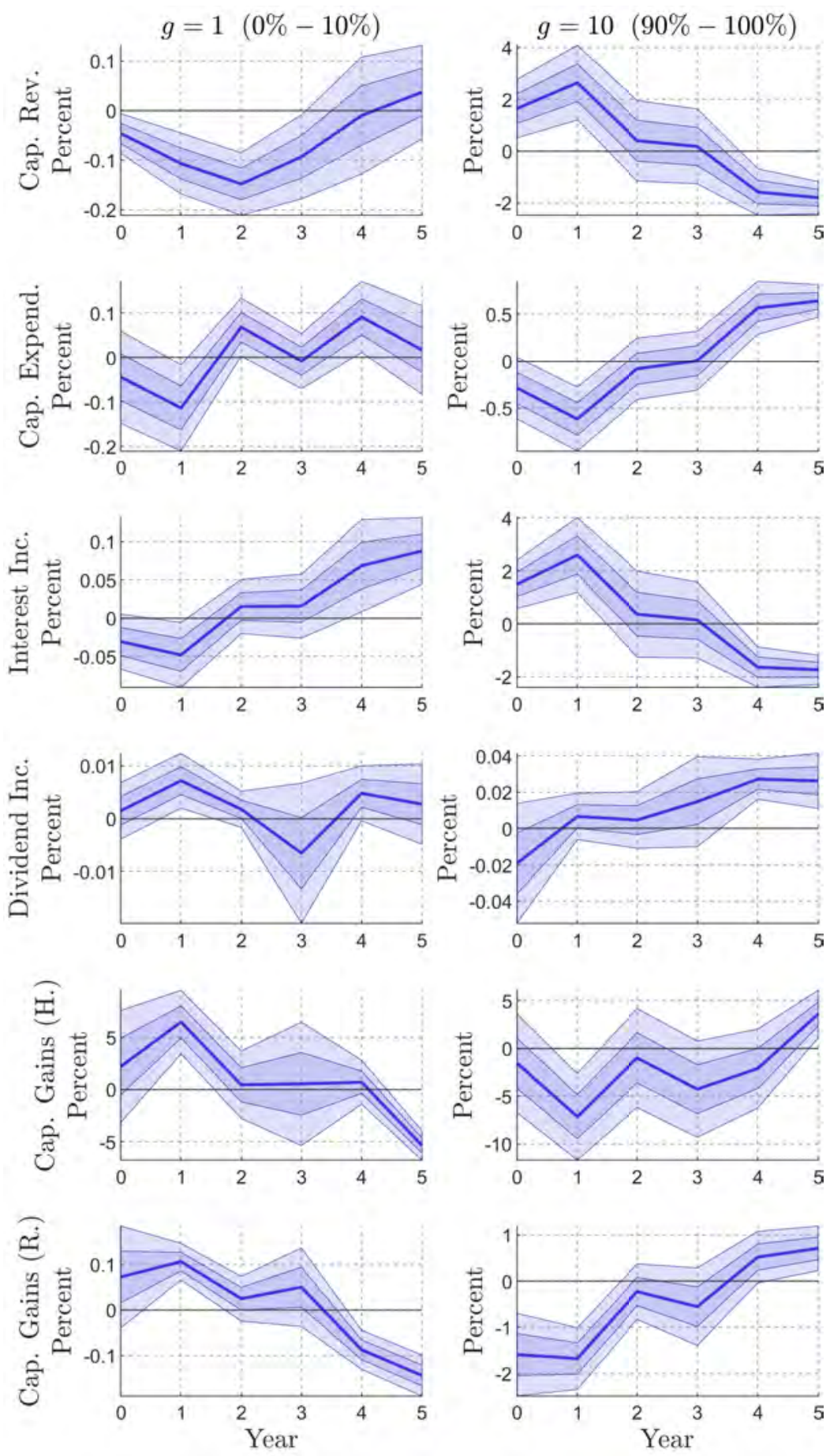

Figure C.5: Impulse Responses at Bottom and Top Relative to Group at Median (Continued).

Notes: Differences between impulse responses of 0-10 percent group and 40-50 percent group (left column); differences between impulse responses of 90-100 percent group and 40-50 percent group (right column). Changes relative to lagged net income at segments of the liquid asset distribution.

The model estimated is given by $\left(y_{i, t+h}-y_{i, t-1}\right) / i n c_{i, t-1}=\delta_{i, g}^{h}+\beta^{h} \cdot \epsilon_{t}^{M P}+\sum_{g=1,10} \beta_{g}^{h} D_{i, t-1}^{g} \cdot \epsilon_{t}^{M P}+$ $\sum_{g=1,5,10} \sum_{k=1}^{K} \gamma_{g, k}^{h} X_{i, t-k} D_{i, t-1}^{g}+u_{i, t}^{h}$ for all $i$ in groups $g=1,5,10$, where $D_{i, t-1}^{g}$ equals 1 if $i$ is in $g$ in $t-1$. $\beta_{1}^{h}$ and $\beta_{10}^{h}$ shown with 95 and 68 percent confidence bands based on Driscoll and Kraay (1998) std. errors. 


\section{C.3 Robustness}

\section{C.3.1 Alternative Specifications}
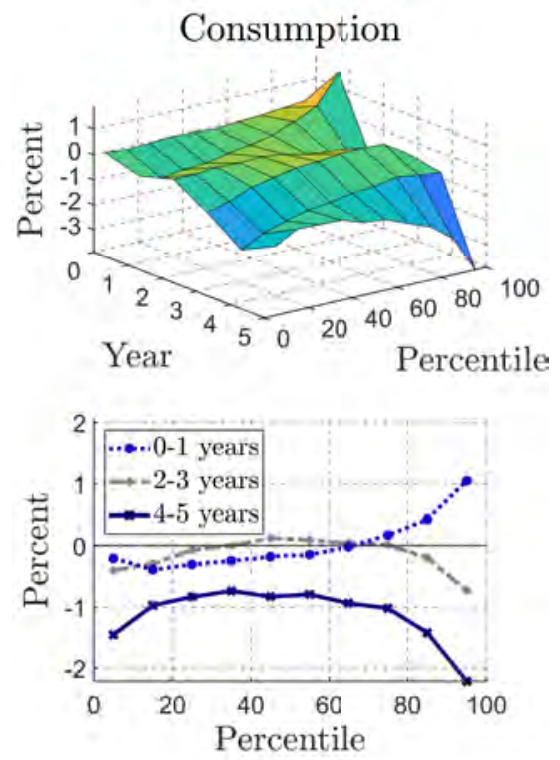

Figure C.6: Impulse Responses of Consumption Growth.

Notes: Dependent variable given by cumulative growth rate $\left(c_{i, t+h}-c_{i, t-1}\right) / c_{i, t-1}$. Model otherwise as specified in equation (5). Plotted are percentage changes at segments of the liquid asset distribution.
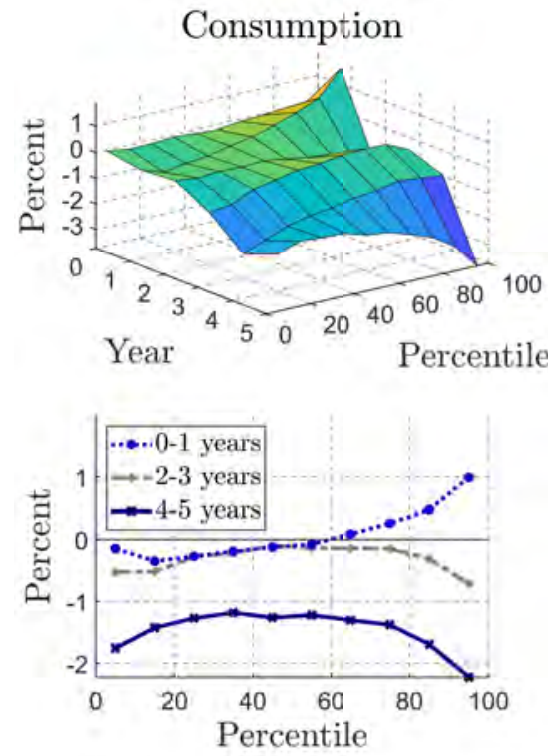

Figure C.7: Impulse Responses of Consumption with Housing Service Flow.

Notes: Changes relative to lagged net income at segments of the liquid asset distribution. Housing service flow computed as ratio of aggregate housing service flow from owner-occupied housing in national accounts and aggregate housing wealth multiplied by household's beginning-of-year housing wealth. Aggregate housing service flow ratio fell from 3.7 percent in 1995 to 1.8 percent in 2015 (average 2.3 percent). 

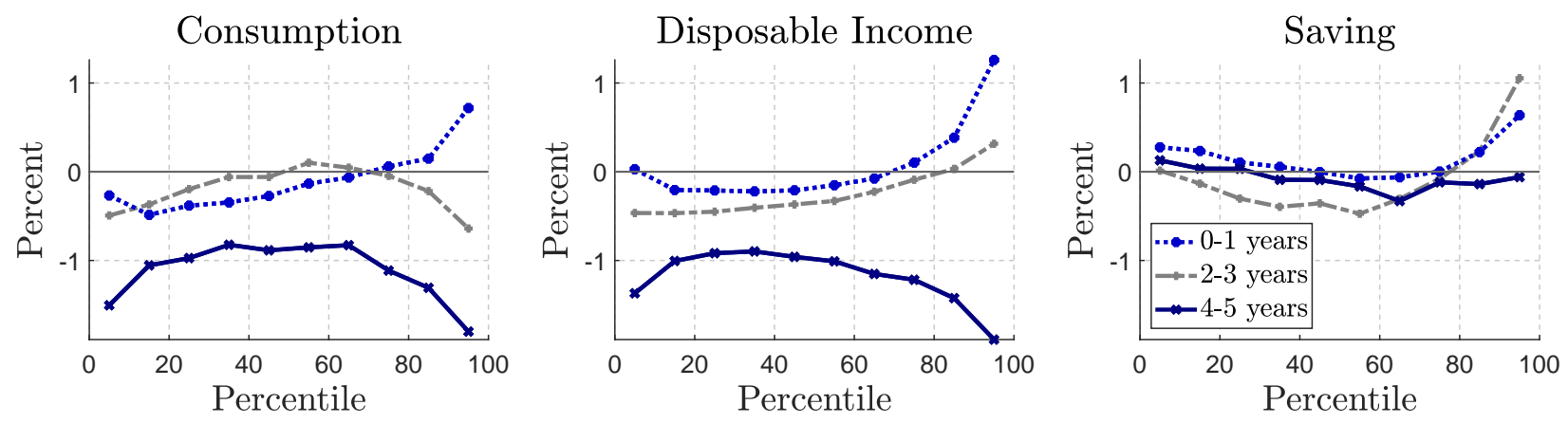

Figure C.8: Impulse Responses by Lagged Liquidity-to-Income Ratio.

Notes: Changes relative to lagged net income at segments of the distribution of liquid assets over income.

\section{C.3.2 Consumption Imputation}

This section presents a number of robustness exercises performed to verify that our results are not an artifact of measurement error in consumption expenditure. Note that we observe housing transactions and therefore the active component of saving in housing wealth. Hence, mismeasured capital gains in housing do not affect our imputed measure of consumption. The robustness checks are therefore centered around capital gains in stocks.

We perform two exercises to test the robustness of the sizable and positive short-run consumption responses among high-liquidity households. First, we compute the same responses for a sample of households that do not hold stocks (around 36 percent of households within the top ten percent). For these households, the saving measure required to impute consumption expenditure (active saving) is directly observed. To make the results comparable to the responses across the liquid asset distribution in the paper, we do not reorder households, but keep them "fixed" at their position in the liquid asset distribution in the full sample. The results are shown in Figure C.9. Reassuringly, the estimated consumption expenditure response for nonstockholders at the top of the distribution is slightly higher but of similar magnitude as the consumption expenditure response of high-liquidity households in the full sample. 

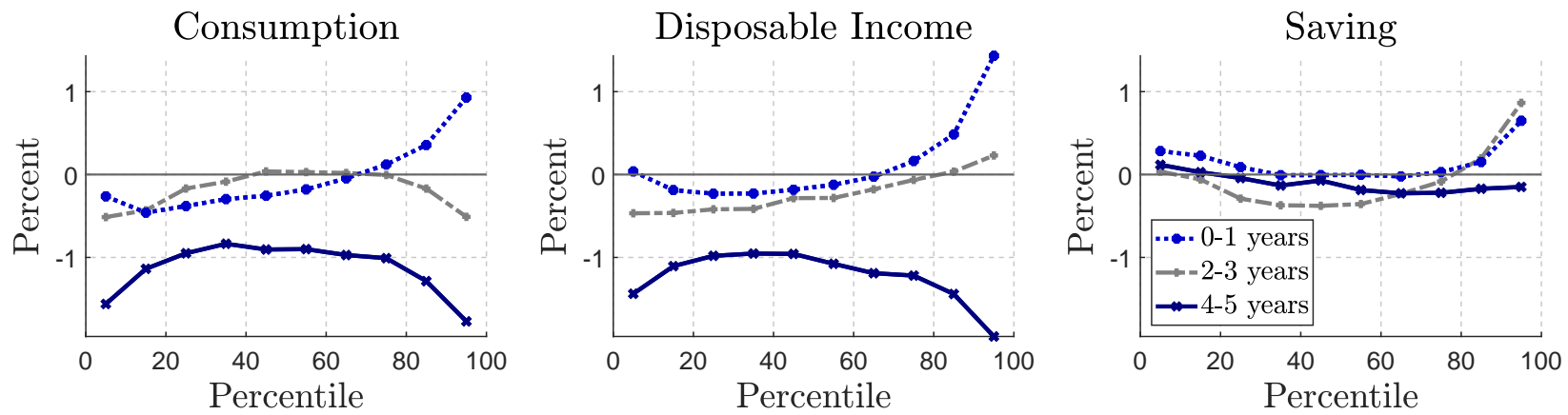

Figure C.9: Impulse Responses for Nonstockholders.

Notes: Changes relative to lagged net income at segments of the liquid asset distribution.

Second, we perform an additional sensitivity exercise that considers two extreme assumptions about the error in imputed capital gains. Recall that the benchmark imputation is constructed such that holders of assets experience the average capital gains of an asset class or of a specific asset. However, it could be that certain groups of households in our sample systematically underperform or outperform the market. For example, it could be the case that wealthy individuals tend to experience systematically higher returns on risky financial assets (as documented by Fagereng et al., 2020). To test for such heterogeneity, we construct two alternative consumption expenditure measures, one that assumes that households always perform 33 percent better than the market (33 percent higher capital gains when positive and 33 percent lower capital losses when negative) and one that assumes the opposite, that is, households perform 33 percent worse than the market. The results are shown in Figure C.10, which also includes the response of nonstockholders for comparison. The consumption and saving responses are very similar across the various robustness exercises and to their respective benchmarks.
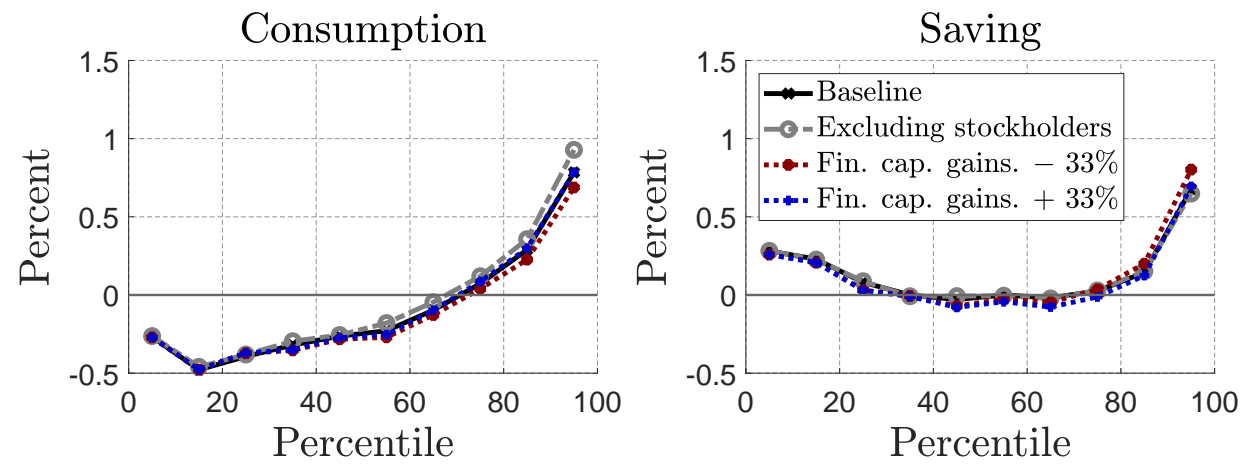

Figure C.10: Impulse Responses along the Liquid Asset Distribution.

Notes: Changes relative to lagged net income at segments of the liquid asset distribution. The figure shows year 0-1 consumption and saving responses to a $1 \mathrm{pp}$. monetary policy shock along the liquid asset distribution using alternative imputation assumptions. 


\section{C.3.3 Additional Robustness Exercises}
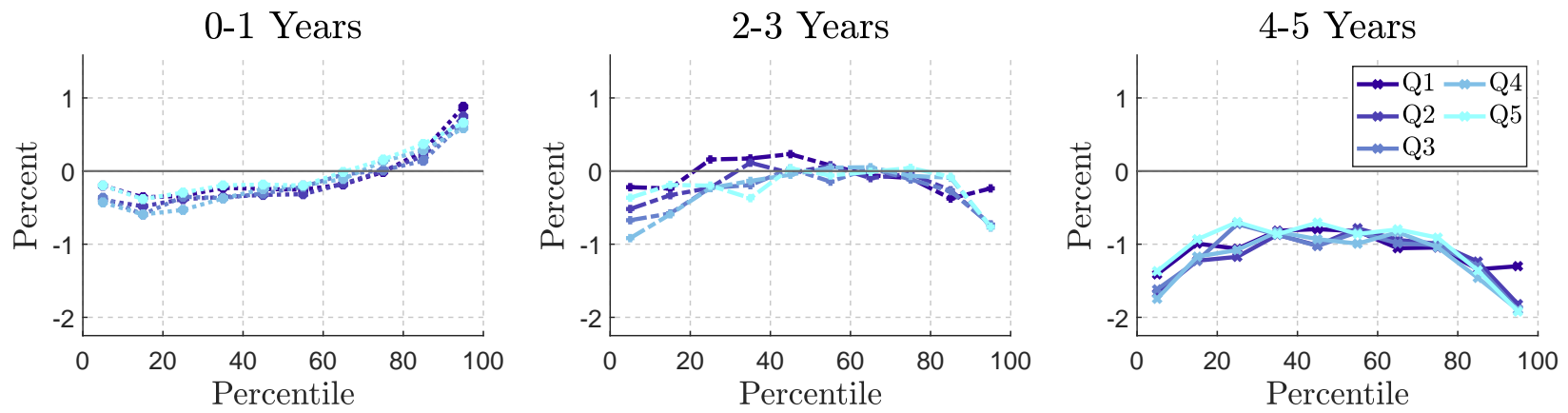

Figure C.11: Consumption Responses by Lagged Income Quintile.

Notes: Changes relative to lagged net income at segments of the liquid asset distribution. Q1 to Q5 are quintiles of the income distribution.
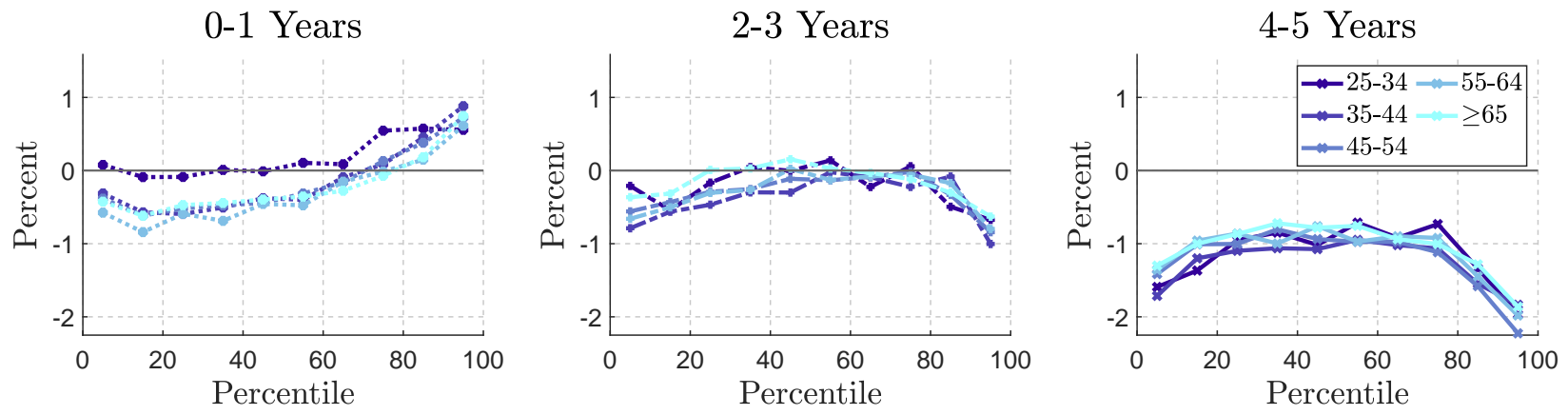

Figure C.12: Consumption Responses by Age.

Notes: Changes relative to lagged net income at segments of the liquid asset distribution for five age groups.

\section{C.4 Decomposing the Aggregate Effects of Monetary Policy}

In this part, we investigate the importance of normalizing the dependent variable in (5) by inci,t-1. Normalizing by average disposable income instead also allows us to evaluate if individual household groups are of particular importance for the aggregate response.

The model estimated is now given by

$$
\frac{y_{i, t+h}-y_{i, t-1}}{\overline{i n c}_{t-1}}=\delta_{i}^{h}+\beta_{g}^{h} \cdot \epsilon_{t}^{M P}+\sum_{k=1}^{K} \gamma_{g, k}^{h} X_{i, t-k}+u_{i, t}^{h} \quad \forall i \in g,
$$

where $\overline{i n c}_{t}=\left(\sum_{i} i n c_{i, t}\right) / N_{t}$ and $N_{t}$ is the number of households contained in the sample in year $t$. 


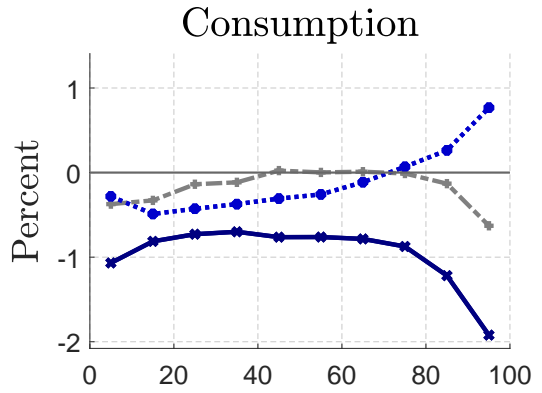

Financial Income (Net)

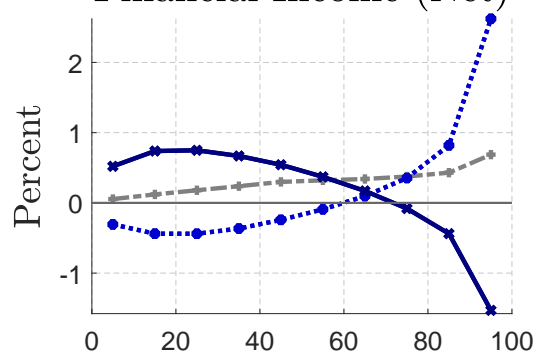

Capital Expenditures

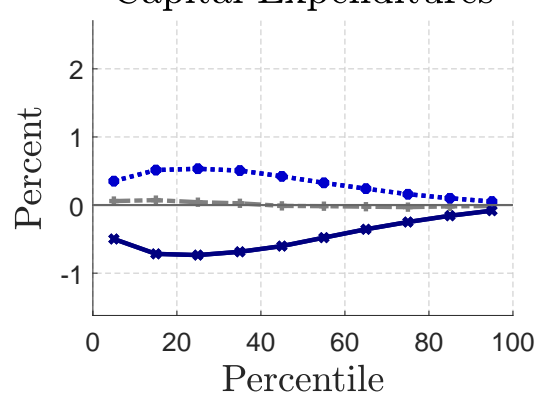

Disposable Income

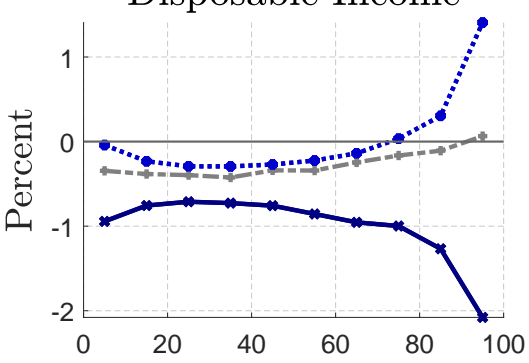

Nonfinancial Income

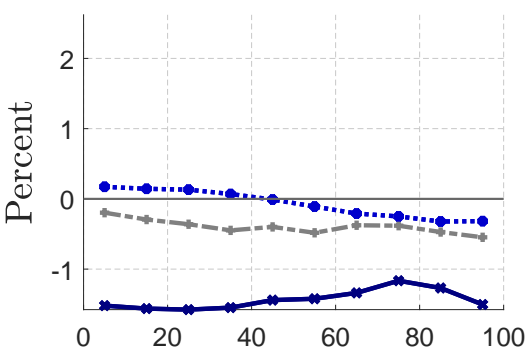

Interest Income

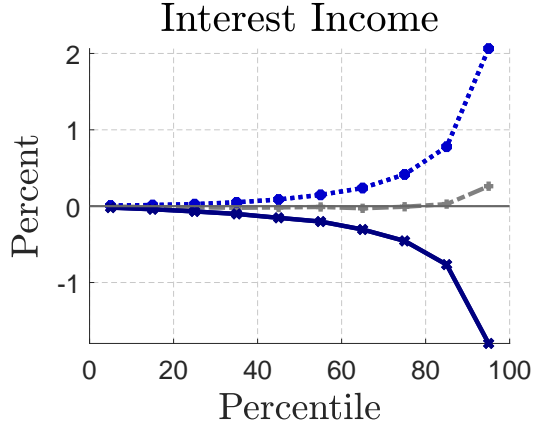

Saving

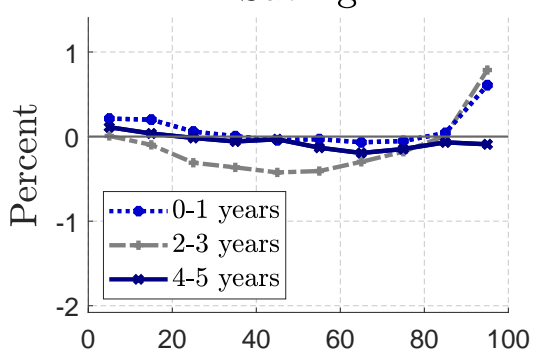

Capital Revenues

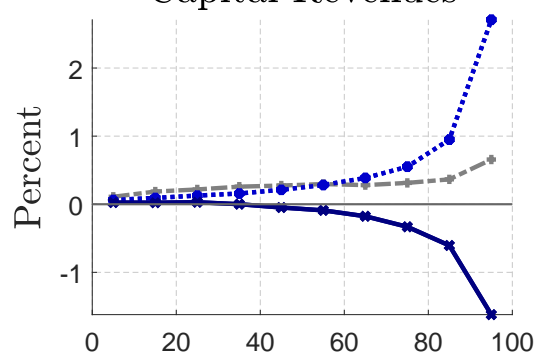

Dividend Income

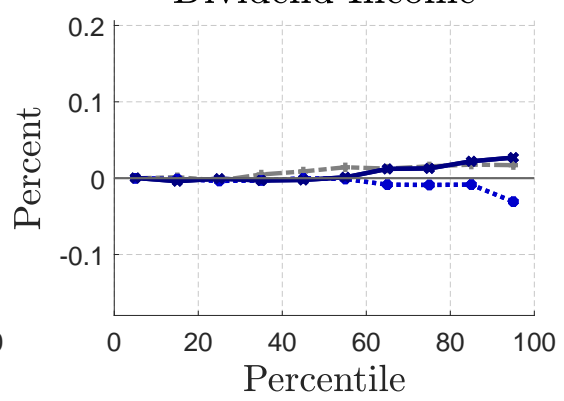

Figure C.13: Impulse Responses in Units of Average Net Income.

Notes: Changes relative to average lagged net income along the liquid asset distribution. See Figures C.15C.18 for group responses and group comparisons with confidence bands.

The results are plotted in Figure C.13. Several of the patterns described in the previous section remain visible since disposable income is relatively equally distributed across liquid asset groups. ${ }^{50}$ As shown in Section 4.2, households at the bottom exhibit a larger consumption response relative to their own income than those around the mid-point. Figure C.13 illustrates that low-liquidity households do not make a substantially larger contribution to the aggregate response. The average response in years 4 and 5 following the shock is remarkably stable across all groups below the 80th percentile. In contrast, the average consumption response in the top group is more than twice as large as that of the group containing the median household $(g=5)$. The difference between both groups becomes significant at the 5 percent level in the final year. Thus, households with large liquid asset holdings have a disproportionately strong influence on aggregate consumption.

As the upper 10 percent of households hold more than half of all interest rate-sensitive financial

\footnotetext{
${ }^{50}$ Average disposable income across all years ranges between $\$ 34,841$ and $\$ 53,916$ in the group with the lowest and highest liquid asset holdings, respectively. The average across all groups is $\$ 43,488$. Hence, according to a simple back-of-the-envelope calculation, one percentage point in Figure C.13 is roughly equivalent to $\$ 435$.
} 
assets, their capital income response is significantly larger than that of any other group. In combination with a nonfinancial income response of similar size four to five years after the shock, disposable income in the top group falls almost three times as much as in the groups surrounding the median household. The changes in capital expenditures at the bottom are of smaller magnitude than the changes in capital revenues at the top. Figure 5 shows that this can be explained by the fact that the concentration of debt at the bottom is smaller than the concentration of deposits and bonds at the top.
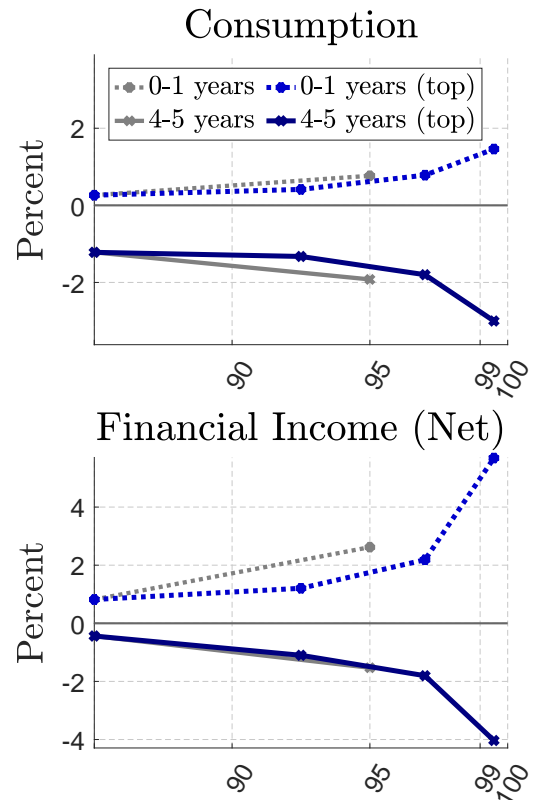

Capital Expenditures

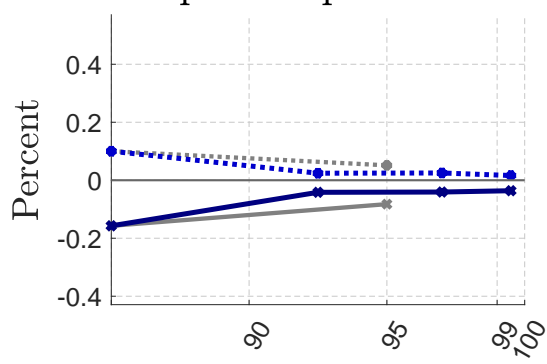

Percentile

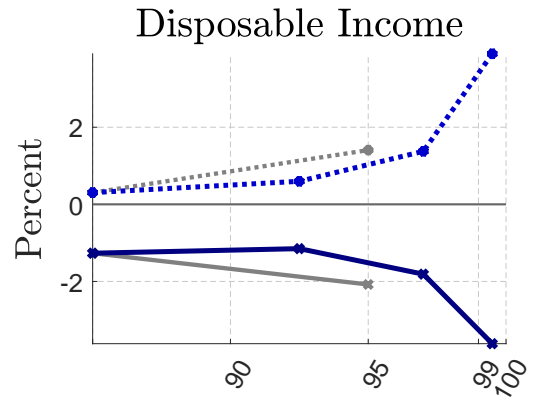

Nonfinancial Income

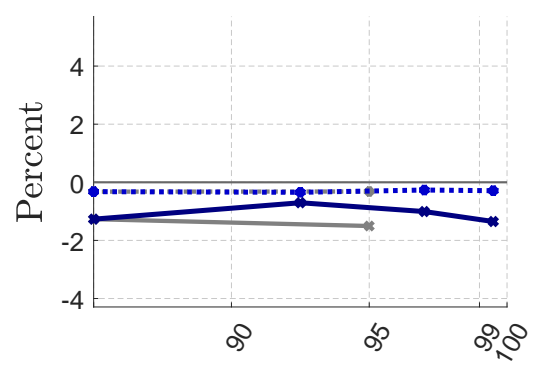

Interest Income

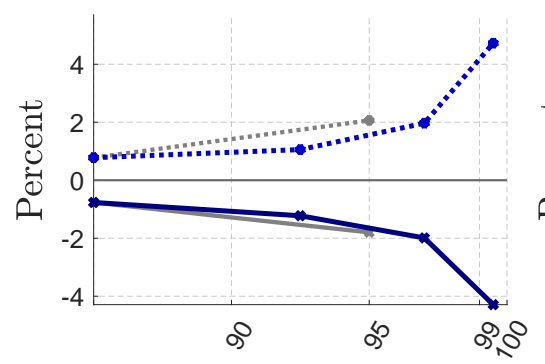

Percentile

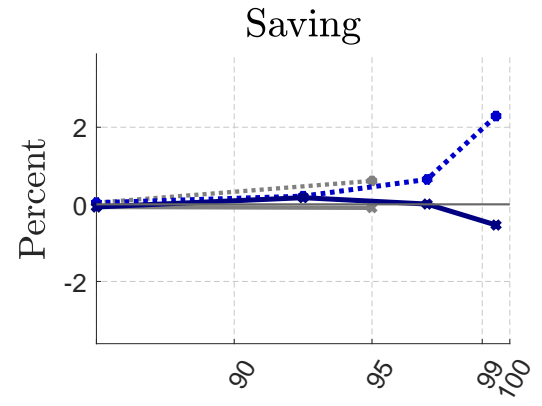

Capital Revenues

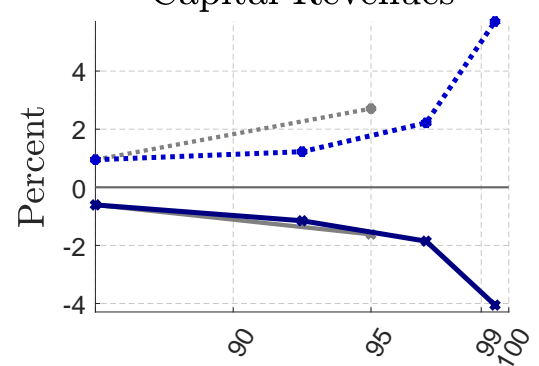

Dividend Income

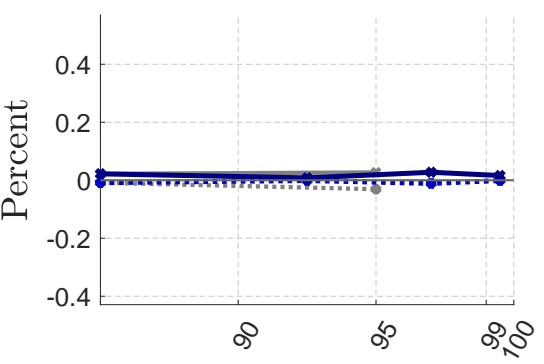

Percentile

Figure C.14: Impulse Responses for Top 10 Percent of Liquid Asset Distribution.

Notes: Changes relative to average lagged net income along the liquid asset distribution. Estimates for $g=9$ and $g=10$ against responses of groups 90-95, 95-99, and 99-100 (labeled "top"). All estimates plotted at midpoint of respective segment. See Figures C.19-C.22 for group responses and group comparisons with confidence bands.

Since the households located above the 90th percentile of the liquid asset distribution contribute most to the aggregate consumption response, we disaggregate the estimates in this group further. Figure C.14 shows the results from estimating the local projections in (12) for the three subgroups formed by the households located between the 90th and 95th, the 95th and 99th, and above the 99th percentile. For nearly all variables, there is a clear ordering of the response magnitudes among the subgroups that is a continuation of the patterns observed along the entire distribution. 
The top 1 percent of households shows particularly strong consumption, disposable income, and saving responses, for example. However, the differences within the top decile are too small for the top 1 percent to exert a large impact on the total response.
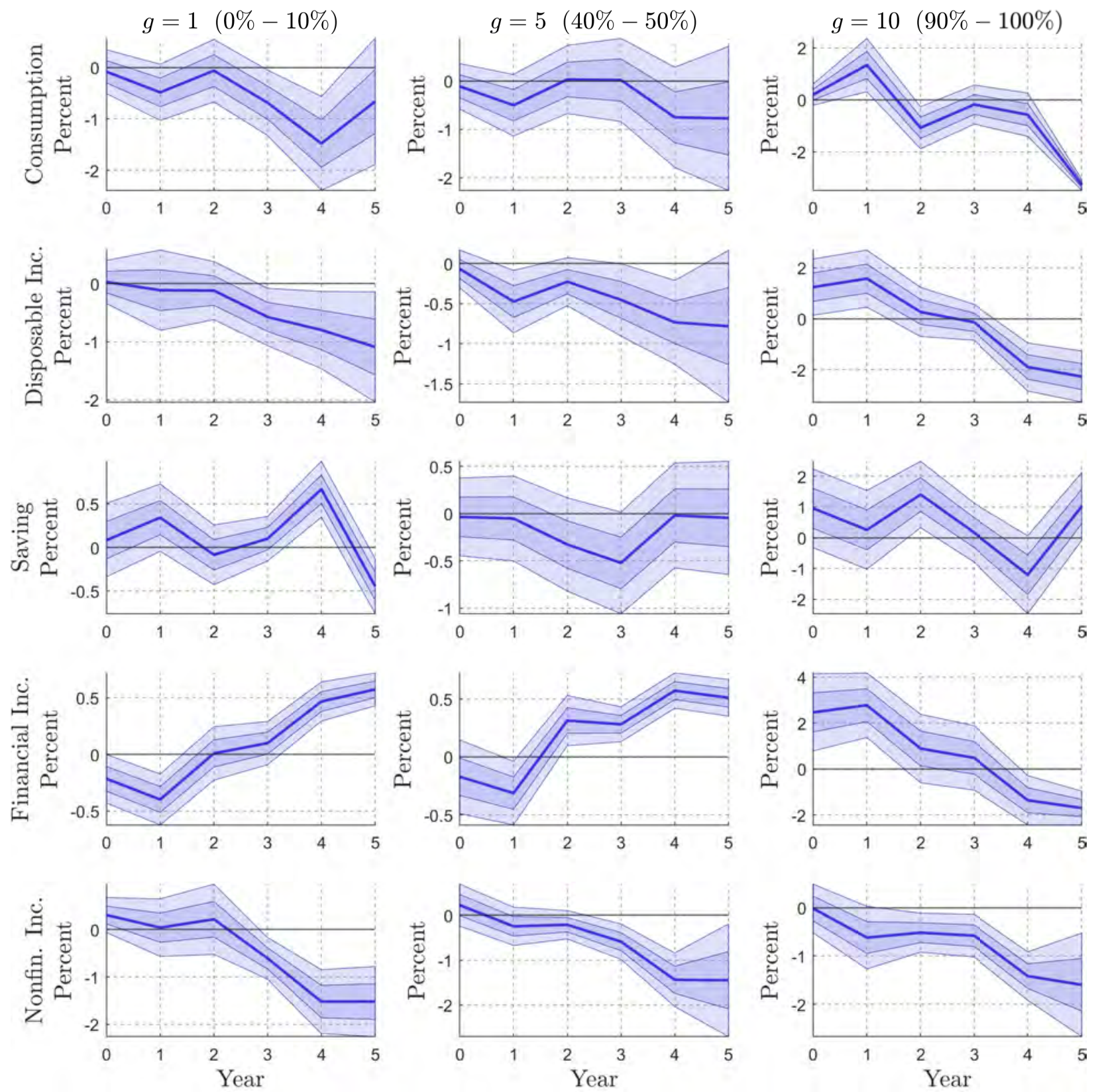

Figure C.15: Impulse Responses of Selected Groups in Units of Average Net Income.

Notes: Changes relative to average lagged net income at segments of the liquid asset distribution. 95 and 68 percent confidence bands shown, computed using Driscoll and Kraay (1998) standard errors. 

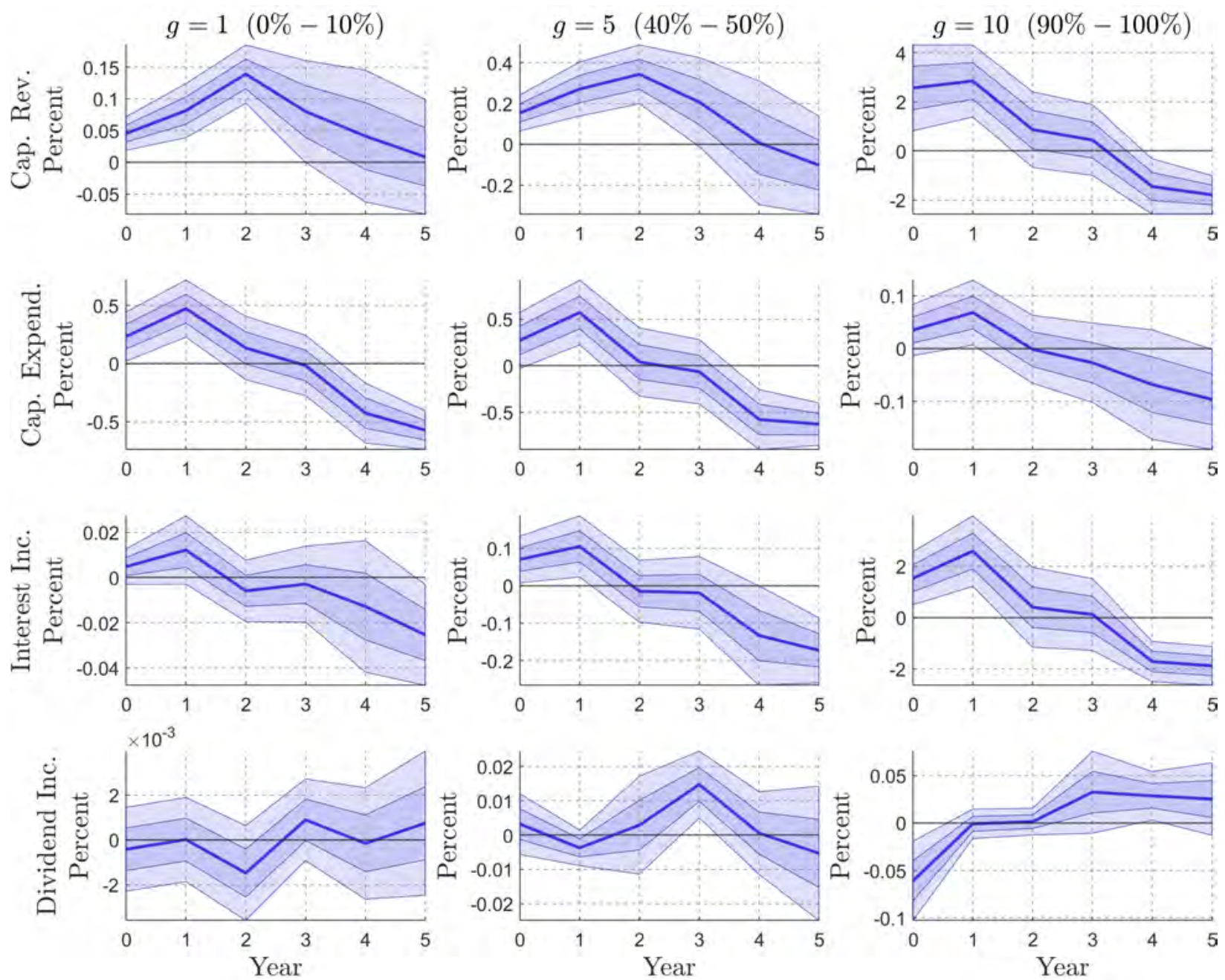

Figure C.16: Impulse Responses of Selected Groups in Units of Average Net Income (Continued).

Notes: Changes relative to average lagged net income at segments of the liquid asset distribution. 95 and 68 percent confidence bands shown, computed using Driscoll and Kraay (1998) standard errors. 

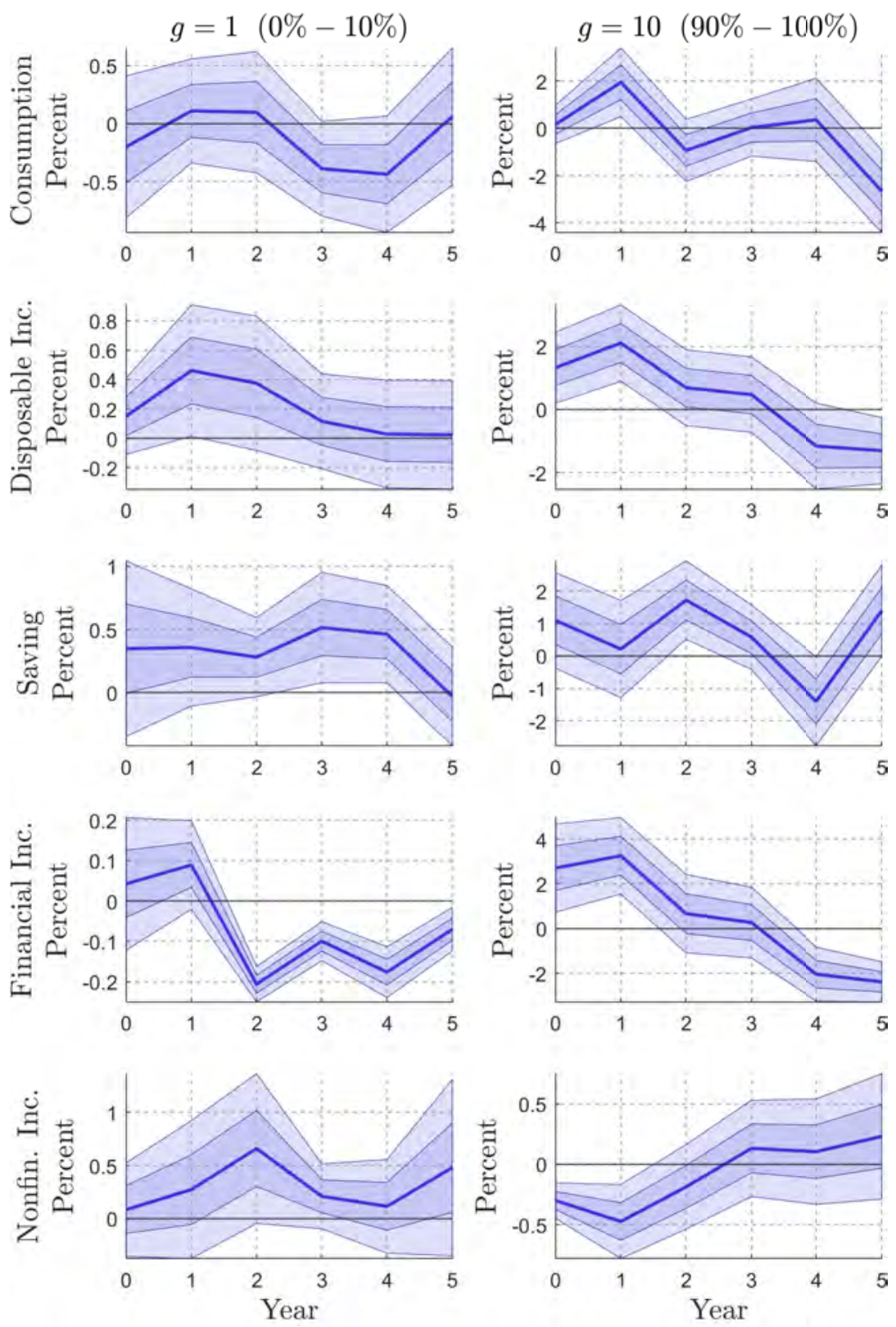

Figure C.17: Impulse Responses at Bottom and Top Relative to Group at Median in Units of Average Net Income.

Notes: Differences between impulse responses of 0-10 percent group and 40-50 percent group (left column); differences between impulse responses of 90-100 percent group and 40-50 percent group (right column). Changes relative to average lagged net income at segments of the liquid asset distribution.

The model estimated is given by $\left(y_{i, t+h}-y_{i, t-1}\right) / \overline{i n c}_{i, t-1}=\delta_{i, g}^{h}+\beta^{h} \cdot \epsilon_{t}^{M P}+\sum_{g=1,10} \beta_{g}^{h} D_{i, t-1}^{g} \cdot \epsilon_{t}^{M P}+$ $\sum_{g=1,5,10} \sum_{k=1}^{K} \gamma_{g, k}^{h} X_{i, t-k} D_{i, t-1}^{g}+u_{i, t}^{h}$ for all $i$ in groups $g=1,5,10$, where $D_{i, t-1}^{g}$ equals 1 if $i$ is in $g$ in $t-1$. Shown are $\beta_{1}^{h}$ and $\beta_{10}^{h}$ with 95 and 68 percent confidence bands, computed using Driscoll and Kraay (1998) standard errors. 

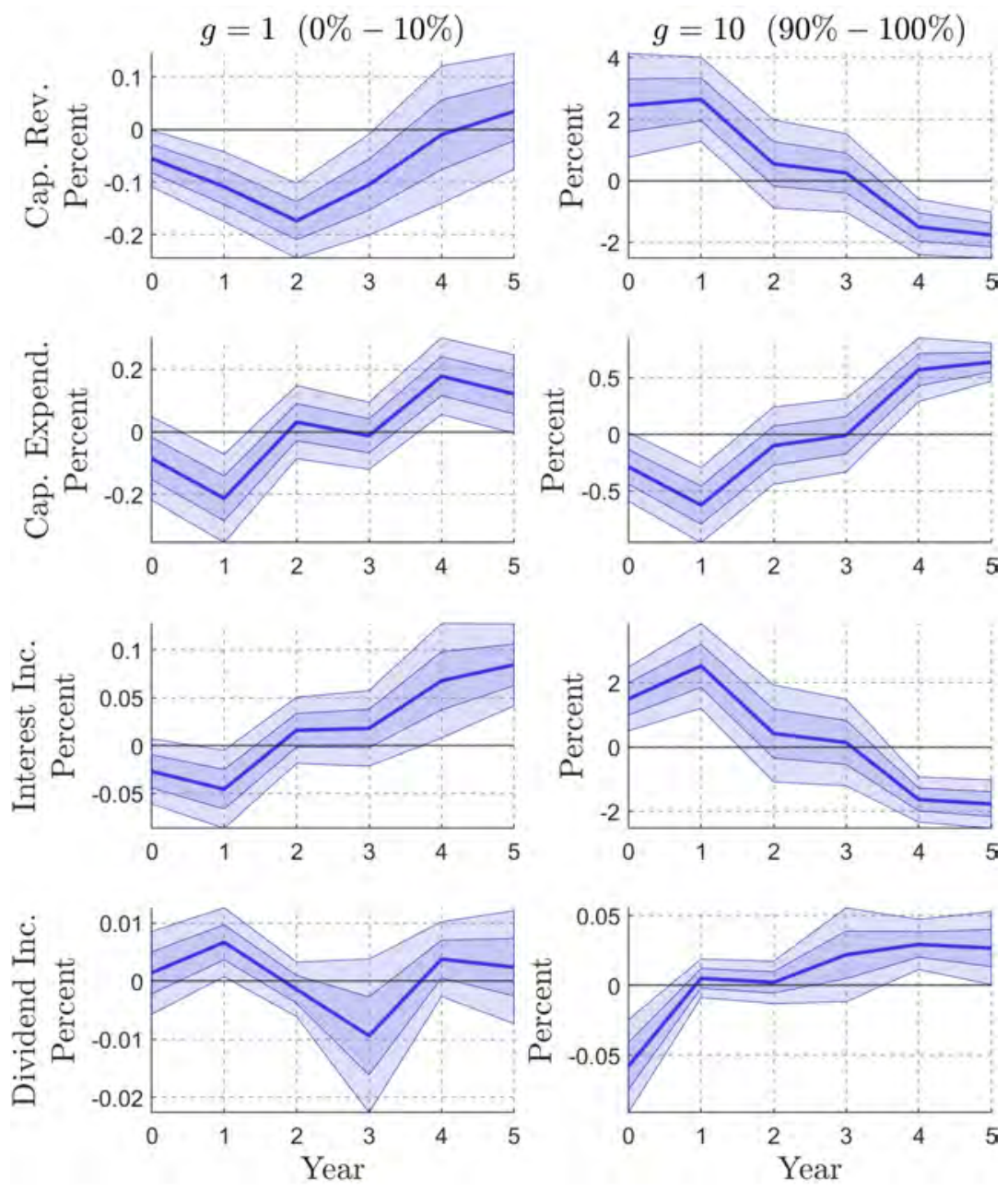

Figure C.18: Impulse Responses at Bottom and Top Relative to Group at Median in Units of Average Net Income (Continued).

Notes: Differences between impulse responses of 0-10 percent group and 40-50 percent group (left column); differences between impulse responses of 90-100 percent group and 40-50 percent group (right column). Changes relative to average lagged net income at segments of the liquid asset distribution.

The model estimated is given by $\left(y_{i, t+h}-y_{i, t-1}\right) / \overline{i n c}_{i, t-1}=\delta_{i, g}^{h}+\beta^{h} \cdot \epsilon_{t}^{M P}+\sum_{g=1,10} \beta_{g}^{h} D_{i, t-1}^{g} \cdot \epsilon_{t}^{M P}+$ $\sum_{g=1,5,10} \sum_{k=1}^{K} \gamma_{g, k}^{h} X_{i, t-k} D_{i, t-1}^{g}+u_{i, t}^{h}$ for all $i$ in groups $g=1,5,10$, where $D_{i, t-1}^{g}$ equals 1 if $i$ is in $g$ in $t-1$. Shown are $\beta_{1}^{h}$ and $\beta_{10}^{h}$ with 95 and 68 percent confidence bands, computed using Driscoll and Kraay (1998) standard errors. 

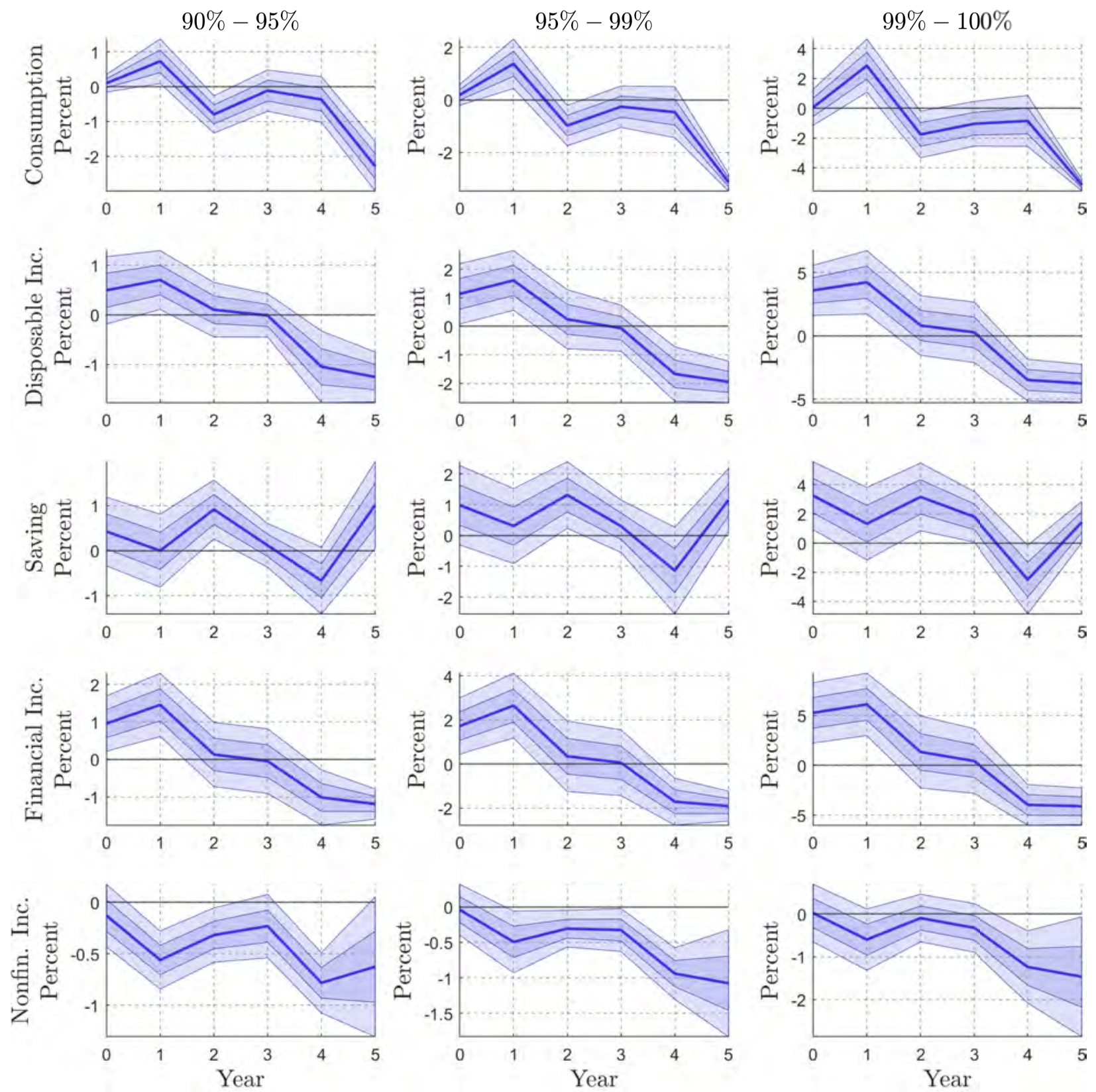

Figure C.19: Impulse Responses among Top 10 Percent in Units of Average Net Income.

Notes: Changes relative to average lagged net income at segments of the liquid asset distribution. 95 and 68 percent confidence bands shown, computed using Driscoll and Kraay (1998) standard errors. 

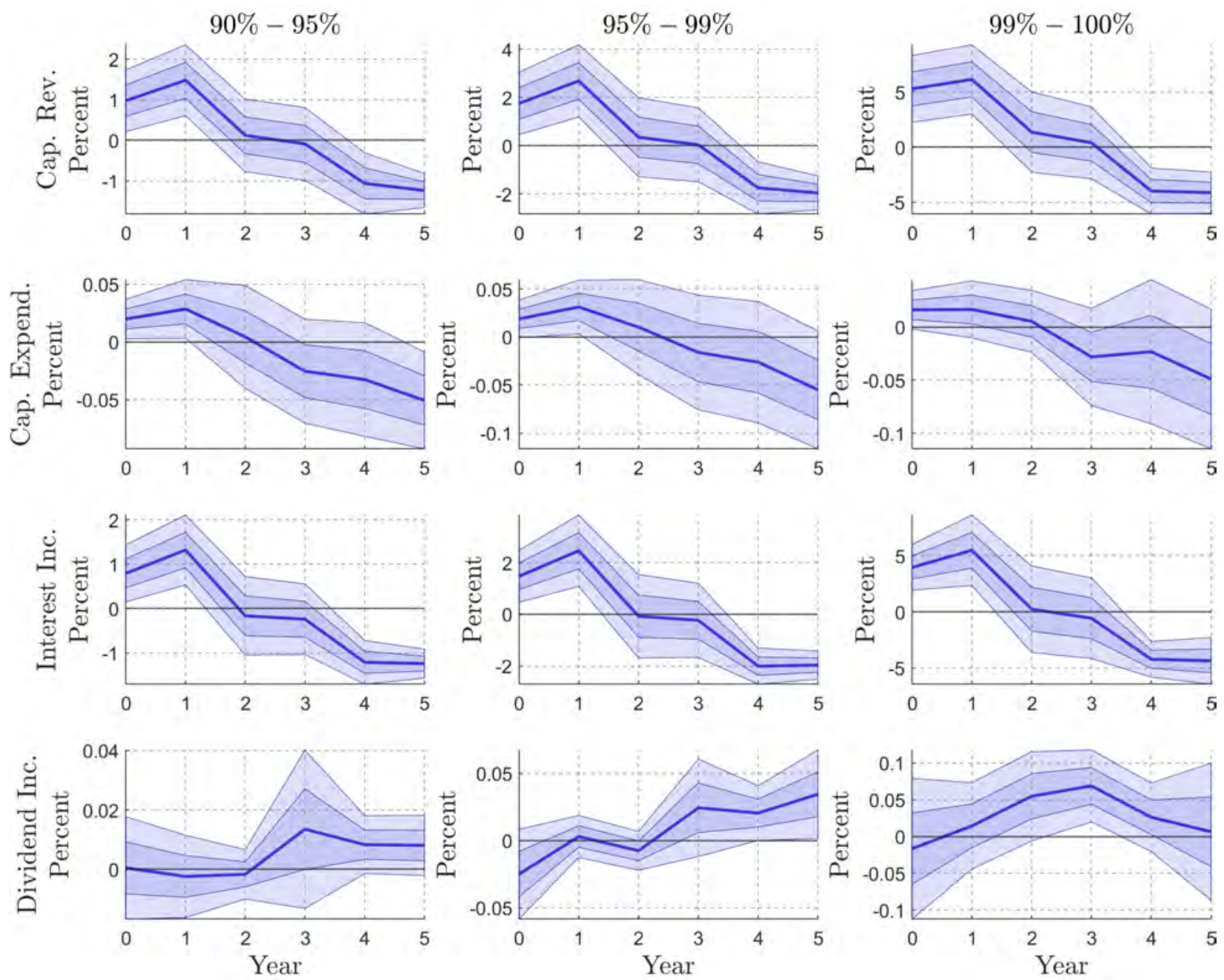

Figure C.20: Impulse Responses among Top 10 Percent in Units of Average Net Income (Continued).

Notes: Changes relative to average lagged net income at segments of the liquid asset distribution. 95 and 68 percent confidence bands shown, computed using Driscoll and Kraay (1998) standard errors. 

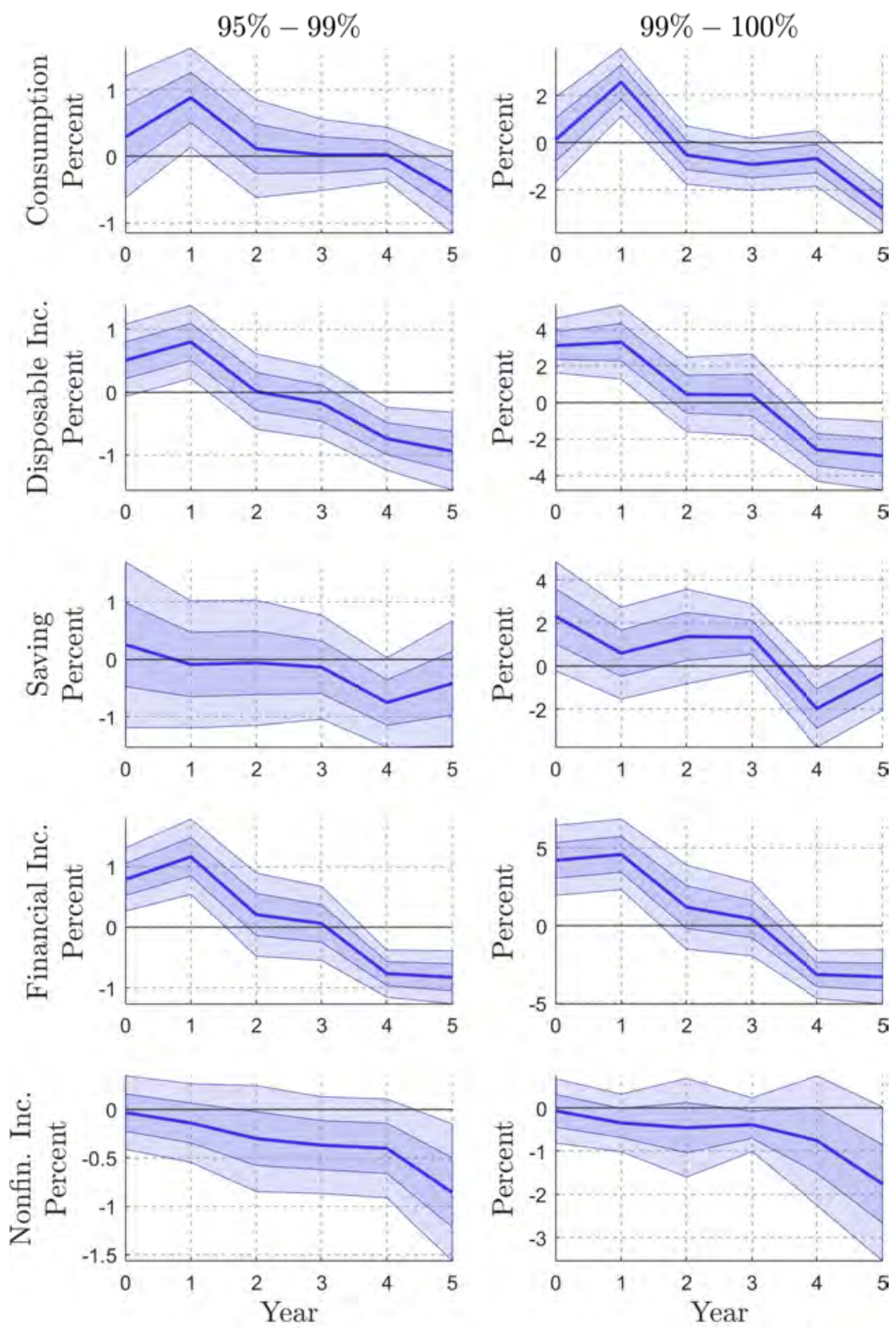

Figure C.21: Impulse Responses at Top Relative to 90-95 Percent Group in Units of Average Net Income.

Notes: Differences between impulse responses of 95-99 percent group and 90-95 percent group (left column); differences between impulse responses of 99-100 percent group and 90-95 percent group (right column). Changes relative to average lagged net income at segments of the liquid asset distribution.

The model estimated is given by $\left(y_{i, t+h}-y_{i, t-1}\right) / \overline{i n c}_{i, t-1}=\delta_{i, l}^{h}+\beta^{h} \cdot \epsilon_{t}^{M P}+\sum_{l=2,3} \beta_{l}^{h} D_{i, t-1}^{l} \cdot \epsilon_{t}^{M P}+$ $\sum_{l=1,2,3} \sum_{k=1}^{K} \gamma_{l, k}^{h} X_{i, t-k} D_{i, t-1}^{l}+u_{i, t}^{h}$ for all $i$ in groups $l=1,2,3$, where $D_{i, t-1}^{l}$ equals 1 if $i$ is in $l$ in $t-1$. Groups considered are percentiles 90-95 $(l=1)$, 95-99 $(l=2)$, and 99-100 $(l=3)$. Shown are $\beta_{2}^{h}$ and $\beta_{3}^{h}$ with 95 and 68 percent confidence bands, computed using Driscoll and Kraay (1998) standard errors. 

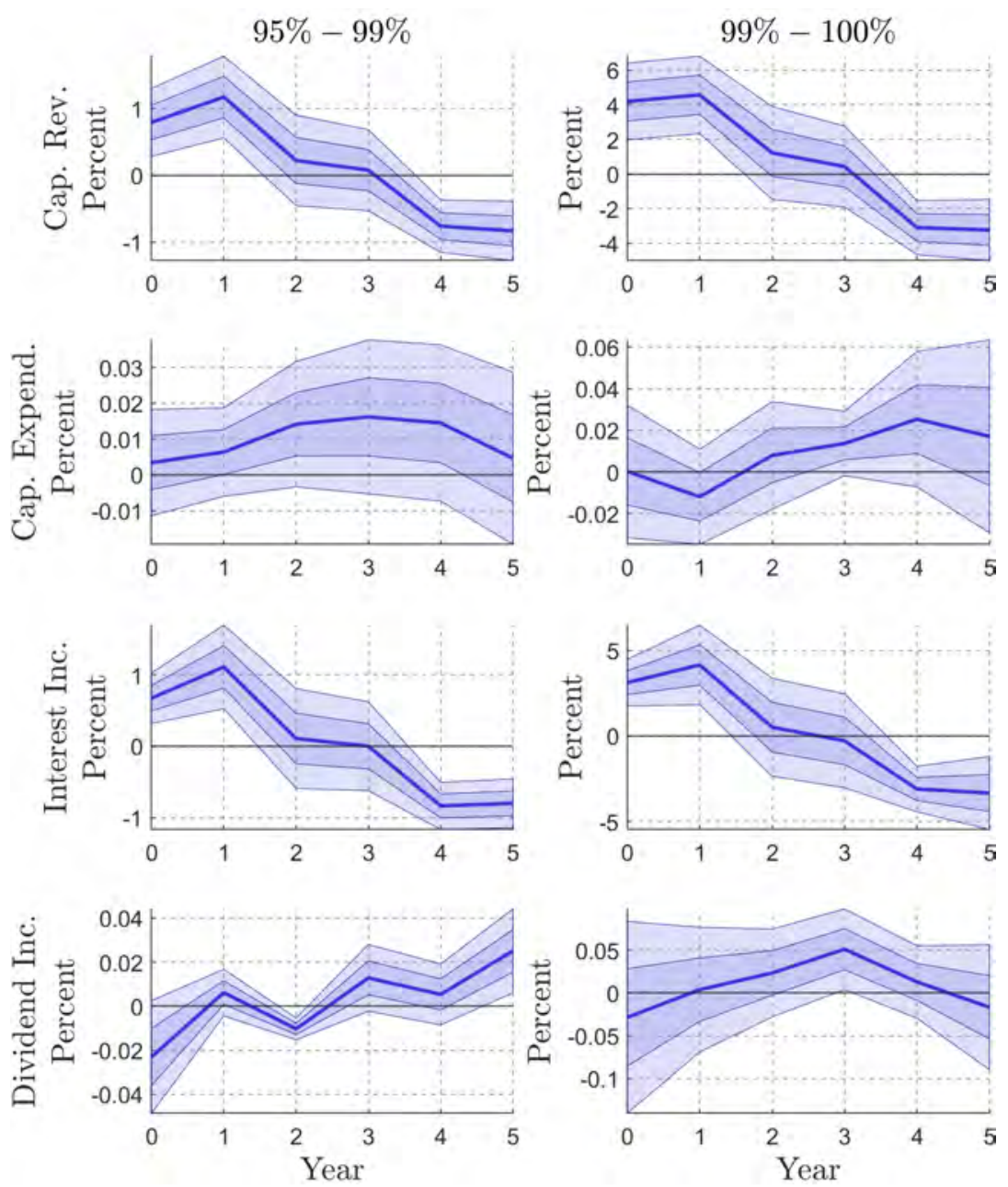

Figure C.22: Impulse Responses at Top Relative to 90-95 Percent Group in Units of Average Net Income (Continued).

Notes: Differences between impulse responses of 95-99 percent group and 90-95 percent group (left column); differences between impulse responses of 99-100 percent group and 90-95 percent group (right column). Changes relative to average lagged net income at segments of the liquid asset distribution.

The model estimated is given by $\left(y_{i, t+h}-y_{i, t-1}\right) / \overline{i n c}_{i, t-1}=\delta_{i, l}^{h}+\beta^{h} \cdot \epsilon_{t}^{M P}+\sum_{l=2,3} \beta_{l}^{h} D_{i, t-1}^{l} \cdot \epsilon_{t}^{M P}+$ $\sum_{l=1,2,3} \sum_{k=1}^{K} \gamma_{l, k}^{h} X_{i, t-k} D_{i, t-1}^{l}+u_{i, t}^{h}$ for all $i$ in groups $l=1,2,3$, where $D_{i, t-1}^{l}$ equals 1 if $i$ is in $l$ in $t-1$. Groups considered are percentiles 90-95 $(l=1), 95-99(l=2)$, and 99-100 $(l=3)$. Shown are $\beta_{2}^{h}$ and $\beta_{3}^{h}$ with 95 and 68 percent confidence bands, computed using Driscoll and Kraay (1998) standard errors. 


\section{C.5 Net Interest Rate Exposure}
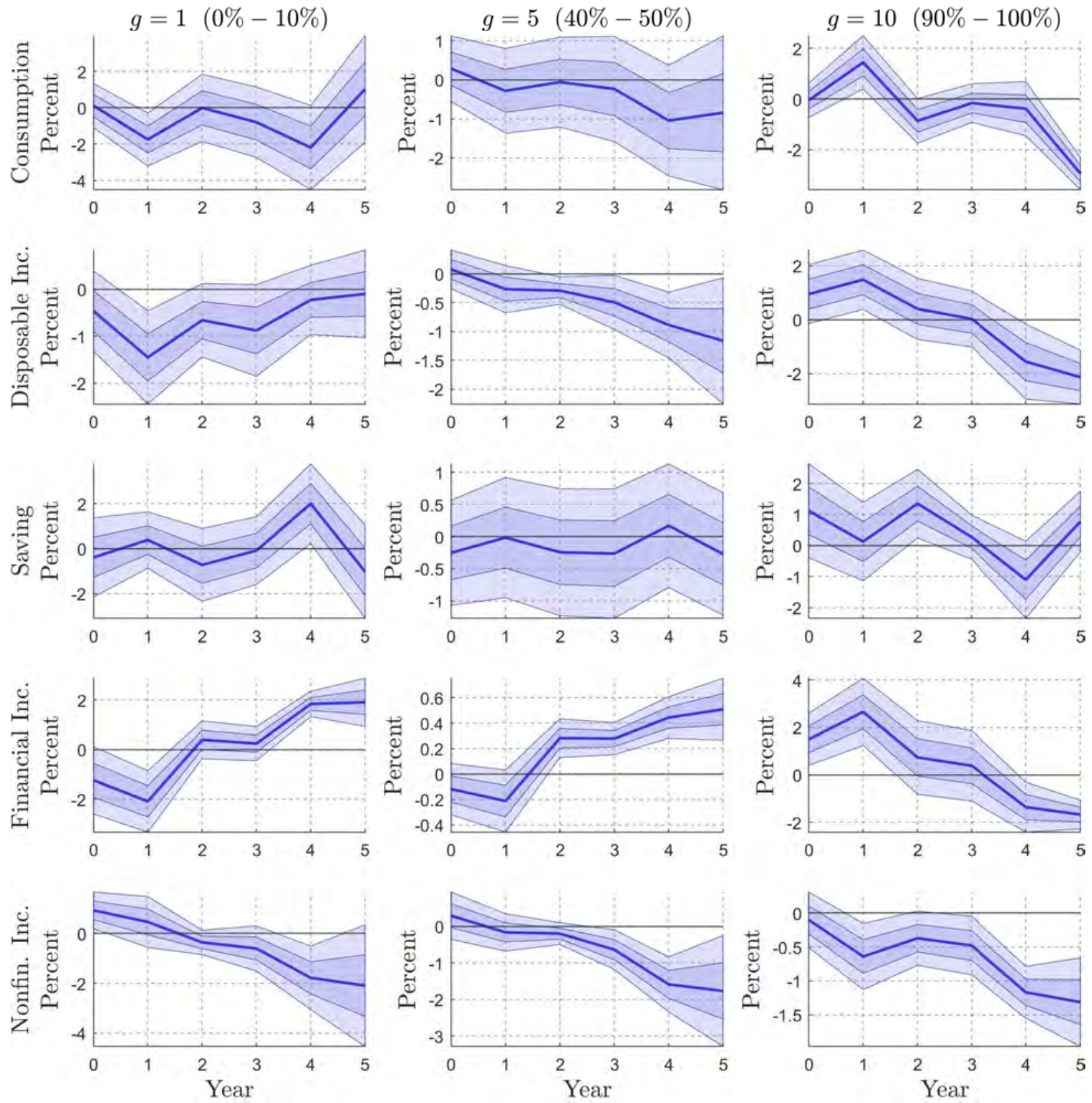

Figure C.23: Impulse Responses of Selected Groups by Net Interest Rate Exposure.

Notes: Changes relative to lagged net income at segments of the distribution of net interest rate exposure. 95 and 68 percent confidence bands shown, computed using Driscoll and Kraay (1998) standard errors. 

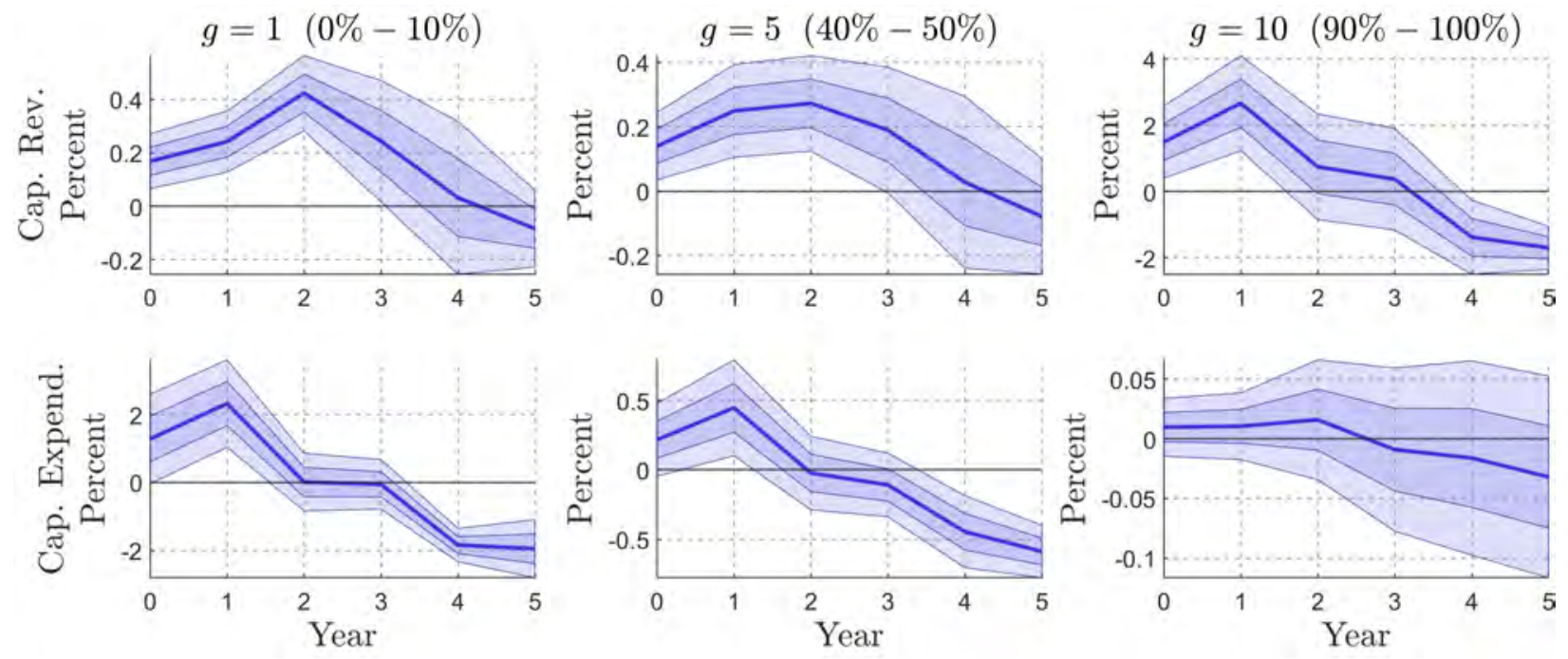

Figure C.24: Impulse Responses of Selected Groups by Net Interest Rate Exposure (Continued). Notes: Changes relative to lagged net income at segments of the distribution of net interest rate exposure. 95 and 68 percent confidence bands shown, computed using Driscoll and Kraay (1998) standard errors. 

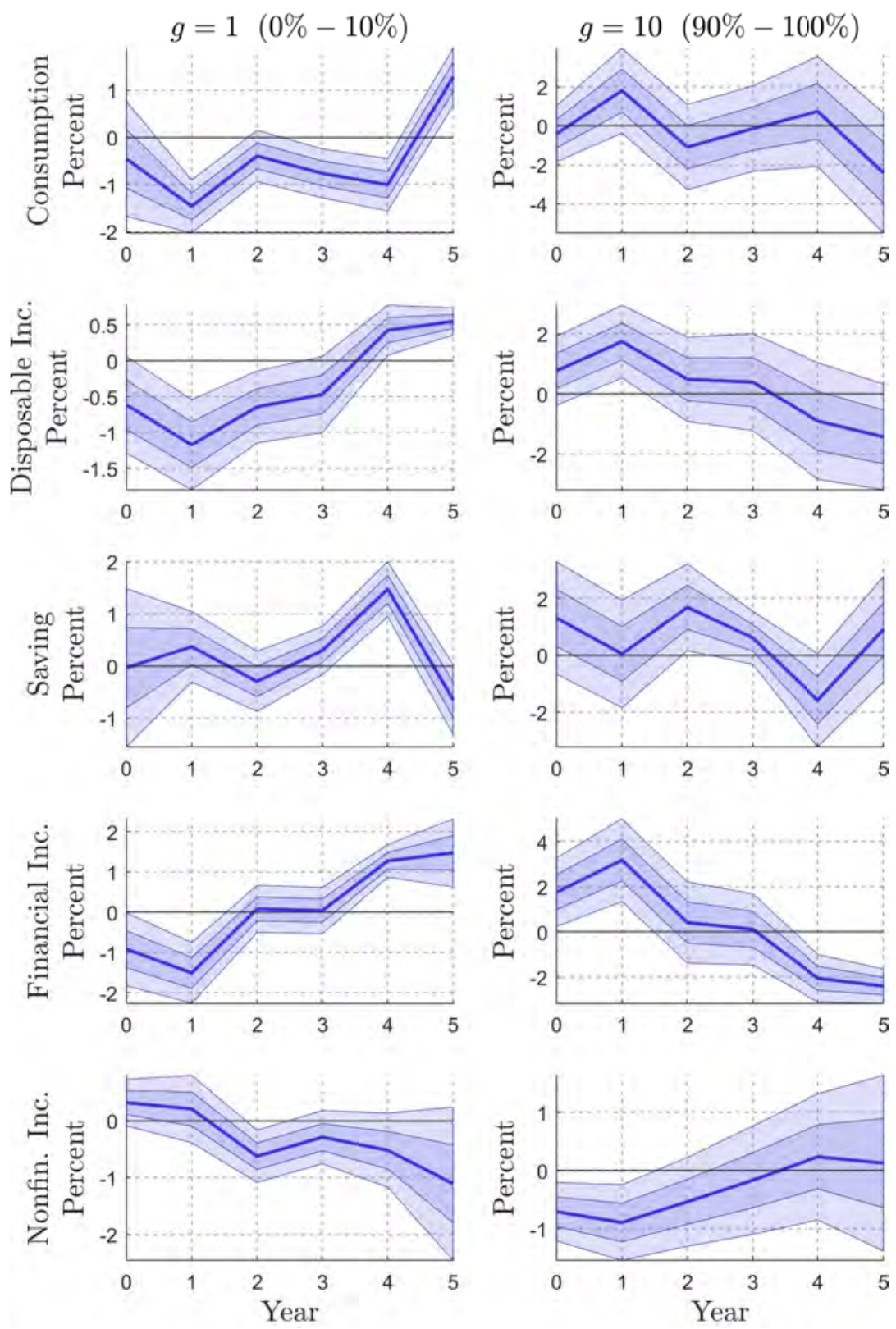

Figure C.25: Impulse Responses at Bottom and Top Relative to Group at Median by Net Interest Rate Exposure.

Notes: Differences between impulse responses of 0-10 percent group and 40-50 percent group (left column); differences between impulse responses of 90-100 percent group and 40-50 percent group (right column). Changes relative to lagged net income at segments of the distribution of net interest rate exposure.

The model estimated is given by $\left(y_{i, t+h}-y_{i, t-1}\right) / i n c_{i, t-1}=\delta_{i, g}^{h}+\beta^{h} \cdot \epsilon_{t}^{M P}+\sum_{g=1,10} \beta_{g}^{h} D_{i, t-1}^{g} \cdot \epsilon_{t}^{M P}+$ $\sum_{g=1,5,10} \sum_{k=1}^{K} \gamma_{g, k}^{h} X_{i, t-k} D_{i, t-1}^{g}+u_{i, t}^{h}$ for all $i$ in groups $g=1,5,10$, where $D_{i, t-1}^{g}$ equals 1 if $i$ is in $g$ in $t-1$. Shown are $\beta_{1}^{h}$ and $\beta_{10}^{h}$ with 95 and 68 percent confidence bands, computed using Driscoll and Kraay (1998) standard errors. 

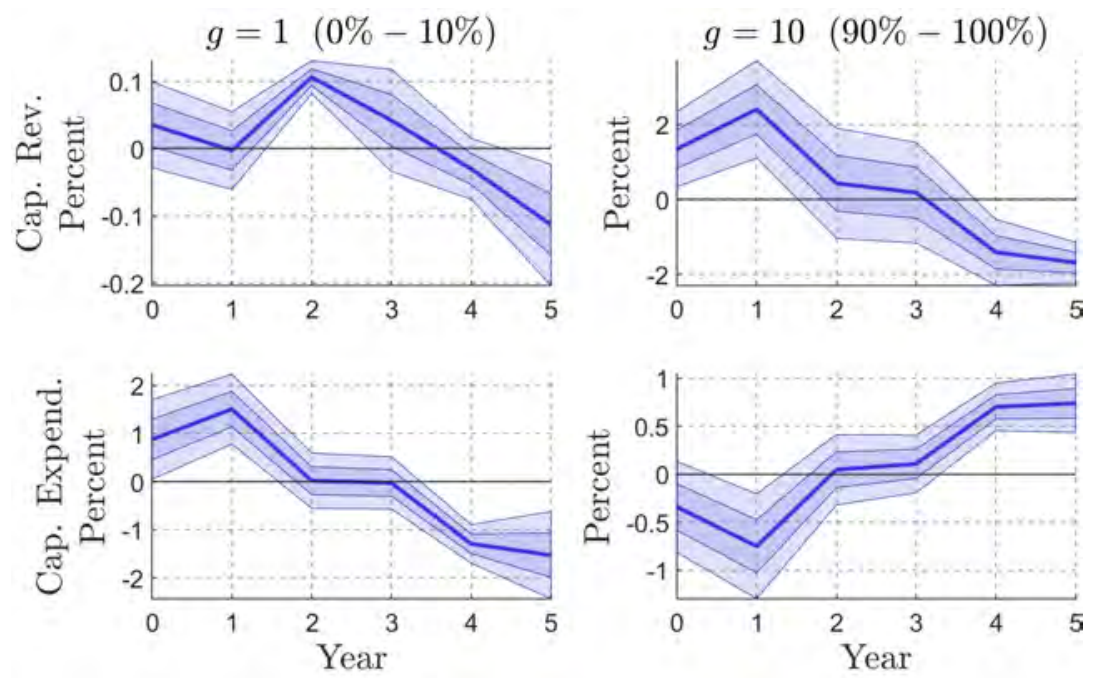

Figure C.26: Impulse Responses at Bottom and Top Relative to Group at Median by Net Interest Rate Exposure (Continued).

Notes: Differences between impulse responses of 0-10 percent group and 40-50 percent group (left column); differences between impulse responses of 90-100 percent group and 40-50 percent group (right column). Changes relative to lagged net income at segments of the distribution of net interest rate exposure.

The model estimated is given by $\left(y_{i, t+h}-y_{i, t-1}\right) / i n c_{i, t-1}=\delta_{i, g}^{h}+\beta^{h} \cdot \epsilon_{t}^{M P}+\sum_{g=1,10} \beta_{g}^{h} D_{i, t-1}^{g} \cdot \epsilon_{t}^{M P}+$ $\sum_{g=1,5,10} \sum_{k=1}^{K} \gamma_{g, k}^{h} X_{i, t-k} D_{i, t-1}^{g}+u_{i, t}^{h}$ for all $i$ in groups $g=1,5,10$, where $D_{i, t-1}^{g}$ equals 1 if $i$ is in $g$ in $t-1$. Shown are $\beta_{1}^{h}$ and $\beta_{10}^{h}$ with 95 and 68 percent confidence bands, computed using Driscoll and Kraay (1998) standard errors.

\section{Model}

This section computes the effects of monetary policy on households with different levels of liquid asset holdings in a standard consumption-saving model with a borrowing constraint.

There is a continuum of infinitely-lived households with access to a risk-free bond, which they can use to insure against idiosyncratic income risk. Period utility is of CRRA form with elasticity of intertemporal substitution $1 / \gamma$. The households maximize the expected utility from consumption $c$, discounted at rate $\rho$,

$$
\max _{\left\{c_{t}\right\}_{t \geq 0}} \mathbb{E}_{0} \int_{0}^{\infty} e^{-\rho t} \frac{c_{t}^{1-\gamma}}{1-\gamma} d t .
$$

Household wealth $a_{t}$ evolves according to

$$
d a_{t}=\left(r_{t} a_{t}+w_{t} z_{t}-c_{t}\right) d t
$$

where $r_{t}$ is the (real) interest rate, $w_{t}$ is the wage, and $z_{t}$ is the idiosyncratic component of income. $z_{t}$ evolves according to an Ornstein-Uhlenbeck process given by

$$
d z_{t}=-v\left(z_{t}-\bar{z}\right) d t+\sigma d W_{t}
$$


$v$ is the rate of convergence, $\sigma$ is diffusion, and $W_{t}$ is a Wiener process. Households face an exogenous borrowing constraint $\underline{a}$, i.e.

$$
a_{t} \geq \underline{a} .
$$

Figure D.1 depicts the model responses following an unanticipated 1 percentage point increase in the interest rate that mean reverts with an annual autocorrelation of 0.25 for two groups of households. In our calibration, high-liquidity households (top 10 percent) hold significantly more bond holdings relative to annual income compared with the data (16 compared with 3). Lowliquidity households (bottom 10 percent) hold debt at the amount of about nine times their annual income. We choose standard parameters for the calibration of the model $(\gamma=2, \sigma=0.1$, and $v=0.03$ ), set the steady-state interest rate to 0.04 , and choose $\rho$ to match a wealth-to-income ratio of $4(\rho=0.45)$.
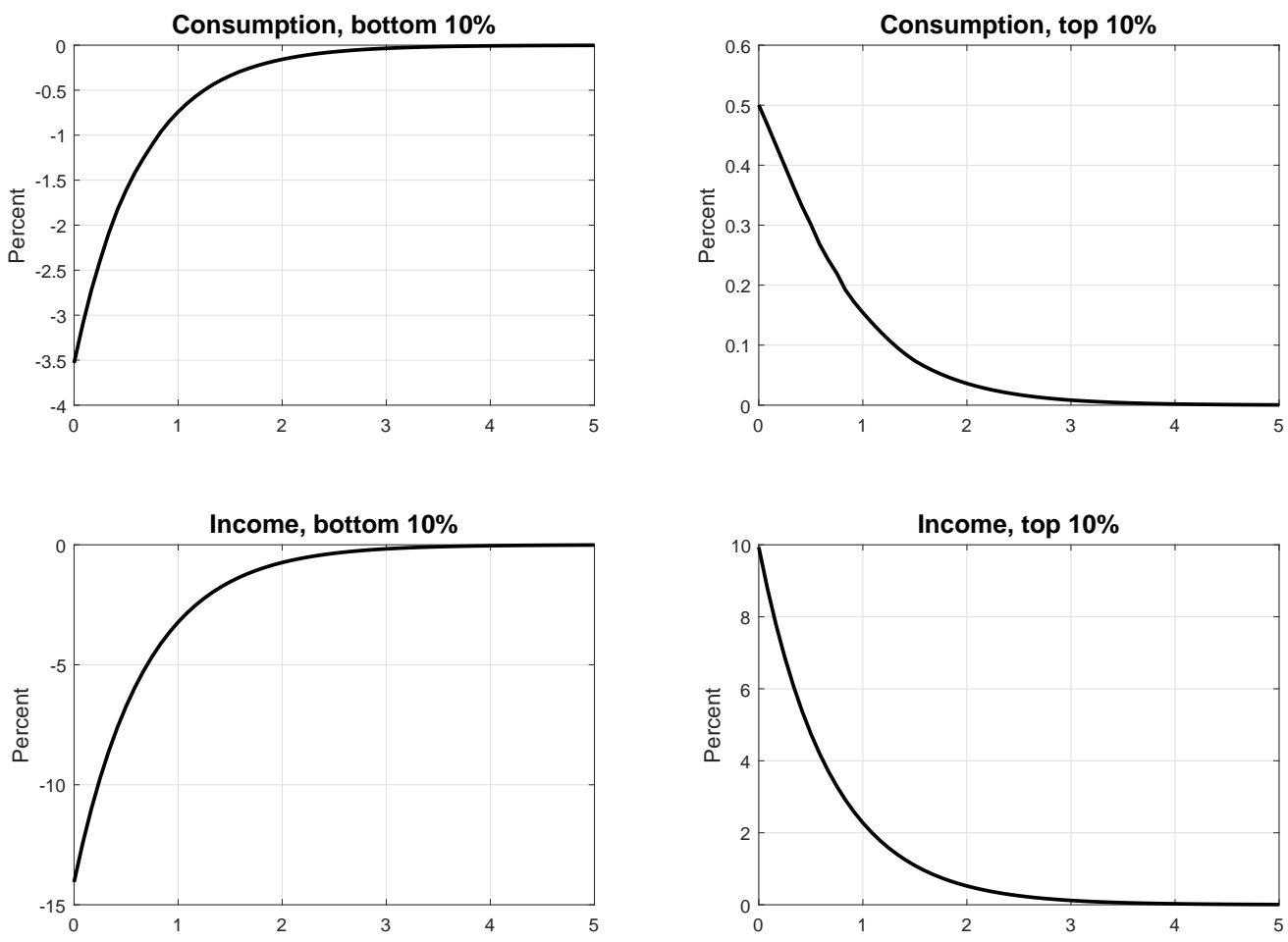

Figure D.1: Impulse Responses in a Consumption-Saving Model.

Notes: The figure shows impulse responses to a 1 percentage point increase in the interest rate. The consumption and income responses are computed relative to lagged net income (prior to the interest rate shock). Initial wealth is about 16 times annual income for the top $10 \%$ and about -9 times annual income for the bottom $10 \%$. The simulation is performed by comparing paths in (i) a benchmark case with no change in the interest rate and (ii) a case with the interest rate change. The parameters used are $\gamma=2, r=0.04$ $\rho=0.045, \sigma=0.10, v=0.03$.

Following the increase in the interest rate, high-liquidity households (top 10 percent) experience a rise in interest income. The change in disposable income triggers a positive consumption response through the income effect. However, the consumption response, although fairly large at about 0.5 percent of pre-shock income, is small relative to the movement in disposable income (10 percent). Low-liquidity households, on the other hand, see an increase in interest expenses. Since they hold 
debt, their consumption response is large and negative at about -3.5 percent of pre-shock income, and since they are close to their constraint and have high MPCs, their consumption response is also large relative to the movement in disposable income.

\section{E Direct and Indirect Effects}

\section{E.1 Interpretation and Identification}

In this section, we show that the decomposition in Section 5 can be interpreted as a typical omitted variable bias problem in empirical work. To gather intuition, and without loss of generality, we simplify the notation. Denote the local projections in (4) and (6) for consumption as

$$
\begin{aligned}
& \Delta^{h} C_{t-1}=\alpha^{h}+\beta^{h} \epsilon_{t}^{M P}+u_{t}^{h} \\
& \Delta^{h} C_{t-1}=\widetilde{\alpha}^{h}+\widetilde{\beta}^{h} \epsilon_{t}^{M P}+\gamma^{h} \Delta^{h} Y_{t-1}+\bar{u}_{t}^{h},
\end{aligned}
$$

where $\beta^{h}$ in (17) gives the response of consumption from $t-1$ to some period $t+h$, denoted $\Delta^{h} C_{t-1}$, to a monetary policy shock $\epsilon_{t}^{M P}$ at time $t$, capturing both direct and indirect effects. Regression (18) replicates (6) and differs from (17) by controlling for the change in income $\Delta^{h} Y_{t-1}$ over the same impulse response horizon. For simplicity, equations (17) and (18) omit all other controls and all household-specific notation. As explained in Section 5, one can interpret $\widetilde{\beta}^{h}$ as the direct effect of monetary policy. Next, consider the auxiliary regression

$$
\Delta^{h} Y_{t-1}=\delta_{0}^{h}+\delta^{h} \epsilon_{t}^{M P}+\bar{u}_{t}^{h}
$$

where $\delta^{h}$ gives the response of income to a monetary policy shock. One can then show that

$$
\begin{aligned}
\beta^{h} & =\operatorname{var}\left(\epsilon_{t}^{M P}\right)^{-1} \operatorname{cov}\left(\epsilon_{t}^{M P}, \Delta^{h} C_{t-1}\right) \\
& =\widetilde{\beta}^{h}+\operatorname{var}\left(\epsilon_{t}^{M P}\right)^{-1} \operatorname{cov}\left(\epsilon_{t}^{M P}, \Delta^{h} Y_{t-1}\right) \cdot \gamma^{h} \\
& =\widetilde{\beta}^{h}+\delta^{h} \cdot \gamma^{h}
\end{aligned}
$$

such that the total effect $\beta^{h}$ can be decomposed into a direct effect $\widetilde{\beta}^{h}$ and an indirect effect $\delta^{h} \cdot \gamma^{h}$, which consists of the response of income to the shock $\delta^{h}$ and the partial effect of income on consumption $\gamma^{h}$. Here, $\delta^{h} \cdot \gamma^{h}$ can be interpreted as the bias of $\beta^{h}$ from the omission of the income controls (see, e.g., Section 2.24 in Hansen, 2019). In fact, this decomposition closely resembles the one in Kaplan, Moll and Violante (2018) (see, e.g., equation (3) in their paper).

To achieve identification of $\widetilde{\beta}^{h}$ using (18), two conditions have to be satisfied. First, income cannot respond to a change in consumption within the same period. For example, that would be the case if a household lowers its consumption and increases its saving, and additionally consumes out of the additional interest income within the same period. However, since interest income and expenses are excluded from the set of income controls, any bias from such a reverse relation is likely to be small within our setup. Second, the structural variation that drives household-level 
income should not have a contemporaneous direct impact on consumption, unless one controls for such variation in (18). For example, if idiosyncratic labor income shocks are the only variation that drive household income aside from the monetary policy shock, (18) identifies the true $\widetilde{\beta}^{h}$.

\section{E.2 Instrumental Variable Estimation}

To ensure that the second condition is satisfied, we test the robustness of our baseline results in Figure 18 by using an instrumental variable regression. To this end, we use lottery winnings as instruments for household idiosyncratic labor income variation based on the Norwegian lottery data from Fagereng, Holm and Natvik (2021). These data contain all individuals who have won a prize greater than USD 1,100 (USD 11,000 after 2006) in a game administered by Norsk Tipping, the state-run gambling monopoly in Norway. All games administered by Norsk Tipping include a significant element of luck such as bingo, scratch cards, sports betting, horse racing, and lotto. There are approximately 30,000 unique lottery winners within our sample. ${ }^{51}$

Continuing with the simplified notation above that omits our standard controls and any householdspecific notation, we estimate the first-stage regression

$$
\Delta^{h} Y_{t-1}=\widetilde{\delta}_{0}^{h}+\widetilde{\delta}_{1}^{h} \epsilon_{t}^{M P}+\widetilde{\delta}_{2}^{h} \text { lottery }_{t+h}+\widetilde{u}_{t}^{h}
$$

where the dependent variable is household nonfinancial income and lotter $y_{t+h}$ is the lottery winning in period $t+h .^{52}$ Since lottery winnings enter into the income definition in (20), we obtain estimated coefficients $\hat{\delta}_{2}^{h}$ that are close to one and statistically significant with p-values below 0.01 for all impulse response horizons. In a second stage, we use the predicted values $\Delta^{h} \hat{Y}_{t-1}$ as income controls in (18). Intuitively, the lottery winnings offset the impact of a monetary policy shock in (18) that is running through income and allow to hold income constant to estimate $\widetilde{\beta}^{h}$. The results based on this IV-setup are shown in Figure 19.

\section{E.3 Accounting for Indirect Wealth Effects}

To account for indirect wealth effects, we add measures of changes in households' risky asset wealth into the specification in (6). In fact, the estimated capital gains as described in Section B.1 directly capture such wealth changes. We therefore extend (6) as

$$
\frac{c_{i, t+h}-c_{i, t-1}}{\bar{c}_{t-1}}=\delta_{i}^{h}+\beta^{h} \epsilon_{t}^{M P}+\sum_{m=1}^{3} \mu_{m}^{h} X_{i, t-m}+\sum_{k=1}^{K} \sum_{m=0}^{h} \gamma_{m}^{h, k} \widetilde{y}_{i, t+m}^{k}+\sum_{m=0}^{h} b_{m}^{h} \frac{C G_{i, m}}{\bar{c}_{t-1}}
$$

where the new term $\sum_{m=0}^{h} b_{m}^{h} \frac{C G_{i, m}}{\bar{c}_{t-1}}$ captures capital gains for household $i$ between period $t-1$ and $t+h$, scaled by $t-1$ per capita consumption. The results based on (21), compared against the

\footnotetext{
${ }^{51}$ We exclude winners of multiple prices and trim the size of the lottery winnings to be below USD 50,000 to account for the fact that monetary policy shocks are unlikely to result in larger income changes.

${ }^{52}$ As in regression (6), we scale the dependent variable, the income controls, and the lottery winnings by average consumption $\bar{C}_{t-1}$ across all households at time $t-1$. We further control for all income changes separately from $t-1$ to any $t+k$ where $k=0, . ., h$.
} 
consumption response without income and capital gain controls, are shown in Figure E.1. Indirect wealth effects turn out to be quantitatively small, such that the results in Figures 18 and E.1 are similar.

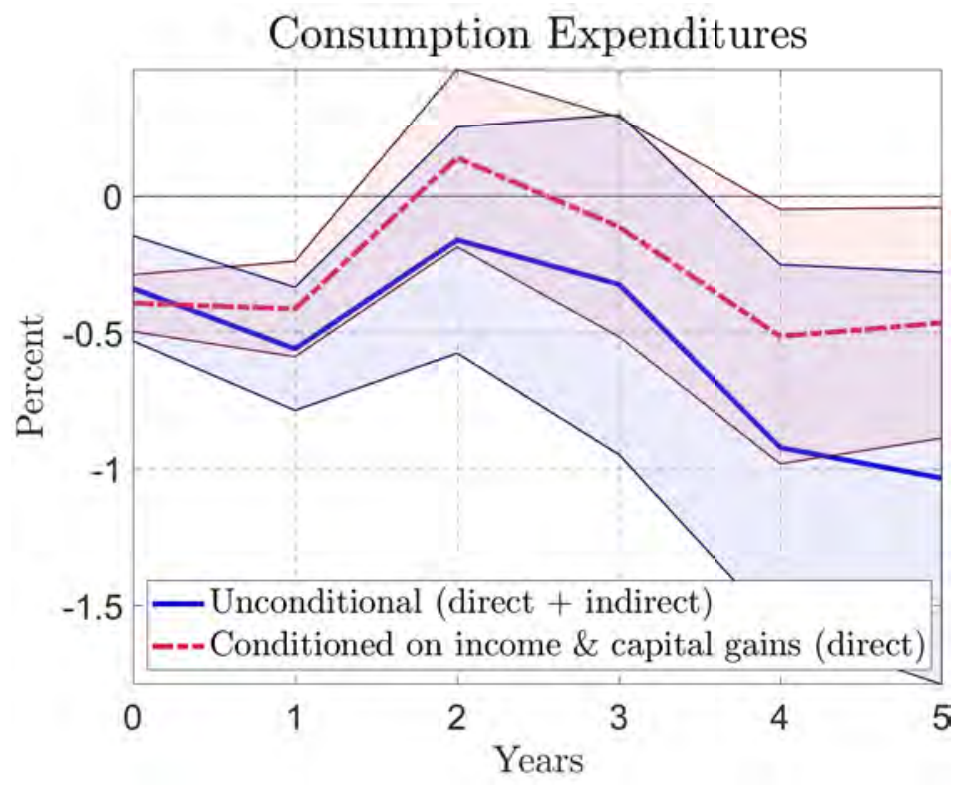

Figure E.1: Direct and Indirect Effects of Monetary Policy.

Notes: Impulse responses to a 1 percentage point contractionary monetary policy shock at an annual frequency, based on the local projection approaches in (4) and (21). The blue line shows the estimated impulse responses without controlling for income, the red dashed line shows the responses with income and capital gains controls. 68 percent confidence bands shown, using Driscoll and Kraay (1998) standard errors.

\section{E.4 Direct and Indirect Effects Across the Liquid Asset Distribution}
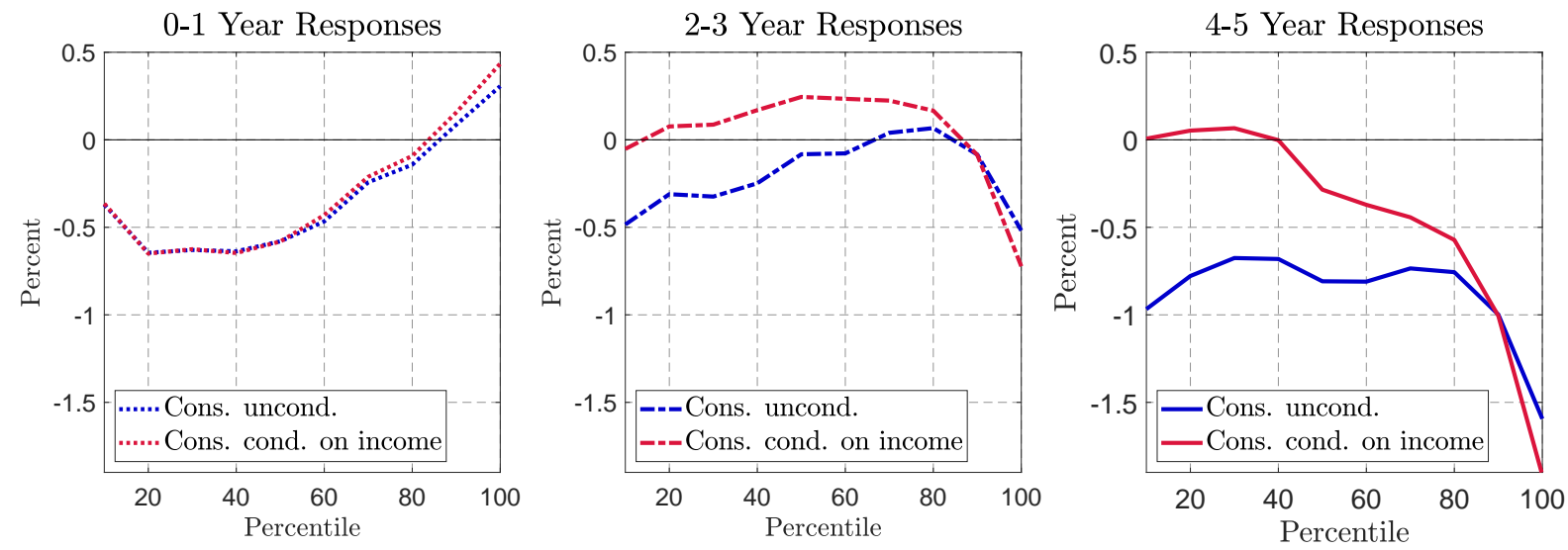

Figure E.2: Direct and Indirect Effects of Monetary Policy.

Notes: Impulse responses to a 1 percentage point contractionary monetary policy shock at an annual frequency, based on the local projection approaches in (4) and (6) for decile groups along the liquid asset distribution. The blue lines show the estimated impulse responses without controlling for income, the red lines show the responses with income controls. 


\section{E.5 MPC Estimates}

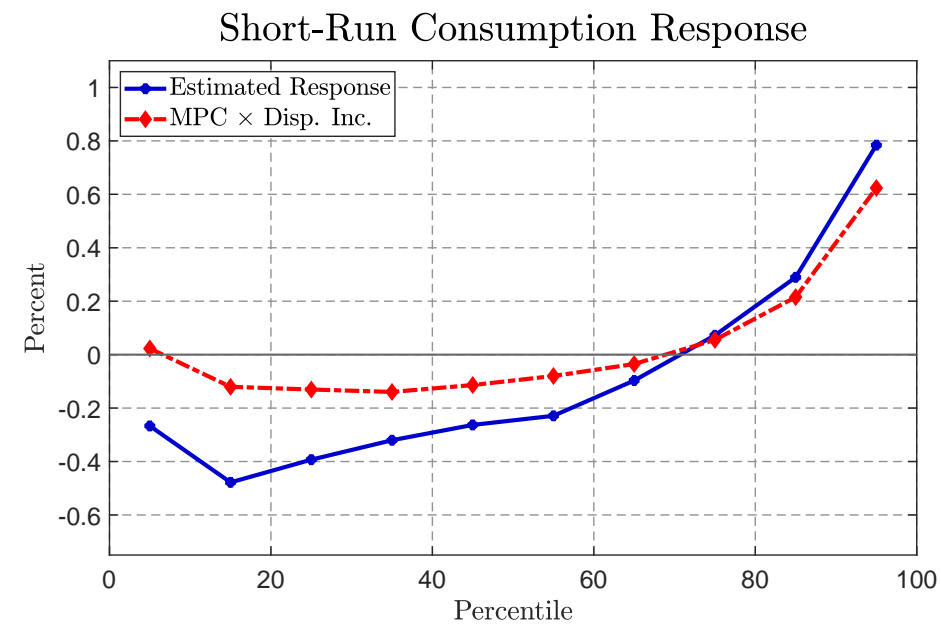

Figure E.3: Implied and Estimated Short-Run Consumption Responses.

Notes: The blue line shows the estimated consumption response for years 0-1 that is shown in Figure 8 across the liquid asset distribution. The red dashed line applies the MPC estimates that are shown in Figure 10, together with the one-year ahead ones, to the estimated short-run disposable income responses (see Figure 9) to obtain an implied consumption response.

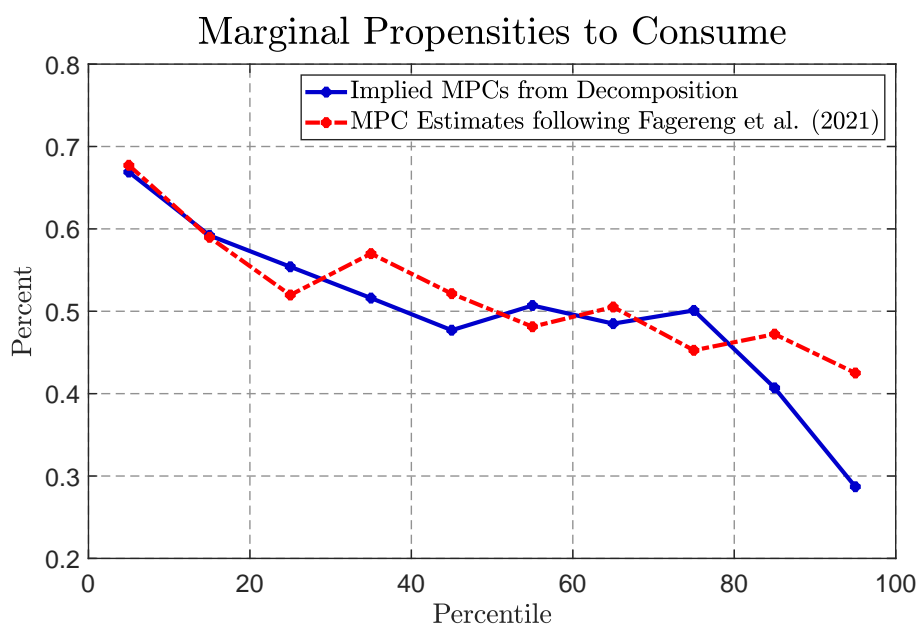

Figure E.4: Implied and Estimated MPCs.

Notes: The red dashed line shows the estimated marginal propensities to consume (MPCs) for the contemporaneous year across the liquid asset distribution from Figure 10. These are estimated from lottery winnings following Fagereng, Holm and Natvik (2021) based on an extended sample that matches the different liquidity groups. The blue line shows the estimated coefficient associated with the contemporaneous nonfinancial income control for the time zero impulse response horizon $\hat{\gamma}_{0}^{0, k}$ based on regression (6) across the liquid asset distribution. 


\section{References}

Barnichon, Regis and Christian Matthes. 2018. "Functional Approximation of Impulse Responses." Journal of Monetary Economics 99(C):41-55.

Cloyne, James and Patrick Huertgen. 2016. "The Macroeconomic Effects of Monetary Policy: A New Measure for the United Kingdom." American Economic Journal: Macroeconomics 8(4):75-102.

Coibion, Olivier. 2012. "Are the Effects of Monetary Policy Shocks Big or Small?" American Economic Journal: Macroeconomics 4(2):1-32.

Coibion, Olivier, Yuriy Gorodnichenko, Lorenz Kueng and John Silvia. 2017. "Innocent Bystanders? Monetary Policy and Inequality in the U.S." Journal of Monetary Economics 88:70-89.

Driscoll, John C. and Aart C. Kraay. 1998. "Consistent Covariance Matrix Estimation with Spatially Dependent Panel Data." Review of Economics and Statistics 80(4):549-560.

Fagereng, Andreas, Luigi Guiso, Davide Malacrino and Luigi Pistaferri. 2020. "Heterogeneity and persistence in returns to wealth." Econometrica 88(1):115-170.

Fagereng, Andreas, Martin B. Holm and Gisle Natvik. 2021. "MPC Heterogeneity and Household Balance Sheets." Forthcoming, American Economic Journal: Macroeconomics .

Hansen, Bruce E. 2019. Econometrics. University of Wisconsin.

Kaplan, Greg, Benjamin Moll and Giovanni L. Violante. 2018. “Monetary Policy According to HANK." American Economic Review 108(3):697-743.

Newey, Whitney and Kenneth West. 1987. "A Simple, Positive-Definite, Heteroskedasticity and Autocorrelation Consistent Covariance Matrix." Econometrica 55:703-708.

Olivei, Giovanni and Silvana Tenreyro. 2007. "The Timing of Monetary Policy Shocks." American Economic Review 97(3):636-663.

Paul, Pascal. 2020. "The time-varying effect of monetary policy on asset prices." Review of Economics and Statistics 102(4):690-704.

Romer, Christina D. and David H. Romer. 2004. "A New Measure of Monetary Shocks: Derivation and Implications." American Economic Review 94(4):1055-1084. 